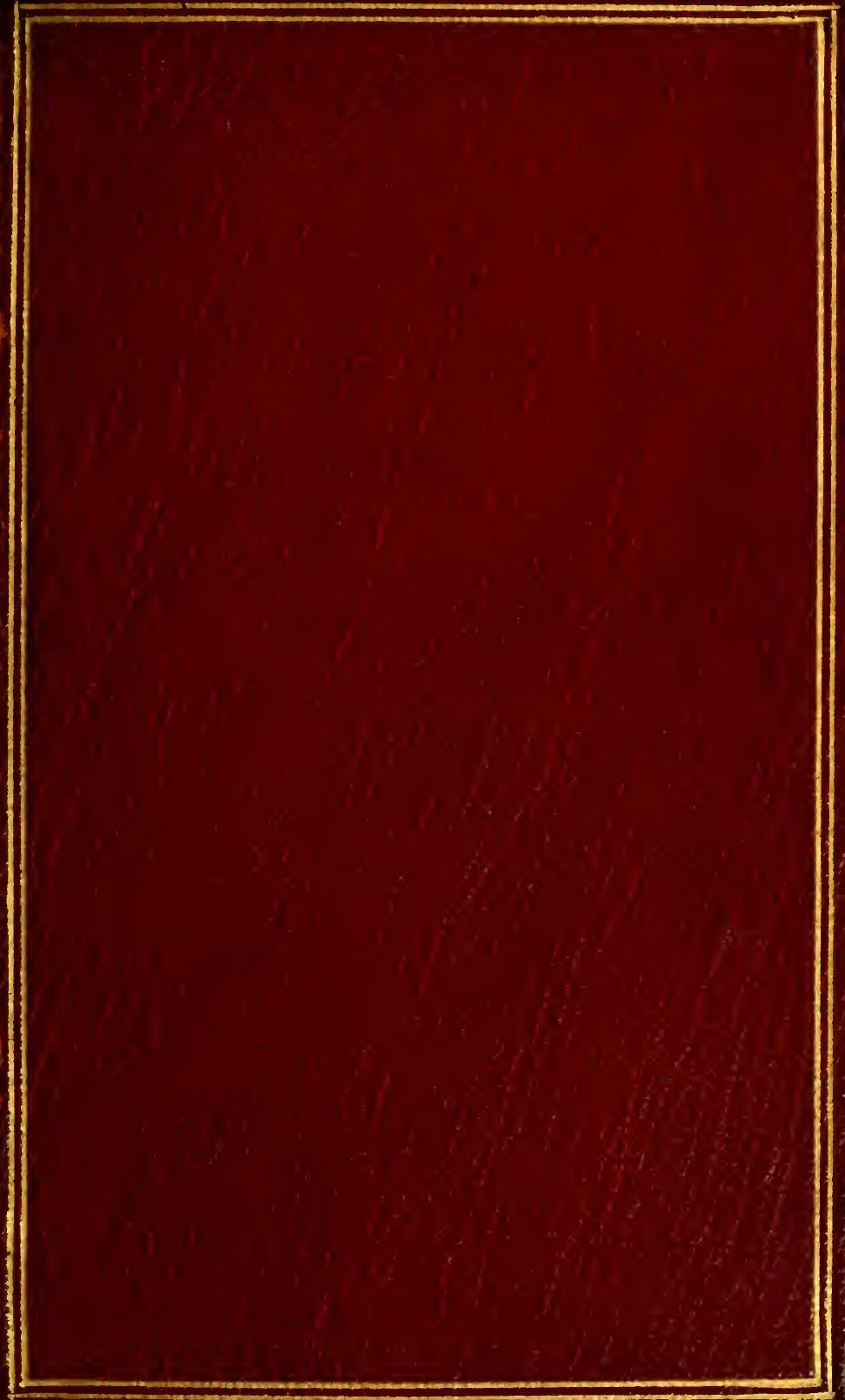




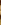

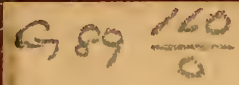

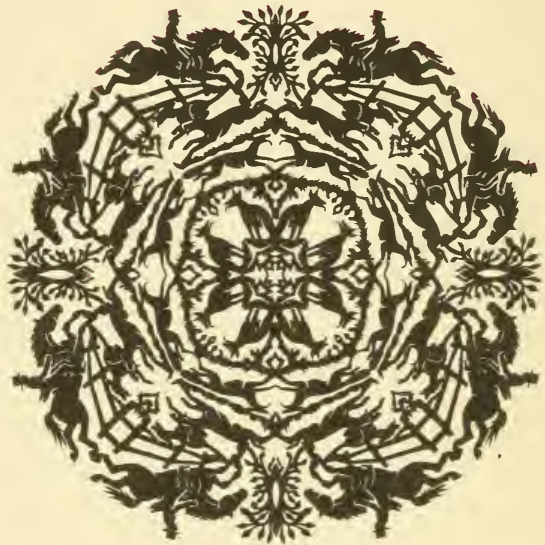

JOHN A.SEAVERNS 


$$
\text { masol }
$$








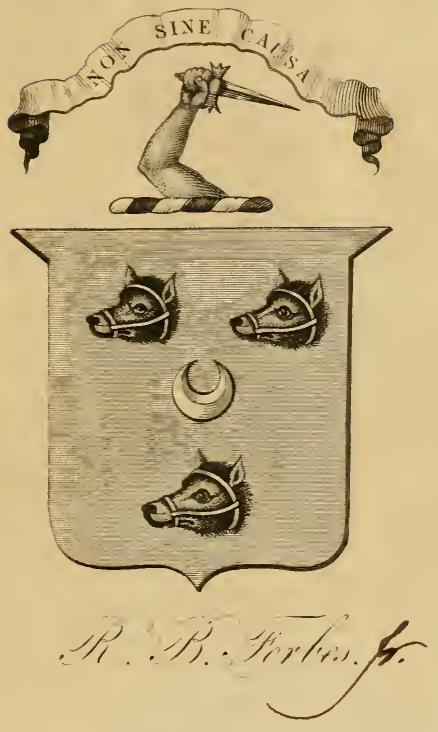




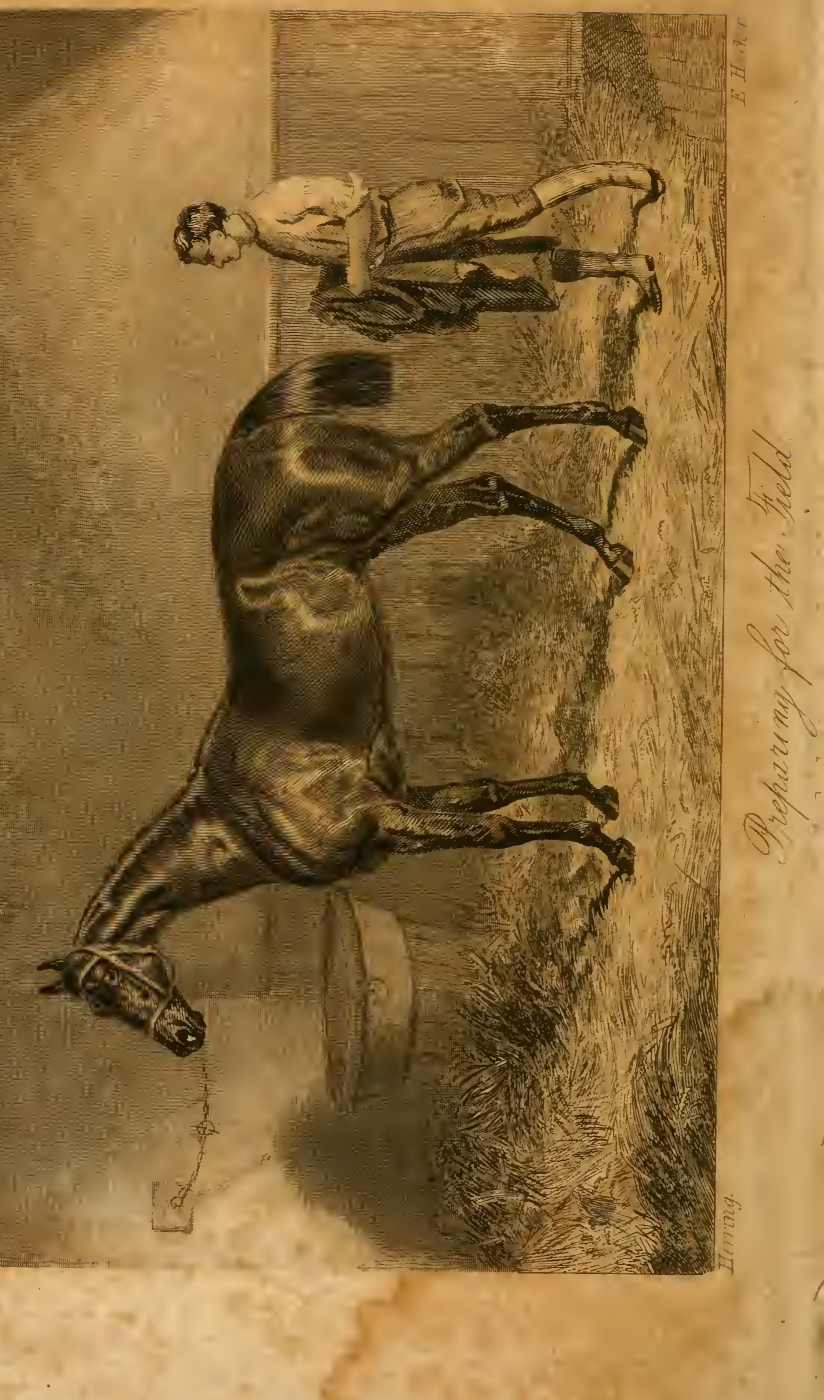




\title{
STABLE PRACTICE;
}

OR,

HINTS ON TRAINING

FOR

THE TURF, THE CHASE, AND THE ROAD:

WITH OBSERVATIONS

ADDRESSED TO ALI WHO ARE CONCERNED IN

RACING, STEEPLE-CHASING, AND FOX-HUNTING.

\author{
BY CECIL, \\ AUTHOR OF "THE STUD FARM."
}

\section{LONDON :}

LONGMAN, BROWN, GREEN, AND LONGMANS. 1852. 
LONDON :

Spottiswoodes and SHaw, New-street-Square. 


\section{PREFACE.}

THE object of this work is to point out the best means to render the horse fit for "actual service" of every kind.

The mysteries which formerly enshrouded the stable have long been laid bare; and we trust that we shall here offer to the young aspirant for racing fame, and the no less ardent admirer of the chase, such hints as may assist both in the treatment of their respective coursers.

Any person who is fond of horses, endowed with moderate assiduity, observation, and judgment, may direct the management of a few race-horses or steeplechasers, so as to find in it a source of vast amusement and excitement without encountering the expense of public training stables.

With respect to hunters, the majority of those who delight in the chase generally superintend their own stables. Those who keep stud grooms, have other 
pursuits and pleasures. To the latter, I can scarcely expect that many of these hints will be of great use; but to the former who are just entered in the field of life I presume that they may; and even to those who have made some further progress in the run, in which it is the ambition of all to excel, I flatter myself with the hope of being able to add a few wrinkles, not such as shall emanate from, but be a means of softening, care.

In the "Stud Farm" - a companion volume - all the subjects connected with a breeding establishment and the management of horses up to a certain point, are fully discussed; particularly those which treat on Food, Physic, and Shoeing : hence I have not thought it necessary to enter upon these topics further than appeared indispensable to a clear understanding of the work.

CECIL. 


\section{CONTENTS.}

CHAPTER I.

STABLES.

Imperfection of Stables in general. - Habits of the Horse. - Importance of adequate Stabling.-Aspect. - General Arrangement.Loose Boxes.-Security.-Social Disposition of Horses.-Uniform Temperature. - Construction of Stables. - Arrangement of Doors. - Interior of Loose Boxes. - Precaution against Crib-biting. Reference to the "Stud Farm." - Neatness._Economy - Saddleroom.-Hot or Drying-closet - - - - - Page 1

\section{CHAP. II.}

\section{EXERCISE-GROUND.}

Varieties of Soils. - Effects on Legs and Feet. - Elasticity of some. Kinds of Turf._Clay Land deprecated._-Dry Land recommended. -Gravel objectionable.-Kind of Soil most suitabt.-Application of Tan. - Newmarket. - Arrangements of the Jockey Club. Worm-casts.-Variety of Training-ground.-Affected by Weather. - The Warren Hill._Cambridge Hill._Other Gallops.-Epsom. - Influence of Railways. - State of the Ground. - Leatherhead and Mickleham Downs. - Interesting Scenery. - The Hednesford Hills. - Cleeve Hill. - Berkshire, Wiltshire, Dorsetshire, and Hampshire Downs. - Whitewall. - Noblemen and Gentlemen's Parks. - Natural Formation, and the Effects. - Management of Exercise-ground. - Ploughed Gallop. - Riding Race-horses with Hounds._Objection to Ploughed Gallops when dusty. - Extent of Exercise-ground. - Fences for Steeple-chasers and Hunters. -Proximity of Training-ground to the Stables 


\section{CHAP. III.}

THE DUTIES OF A TRAINER.

A responsible and arduous Undertaking.-Difficulties.-Vicissitudes of Fortunc - Suspicion. - Indiscretion. - Opportunities of Betting.-Comparative Position of Private and Public Trainers. Invidious Characters. - Calumny. - Trying Horses. - Motives of Owners of Horses.-Abstract Duties -Economy. - True Definition of Economy. - Charges for Training. - Argument thereon. - A Trainer's Calculation. - Abatement when Provender is reasonable. - Proposal of Agreement._Combined Interests._Partnerships.— Conditions._Objections.-Aggregate Number of Persons engaged in training Horses.-List of Public Trainers

Page 16

\section{CHAP. IV.}

HEAD LADS AND STABLE-BOTS.

Employment of Head Lads. - The Title. - Arocation. - Necessary Qualities. - Temptations. - Tact. — Anecdote. - Discretion. Advantages of Light Weights. - Regnlarity. - Correction of Boys. - Obedience. - Number of Boys required. - Selection of Boys. Terms of Engagement. - First Employments. - Horscmanship. Degrees of Superiority. - Anatomical Proportions. - Confidence. - Instruction to Boys in the Art of Riding. - Seat. - Management of the Reins. - Error of inexperienced Riders. - The Power of Horsemen accounted for. - Hands, and their Position. - Neglect of teaching Boys properly. - Tricks played by Stable-boys. Mischief occasioned

\section{CHAP. V.}

\section{HCXTING-GROOMS AND HELPERS.}

Comparative Duties of Trainers and Hunting-Grooms. Gradations. — Gentlemen Grooms. - Single-handed Grooms. - Occasional $\Lambda$ ssistance. - Inexperienced Servants. - Anecdote of a Gentleman Groom.-The Lse of Drugs restricted. - A Veterinary Education for Hunting-Grooms deprecated. - Helpers and their Duties. Corert Lads. - Second Horse Lads 


\section{CḦAP. VI.}

BREAKING.

Effects of Education. - A Comparison. - Progressive Tuition of Race-horses. - Young Hunters. - Reference to the "Stud Farm." - Good Horsemen essential on young Horses. - Alarm to be aroided with young Race-horses when at Exercise. - Pace proportioned to the $\Lambda$ dvancement in Condition. - Importance of a good Mouth. - Improvement of Action. - Effected by appropriate Bridles judiciously handled. — One-sided Mouths. Disadrantages which ensue. - Remedies. - Teaching Horses to leap. - May be done without Hounds. - Confidence necessary to make good Fencers. - Falls to be avoided. — Leading orer a Bar or Fence. - Impropriety of Hurry or Confusion. - Riding at Fences. - Horses ought not to be taken repeatedly over the same Fence.-Accomplished Hunters from Stables of eminent Dealers. -Distinct Characters of Riders to Hounds.-Difficulty in procuring first-rate Hacks.-Reason why they are found in the Stables of the Affluent. - Time requisite to cultivate Perfections.-Temper.Proper Age to endure IVork.-Ladies' Horses, and the Accomplishments requisite in Hacks. - Shying. - Alternatives. - Objects which Horses encounter in Towns. - Starting. - Young Horses should be accustomed to various Objects. - Harness Horses. Breaking to Harness. - Putting Horses to Carriages. - A precautionary Method, and its Advantages. - Reasons why some Horses are refractory. - The Duties of an Assistant. - Carts deprecated. -Vicious Horses. - Effects of mild Treatment illustrated. - On Bridles. - Mouths. - Hands. - Serere Bits, Objections to. Snaffles. - Pelhams. - Curb Bits. - Nose-bands. - Choice of Bits. - Bridles for pleasure Horses. - A Change recommended. Exercise Bridles
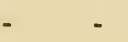

- $\quad$ Page 43

\section{CHAP. VII.}

STABLE DISCIPLINE.

Comments. - System. - Importance of minor Observances. - Applicable alike in Racing and Hunting Stables. - Adrantages of Regularity. - Time of commencing Stable-work. - Routine Duties. 
- Preparing for Exercise. - Going to Exercise. - Dressing after Exercise. - Feeding. - Afternoon Performances. — Washing Hunters. - Two Helpers employed. — Quietude

- Page 68

\section{CHAP. VIII.}

TRAINING AT TWO YEARS OLD.

Diversity of Opinions. - Events which determine the Propriety of early Racing. - Overgrown Stock. — Undersized Stock. - Effects of early Racing on overgrown Colts. - Distinction between the Work necessary for present and future Engagements. - Large Horses require much Time for Training. - Reasons why small Horses are capable of running at an earlier Age than large Ones. - Weedy Stock. - Consequences of Procrastination. - Opinions formed from extreme Cases. - Circumstances calculated to determine the Propriety of running at Two Years old.-Action._-Change of Action. - Causes thereof. - Action in some Cases restored by Rest. Management of a Candidate for a forthcoming Derby. - Moderate Work recommended at Two Years old. - Paramount Object. Betting Adventures. - Comparison of Work between young and old Horses and between Boys and Men. - Customs of Trainers.State of young Stock. - Their Nutrition, Growth, and Work considered. - Reference to the "Stud Farm." - Time when Yearlings should become Inmates of the Training Stables. - Gradual Preparation. - Increase of Work. - Successful Treatment in certain Stables. - Owners of Horses. - Patronage. — Two Years Old Stakes

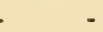

\section{CHAP. IX.}

FIRST AND SECOND PREFARATIONS.

Physic. - Indications. - Cooling Lotions. — The Tendons. - The Hocks. - Concussion. - Over-exertion, its Effects. - Rest. Diuretics. - Increase of Work. - Trainer's or Groom's Judgment. — Objects to be gained. - Healthy State of the Blood. - Disorders produced. - Faculties of Animals. - Inereased Power of sustaining Work. - Duration of daily Excrcise. - First Preparation connected with Breaking. - Period required. - Circumstances which 
denote the Necessity of Physic. - Distinction between First and Second Preparations. - Sweating. - All Horses eannot bear the same Quantity of Exercise. - Trials - _ $\quad$ - Page 82

\section{CHAP. $\mathrm{X}$.}

\section{FINAL PREPARATION:}

Work to be regulated by Circumstances. - Symptoms denoting the requisite Quantity of Work. - When insufficient. - When properly apportioned. - When too severe. - Venial Error. - Comparison between old and young Horses. - Daily Exercise. Walking. - State of the Evacuations. - Irritability of the Bowels. - Sometimes produced by Cold. - Remedy. - Cantering. - Position for the Trainer. - Examination after pulling up. - To be brought Home cool, but not suffered to become chilled.-Time when the strongest Work is recommended. - Sweats preferable to rattling Gallops. - Notes of Preparation. - The final Gallop. Indications of Fitness to run.-'Treatment on the Day prior to running. - Necessary Examinations. - The Muzzle. - Alternatives with irritable Horses. - Examples. — Quietude of Stables desirable. - Treatment on the Morning of running. - Leading out. - Treatment on returning. - Exercise distinguished from Work. - Circumstances under which Exercise is proper. - Difference of Constitution. - Stout, muscular Horses. - Delicate Horses. - Every Horse has his Distance. - Hunters. - Exercise during the Hunting Season. - Analogy between Hunters and Race-horses. - Steeplechase Horses

\section{CHAP. XI.}

\section{SWEATING.}

General Knowledge of the Term. - Necessity for the Process. Distinction between fat and muscular Horses. - Fat and its Use described. - Phenomenon of the Blood. - Congestion of the Lungs. - Nourishment from Fat. - Parts where Fat is deposited. - Importance of Fat. - Effects of serere Sweating. - Young Horses deposit Fat more constantly than old Ones. - Importance of maintaining the Condition of old Horses. - The muscular System considered. - The Action of the Muscles. - Muscular 
Development. - Process of Sweating. - The proper Adaptation of Clothing. - Material. - Distance. - Preparations. - Objection to the Muzzle. - The Canter. - The Sweat. - Kind of Ground to be selected. - Pace. - Idle Horses. - Caution against destroying the Courage. - Rubbing-lıouse or Place for Seraping. - Scraping out of Doors. - Objection to Sweating in windy Weather. Observances at the Time of Scraping. - Scraping. - Gallop after Sweating. - Routine of the Stable. - Expedition in Dressing. Danger from taking Cold. - Dry Hay preferable to Wet. - Temperature of the Stable. - Breaking out. - Practice at Afternonn Stable Time._ Causes of Horses breaking out. - Exercise on the Day after Sweating. - Intervals between Sweats. - Varieties of Constitutions. - Sweating Hunters

- Page 109

\section{CHAP. XII.}

TRIALS.

Importance of Trials. - Causes of Mistakes. - Participation of Trainers and Jockies. - Indifference respecting Trials._Errors of Judgment. - Comparison between Trials and public Races. Sceptical Opinions concerning Trials. - Touts. - Cireumspection necessary. - Trying Two Year Olds. - Preparation requisite. Placing Horses. - Qualifications. - Weights. - Reference to Handicaps. - False Conclusions. - Speed of aged Horses. - Pace. -Boys not eligible to ride Trial Horses. - Sagacity of old Horses. —Contradictory Results. — Flat and hilly Courses. - Inference in Work, but actual Trials necessary.-Case of Prejudice.-Caution against Touts. - Trial Saddles. - Caution with Boys. - Place of finishing Trial._Skill of Touts. - Indiscretion._Anecdote - 122

\section{CHAP. XIII.}

MANAGEIENT OF THE LEGS AND FEET.

Difficulty of training Horses with bad Legs and Feet. - Hunters. Causes, Remedies, and restorative Measures. - The back Sinews, and Treatment of them. - Caution. - Injurious Effects of hard Ground. - Alternative. - Comparison between Race-horses and Hunters. - Remedy. - Rest sometimes imperative. - Treatment after the Sinews have given way. - Recipe.-Sore Shins. - Relief. 
- Cooling Applications, and Mode of applying them. -- Arnaca. -Keeping Horses at Work. - Stimulants. - Biniodicle of Mercury.-Injuries to which Hunters are liable. - Fomentations.Bandages. - Blows. - Thorns. - Poultices. - Stubs. - Cold Water. - Over-reaches. - The Pastern Joints. - Synovia, its Use. - The Hind Legss. - Cracked Heels. - Ointments. - Recipe for cracked Heels. - Preventive Agency of Food and Exercise. Case in point. - Bruises of the Soles. - No Protection afforded to the Soles of the Feet by Plates. - Fomenting the Feet. - Tar Ointment. - Precaution. - Plating. - Texture of the Feet, and Treatment. - Bad Feet. - Good Feet. - Consequences of Neglect. -Observances after Removal of Shoes,-Cantion to Smiths.

Page 133

\section{CHAP. XIV.}

SHOEING.

The Importance of good Shoeing. - Perceptible Improvement in the Art. - Naricular Lameness less frequent. - Causes. - Heavy Shoes deprecated. - Effects of Horses slipping._- Casualties in the Hunting Field from slipping. - Descriptions of Shoes calculated to prevent Horses from slipping. - Shoes for the hind Feet. - Remarks on Shoes. - Corns. - Racing Plates. - Plating Steeplechasers. - Light Shoes recommended

- 150

\section{CHAP. XV.}

BANDAGES AND BOOTS.

Prejudice confuted. - Materials._-Dry Bandages. - Their Use and Effects after washing the Legs. - Their Use and Effects subsequently. - Benefits derived from Bandages. - Linen Bandages. — Cold Water. - Cooling Lotion. - Mode of applying it. - Cold Bandages for Exercise. - Recommended for Hunters. - Treatment of the Legs of Hunters after severe Work. - Distinction between warm Woollen Bandages and cold Linen ones. - Proper Method of adjusting Bandages. - Bandages or Boots for Exercise. - Merits and Demerits of each compared. - India Rubber Boots. - Objections to them. - A Case in point. - Best description of Boots for Hunters 


\section{CHAP. XVI.}

CLOTHING.

Display of Taste. - Colours. -- Texture. - Shape. - Material for Sweaters. - Stable Suits. - Precaution against Dampness. Rollers, and their Adjustment. - Tearing the Clothing. - Preventives. - Example. - Crib-biting. - Remedies. - An incorrigible Crib-biter $\quad$ - $\quad$ - $\quad$ - $\quad$ - $\quad$ - Page 169

\section{CHAP. XVI.}

PHYSIC.

Importance of Physic. - Constitution to be consulted. - Circumstances which indicate the Propriety of giving Physic to Racehorses. - Reference to Formula. - Circumstances which indicate the Propriety of giving Physic to Hunters. - On Alteratives. Reference to the "Stud Farm" $\quad$ - $\quad$ - $\quad$ - $\quad-175$

\section{CHAP. XVIII.}

TRAVELLING.

An Apostrophe. - Exorbitant Charges made to Owners of Racehorses. - Comparison with other Classes of Travellers. - Extortions counteracted by Railways. - Economy of Railway Travelling. - Inconveniences of travelling by the Road. - The Time necessarily occupied.-Touts disappointed._Effects of Road Travelling on the Legs and Feet. - Weather. - Cost per Diem of trarelling by the Road. - Sweating essential afterwards. - Precautions against Alarm and Injury. - Horses to be walked a few Miles after Railway Travelling. - Impertinent Curiosity defeated. Construction of Vans. - Expense of Posting. - Observances when travelling on the Road. - Boys walking with their Horses. Objections thereto. - Road Trarelling seldom imperative. Influence of Railways on Race Meetings - - 
CLIPPING AND SINGEING.

Clipping very generally practised. - Nimrod's approval. - Necessity for artificial Remedies. - Inconvenience of a rough Coat. Trouble and Labour avoided. - Delicate Skins and fine Coats. Singeing preferable to Clipping. - Reasons thereon. - Horses can be singed however long their Coats. - Practical Illustration. Gas versus Naphtha. - The apparatus to use Gas. - Nonsusceptibility of Cold. - Evidence thereon. - Objections. - Phenomenon of blind Horses. - Not accounted for, although attempted. - Blind Horses formerly used in Stage Coaches. - Importance of a fine Coat. - Health of the Skin promoted. - Objectionable Nostrums. - The Skin can be most thoroughly cleansed when the Coat is short

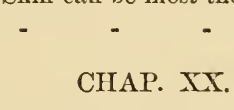

\section{WASTING.}

Effects on the Constitution. - Events which influence those Effects. Caution. - Stimulus to Exertion. - Race Riding, a laborious Occupation,-Importance of Condition in a Jockey.-Recommended to Hunting Men. - Severe abstinence from Food deprecated. Practical Experience of moderate Living and long Walks. - Deprivations of Jockies. - Hunger and Thirst. - Causes which affect Hunger. - Canses which affect Thirst. — Selection of appropriate Food and Drink. - Comparison between Wasting and Training. - Preliminary Observances. - Aperient Medicines. - Excessive Use of Epsom Salts. - Practical Anecdote. - Walking, and the usual Observances. - Pace. - Perspiration promoted. - Remedy for blistered Feet.-Walking on the Morning of a Race.-Amount reduced.-Temptation._Diet._Beverage._Smoking

- 193

\section{CHAP. XXI.}

RACE RIDING.

Race Riding as a Profession for Gentlemen. - Difficulty of the Art. - Incapability of young Jockies. - Attainment of Superiority.Comparison between good and inferior Jockies. - Integrity. Initiation.-Patience-_Pace.-Definition of the Term.-Examples. 
-Peculiarity of Temper and Action.-Indications of Pace.-Starting. - Precautions, - Starting when the Orders are to wait. Starting when the Orders are to make running.-Decuring a good Start._ Challenges in running. - Distinction between Jockies and Boys respecting Orders.-Turning Courses.-A Rule of Racing.Example thereon. - Queries. - A fine Race. - A Stratagem. Disadvantage of making ruming.-CThe Rnsh. - Preparing to set to, and finishing. - Whip and Spurs. - Praise and Censure.-Circumstances which denote the Propriety of making a waiting Race. -Of making Play

\section{CHAP. XXII.}

HANDICAPPIXG, AND THE EFFECT OF WEIGHT.

Prevailing Taste. - Connection between Betting and Handicap Races. - Policy of Handicaps. - Tendency to encourage Frauds. — Protest of the Jockey Club. - Penalties for Frauds. - Useless Punishment censured.-Qualifications of Handicappers. - Difficulties connected with the Duty. - Reasons why the Public are led into Error. - Pace. - Influence of Pace. - Light Weights. - Argument relative to Weights. - Mistaken Notions respecting Weights. - Handicapping dark Horses. - Necessity for a System of Handicapping. - Handicappers should see Horses run. Stratagems detected.-Extra Weights for Frauds. - The Principle denounced by Offenders. - Their Arguments confuted. - Impossibility of Handicapping from Paper. - Handicap Committee. - Illicit Practices defeated by System. - Paid Handicappers. Horses started at Country Meetings for certain Purposes.Advantages of a Committee. - Firmness indispensable in a Handicapper.-An Occurrence. - Responsibility of Stewards and Committees. - Distinction between Handicappers, Starters, and Judges of Races. - Restrictive Powers. - Owners of Horses and Trainers

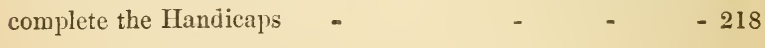

\section{CHAP. XXIII.}

REMARKS.

Commencement of Racing. - Progress of Racing. - Introduction of Betting. - Book-making. - Importance of Betting to Racing. - 
A Delusion.-Way in which Betting is prejudicial to the Turf. Analysis of Betting. - Popularity of Racing. - Effects of populous Meetings. - Present Condition of Racing. - A Glance at the Rules of Racing. - Racing as an Amusement for the People. - Not suitable as a Speculation for the Million. - Effects of Handicaps on the Brced of Horses. - Their Effects on Racing.Comparison of the Condition of Hunters and Race-horses. Condition promoted by suitable Food.-Necessity of pure Air and Exercise. - Large Enclosures not conducive to Exercise. - Comparison. - Evils of large Pasture-fields. - Reasons why half-bred Stock is, in general, longer in coming to Maturity than thoroughbred.-Argument._Conclusion - - - Page 230 



\section{STABLE PRACTICE.}

\section{CHAPTER I.}

STABLES.

Imperfection of Stables in general. - Habits of the Horse. - Importance of adequate Stabling. - Aspect. - General Arrangement. Loose Boxes._Security.—Social Disposition of Horses._- Uniform Temperature. - Construction of Stables. - Arrangement of Doors. - Intcrior of Loose Boxes. - Precaution against Crib-biting. Reference to the "Stud Farm." - Neatness. - Economy. — Saddleroom. - Hot or Drying-closet.

So much has already been written upon Stables, and so many improvements have been made in the construction of these edifices, that it may be doubted whether I can offer anything worthy of notice on this head; but I am bold enough to affirm there are very few stables that are really conveniently constructed for race-horses and hunters. Architects are seldom au fait of stable management, and those who are conversant with the latter have rarely the skill or the knowledge to make designs for buildings. 
By viewing the habits of the horse in a state of nature, we might be led to the conclusion that, when domesticated, he would require no buildings of any kind for his accommodation: experience, however, teaches us that he must be sheltered from the vicissitudes of this climate, and, above all, that the stables which he inhabits imperatively require the most scrupulous nicety of arrangement, if the utmost amount of his powers is to be made subservient to our use.

The aspect of the stable forms the first subject for consideration. It should invariably face the south or west. It may be inquired, if the principal stables are to occupy that position, how the other parts of the yard can be arranged without a considerable waste of ground. The northern and eastern aspects may be appropriated to the back of the dwelling-house, which will thus face the south; outoffices, saddle-rooms, coach-houses, and such like edifices of minor importance will face the east.

General opinion is decidedly in favour of loose boxes, to which, indeed, there can scarcely be a dissentient voice. The space which they afford enables the occupants to enjoy their ease and repose much more perfectly than when they are confined in stalls. The increased security when the doors are closed is another great recommendation in favour of loose boxes; for, although bails may be, and generally are, fitted from the walls, to the stall-posts, they do not exclude the chance which a vicious or restless horse may have of injuring or annoying his neighbours in the event of his getting loose. 
The social disposition manifested by many horses is such as to render them dissatisfied when shut up in boxes which do not communicate with adjoining ones; on the other hand, some horses are restless if not entirely secluded from their species. An extensive range of boxes communicating with each other, as they are usually built, is objectionable when they are not all occupied, because in that case it is difficult, in fact impossible, satisfactorily to regulate the temperature. These objections may be readily obviated in a very simple, economical, and effective manner. Let each box be boarded to the height of five feet and a half, and from thence to the ceiling divided by iron bars. By having shutters to fit from the top of the boarding to the ceiling, each box may be rendered distinct from the adjoining one, or open, as circumstances may require. Thus, whether the building consists of only two boxes or twenty, any number may be thrown open or closed, as most convenient. Where there is a range of boxes, it is desirable to have doors internally communicating from one to the other, so that a passage can be obtained, without opening the external doors, in cold and windy weather. The arrangement which appears superior to all others, for doors to loose boxes, is that of having one spacious entrance door to serve two boxes, the centre of which is midway or parallel with the partition of the boxes: an interior door also to each box, one opening on the right, the other on the left hand. The advan-. tages of this plan are twofold, - a communication is 
effected from one box to another without opening the outer door; and on all occasions, except when the horses are passing in or out, the outer door can be closed, if desirable, before the inner door to either box is opened.

To render the interior complete, the boxes should be boarded all round, to the height of five feet and a half, with strong yellow deal or oak, one inch thick. The latter material is, doubtless, to be preferred, on account of its strength. If the former is made use of, hoop iron in strips will be required to prevent horses from biting it. Ever prone to mischief, unless such a precaution is taken, they will not only destroy the wood, but they will contract bad habits. In fact, all wood-work which they can take hold of with their teeth should be secured with iron, the expense of which is trifling.

Having, in the "Stud Farm," treated on the subjects of roofing, ventilation, paving, fittings, and the materials calculated for stabling, it is unnecessary to repeat them here, as similar arrangements and precautions are applicable for stables occupied by horses in training and hunters. It may be deemed necessary to finish them more elaborately, but that is quite a matter of taste. The inmates will derive no benefit from the ornamental decorations of the buildings they inhabit; and though elegance of design is pleasing to the eye, and on that account commendable, it ceases to be so if introduced at the expense of more urgent conveniences. Well-constructed stables may be erected at a comparatively 
trifling cost, provided the plans are well drawn. Neatness and appropriateness are more in keeping than the ostentatious display of architectural embellishments. The economy of labour is also an item worthy of attention. A never-failing supply of water is indispensable; and, unless the receptacles for hay and straw are conveniently placed, the servants' time will be unnecessarily employed in sweeping away the fragments, in order to preserve that cleanliness and neatness which are essential to the appearance of a well-conducted establishment.

As a necessary addendum to the stable, the saddle-room must not be omitted, the judicious arrangement of which will considerably diminish labour, and be the means of preserving those articles for which it is especially constructed.

On first entering a stable-yard, nothing proclaims more accurately the manner in which the establishment is conducted than the appearance of the saddleroom. Well furnished with nicely arranged appointments made by skilful workmen, a neatly kept saddleroom presents an agreeable show; but, on the other hand, if the various articles are lying about in confusion, imperfectly cleaned, and left to be finished off when wanted, the apartment suggests ideas of chaotic irregularity, which, in all probability, will be found to prevail throughout the establishment.

Among the fittings of a saddle-room, a hot closet for the purpose of drying clothing is a convenience of inestimable value; and, as it can by proper arrangement in the first instance be constructed at a trifling 
expense, and kept in operation by the heat of the ordinary fire, every person who consults economy of labour will assuredly provide for this accommodation.

In hunting stables, a loose box or enclosed shed is almost indispensable for washing the legs and dressing horses after their return from the chase. Where the practice is adopted of washing horses all over, an accommodation of the kind must be provided, as it is out of the question to perform such an operation in the box or stall wherein the inmate remains for the night; and, under any circumstances, such an arrangement is conducive to the order and regular temperature of the apartment in which the wearied creature takes his repose. 


\section{CHAP. II.}

EXERCISE-GROUND.

Effects of Soils on Legs and Feet. - Elasticity of some Kinds of Turf. - Clay Land deprecated. - Dry Land recommended. Grarel objectionable. - Kind of Soil most suitable._Application of Tan. - Newmarket. - Arrangements of the Jockey Club. Worm-casts._Variety of Training-ground.-Affected by Weather. - The Warren Hill. - Cambridge Hill. — Other Gallops. - Epsom. - Influence of Railways. - State of the Ground. - Leatherhead and Nickleham Downs. - Interesting Scenery. - The Hednesford Hills. - Cleeve Hill. - Berkshire, Wiltshire, Dorsetshire, and Hampshire Downs. - Whiterall. - Noblemen and Gentlemen's Parks. - Natural Formation and the Effects. - Management of Exercise-ground.-Ploughed Gallop._Riding Race-horses with Hounds. - Objection to Ploughed Gallops when dusty. - Tanned Gallop. - Extent of Exercise-ground. - Fences for Steeple-chasers and Hunters. - Proximity of Training-ground to the Stables.

Trie effect produced on the legs and feet of horses by the land on which they are worked is so great, that it is of vital importance to select that which is best adapted to the purpose. In some situations the elasticity of the turf is so perfect, that the prints of horses' feet are scarcely visible, although they may be ridlen over it at their best pace, and this without the ground being hard. Where clay prevails, in dry weather it will assume the rugged and unyielding properties of rock, and rain will render it deep, tenacious, and holding, occasioning much undue fatigue 
to the animals compelled to gallop over it. For the purpose of training race-horses it is quite inapposite; and for exercising hunters it should be avoided. A dry surface is found to be mosi suitable to the thoroughbred horse, during every stage of his existence. Those situations where gravel predominates should not be chosen, because of its solid qualities, and the concussion which it occasions. The eligible kinds of land for this purpose are extensive tracts of light loams, approximating to sand, with a substratum of chalk; sandy peats, if the surface be good enough to bear a sound turf, and the bed sufficiently absorbent to take up the wet. If the land be too poor and sandy, it will work in holes, and produce inequalities, but may be improved by care, and judicious application of manure; for which tan is to be preferred to any cther material. It must, however, be laid on with discretion, in thin coats, and renewed as the grass grows through it, by which means, aided by the use of the roller, and abstaining from galloping thereon until a fine texture of sward is established, good ground for training upon may be cultivated.

The ground devoted to the purpose of exercise at Newmarket is naturally good, except in very dry weather, when it becomes somewhat hard. That may be in a degree accounted for by the number of horses trained thereon; but the Stewards of the Jockey Club, having discretionary power as to the management, restrict persons from taking their horses on those parts which have been much trodden or cut up; so that, by giving it rest, a new coat of 
verdure springs up. One of the advantages to be derived from training at Newmarket consists in the variety of ground available for that purpose; more so, perhaps, than from the quality of the soil itself. It is, however, found in excellent order during moderately moist seasons, such as usually prevail in spring and autumn. When requisite, there is the Warren hill, which affords a gallop of nearly two miles : and, taken in certain directions, it is a very severe one, sufficient to bring the respiratory organs into action to the fullest extent; indeed, metaphorically speaking, it is enough to break a horse's heart if injudiciously made use of. The Cambridge hill, on the London side of the town, is less serere, and to be preferred, especially for the juveniles or horses of delicate constitutions, besides being well fitted to make the conclusion of any distance of ground that may be deemed expedient to gallop over.

Ensom Downs were once much resorted to by owners of race-horses, owing to their proximity to the metropolis. The Leatherhead Downs are, in my opinion, preferable to any in this neighbourhood, so far as the nature of the soil is considered; the only sbjection to them is the want of extent, which occasions a good deal of turning to obtain a gallop of sufficient length. The Mickleham Downs, which are close at hand, are also very good. It is scarcely possible to conceive a more animating scene than that which is here presented a few mornings prior to the Derby day. The favourites are generally to be 
seen taking their last gallop, prior to the eventful contest, and many of the owners and others interested in the race are here congregated, watching with intense anxiety the stride of every candidate for the blue ribbon of the turf. The scenery around is picturesque and enchanting, and on a fine May morning nothing can be more delightful.

The Hednesford Hills, in Staffordshire, are much resorted to by the owners of horses connected with the midland counties; but they are not good unless it be in the spring. When dry weather commences they become insufferably hard, the substratum being a dense body of gravel. Several dressings of tan would improve the surface, and, as there is an excellent variety of hill and undulating ground all around it, those remedies would be found well worth attention.

Cleeve Hill, on which Cheltenham races were wont to rejoice, presents a verdure well calculated for training. It is close to the pleasant little village of Prestbury, where the well-known Tom Olliver resides, and combines the training of race-horses and stceple-chasers.

There is a splendid tract of down land in Berkshire, extending from Ilsley and Lambourne to the vicinity of Marlborough and Beckhampton, in Wiltshire. That on which Jones of Rockley trains is superlatively good. Beyond this, at Pimperne, in Dorsetshire, where Percy resides, the exercise-ground is capital.

In Hampshire, at Littleton, William Dilly, one of 
the most respectable men in his vocation, occupies some downs of superior quality. The far-famed Danebury establishment is in the same county. The money and judgment expended by the late Lord George Bentinck have rendered John Day's exerciseground second to none. The application of tan has in this case been adopted with the most beneficial results.

Never having been there, I can only notice the training-ground at Whitewall, occupied by John Scott, from report; the appearance of his horses at the pest sufficiently indicates that everything connected with the establishment is the best of its kind.

There is a rast number of noblemen and gentlemen's parks in various parts of the kingdom admirably adapted to the purpose of training horses, but, with the exception of their hunters, very few are trained at home.

The formation of exercise-ground is a point of importance. To be thoroughly perfect it should have a hill or an ascent, so that it may be used at the conclusion of the gallop, and that for a distance of nearly, if not quite, half a mile. When attainable it is very desirable that the ground should possess an undulating form; this may frequently be acquired by the direction in which the gallop is marked out. It is very important that every muscle of the horse in training should be brought into action, to do which a variety of ground is necessary. Another reason, likewise, may be given for this recommendation :- as the form of race-courses varies, it is requisite that every horse 
should be so trained in his exercise as to accommodate limself to those variations: if only accustomed to take his exercise on the flat he would be much inconvenienced when required to face a hill; or, if invariably trained against a hill, he would be unable to adapt himself to that length of stride essential to success on a flat course. While it may be truly remarked that some animals show their superiority on flat courses and others on hilly ones, yet it is highly necessary that the ground on which they are worked should vary.

Some care is necessary with the soundest and strongest turf to keep it in good order, especially in wet weather, and with a number of horses daily galloping over it. To avoid as much as possible working in the same tracks will further this end very materially, and the use of the roller at proper seasons will press in the foot-marks; but the less that implement is resorted to the better after the aforesaid operation is accomplished, as on most soils it has the effect of rendering them too solid.

Very few soils are of so excellent a quality as not to become hard in dry weather. To meet this difficulty, ploughed gallops have in many instances been provided with success to a certain extent. Years ago a trainer would have gone into hysterics, at the bare suggestion of giving a horse in training a single gallop on ploughed ground, but experience usually overcomes prejudice, at least when the experiment proves successful. I well remember, in my younger days, informing my trainer that $I$ intended to ride 
with the hounds a five-year old horse I then had, which had been in training and was intended to run the ensuing summer. He said all he could to persuade me not to do so, remarking that, independently of accidents, it would render him slow and worthless; but I disregarded his admonitions, and the following season he ran much better than he had done previously, although trained at home. When I rode him with hounds I always had a second horse out, and $I$ am convinced many race-horses are better, when so treated during the winter, than by being only ridden at exercise by boys.

In dry weather, and that is the time when they are generally in requisition, ploughed gallops are apt to be very dusty; which I consider the greatest objection to them. This does not affect the horse that is leading, but those which follow suffer from the dust he throws in their faces, and portions being inhaled must affect the delicate nembranes of the respiratory organs. To obviate this evil as much as possible, not more than three or four horses should be allowed to gallop in company; and those which follow, to use a sailor's term, should "lie to windward" of those which go in front respectively, on every available opportunity, and also keep wide apart; directions which the boys will not fail to attend to for their own convenience. This will not, however, be a means of avoiding the dust when the wind is directly in the horses' teeth, or if blowing hard when point blank on their quarters; for, although horses have been described as possessing "speed to outstrip 
the wind," there are times when they find it difficult to "outstrip the dust." Another alternative, when the ordinary galloping-ground is too hard, is to cover a certain space with tan. This has an advantage over ploughed land, as it does not give forth so much dust. It is, however, rather a costly addendum, but this scarcely appears to be an impediment where horses of great value are trained.

A tract of land where space can be commanded to obtain a gallop of two miles, without a perceptible turn, is a great desideratum: yet horses should be occasionally accustomed to turn; otherwise, when they are brought out to race, they will frequently experience much inconvenience from want of practice, especially on such a course as that at Chester, and many others on which country meetings are held. A small confined exercise-ground, scarcely a mile in circuit, may do to train steeple-chasers or work hunters upon, but is not calculated for race-horses; constantly on the turn, they are no sooner in their stirde but it must be shortened to enable them to get round the turns, to say nothing of the injury they are every moment liable to inflict upon themselves by hitting their legs.

Where steeple-chase horses are trained, or even where hunters are worked, it is desirable to have some temporary fences erected on the ground for practice. Well-disposed and good-humoured as farmers are, taking them as a body, very few are willing to have their land and fences ridden over by horses at exercise. 'The fences require to be as much 
varied as possible, and, without presenting formidable and dangerous barriers, should be sufficiently strong to prevent horses running through them, or knocking them down.

Many persons are of opinion that the exerciseground should be at some distance from the stables, contending that, if the horses have two or three miles to walk to it, their work cannot be commenced too soon on leaving their stables. I cannot subscribe to this opinion. Unless the training-ground is near at hand, there are many days on which the horses will not be able to go out at all, or, if they do, they will get wet before they return. If a man has not sufficient resolution and self-command to keep his horses at walking exercise a proper length of time, without something more than discretion to compel him, he is not fit to have the superintendence of a stud. 


\section{CHAP. III.}

THE DUTIES OF A TRAINER.

A responsible and arduous Undertaking. — Difficulties. — Vicissitudes of Fortune. - Suspicion. - Indiscretion. - Opportunities of Betting. - Comparative Position of Private and Public Trainers. Invidious Characters. - Calumny. - Trying Horses. - Motives of Owner of Horses.-Abstract Dnties.—Economy.-True Definition of Economy. - Charges for Training. - Argument thereon. - A Trainer's Calculation. - $A$ batement when Provender is reasonable. Proposal of Agreement. - Combined Interests. - Partnerships. Conditions. - Objections. - Aggregate Number of Persons engaged in training Horses. - List of Public Trainers. .

Tre duties of a trainer are amongst the most difficult to fulfil with satisfaction. No ordinary vigour of mind is necessary to enable him at once to direct effectually the details of his calling, so that each animal may be brought to the post in the best possible condition, and to withstand the fearful temptations with which he may be at times assailed. It is not only necessary that he should be an adept in the art of training, but he must also be conversant with the arts of men, that he may be able to detect their treacherous schemes, and, by detecting, avoid them. Vigour of body is also necessary, that he may be able to clischarge his duties, which are at times fatiguing, enhanced by the excitement which awaits the result of every race. The current of prosperity will fre- 
quently carry men of weak minds into a Charybdis of trouble; more so than disappointment, which may be overcome by assiduity. In racing affairs, the vicissitudes of fortune are very frequent, and often very extensive. Most trainers bet; and he who was worth but little at the time of breaking his fast in the morning, should he be successful in winning a stake upon which his investments are extensive, may be entitled to thousands ere he partakes of his dinner. In the long run, I believe such speculations are not profitable. A trainer has, of all other persons, the best opportunity, when he finds a horse worthy of an investment, of backing him at long odds, and then, when the animal becomes a favourite, of hedging his money. Into how many temptations does this lead him? In the first place, he must use every endeavour to enhance the merits of the horse; in the second, no person but himself knows how much hedging money he sends into the market, or, in plain English, if he is not tempted to stand heavily against his charge.

Of the two, the duties of a private traincr are light and easy compared with those who train for the public. The former has simply the interests of his master to consult; but the latter, who has numerous employers to please, sometimes finds it a difficult, indeed a very arduous task, to steer clear of the perplexities which beset him. It is too true that all men have enemies, and those are the most dangerous who ingratiate themselves under the mask of friend- 
ship. There is a class of men connected with the betting community, who will stop at nothing to accomplish their purposes. It is not reasonable to imagine, that an individual who will risk his own character, will be very scrupulous about the reputation of others. Such men, if they cannot insinuate themselves under the cloak of miscalled confidence, will not hesitate to circulate calumniating and false reports. They are the most dangerous persons a trainer can associate with.

A public trainer, having various horses under his care, the respective property of different persons, is not unfrequently supposed to have availed himself of the information which he has the power of obtaining, by trying the horses of his employers, or, at all events, if not by trying them together, of obtaining a measure by indirect means. In fact, some persons send their horses to public trainers, under the impression that they shall have the qualifications of their horses scrupulously tested by this means. Others there are who revolt at the idea of such a proceeding. That such trials never ought to be permitted without the express sanction of the respective owners, there can be no doubt. It is no doubt a trainer's duty to prepare every horse that may be placed under his care to the best of his ability, but it is not a part of his duty to try horses belonging to different employers for his own especial advantage, or for the advantage of an individual employer. 
Most persons, whether they be owners of racehorses or not, are desirous of practising economy; but they frequently attempt it upon erroneous principles. If the term be rightly defined in such cases, it should signify the method of regulating expenditure under circumstances the most likely to produce profitable results; it is not the mere saving of money that will on all occasions lead to a favourable termination, without the judicious calculation of contingencies. With a view of having their stables filled, trainers will, in some instances, engage to take a lot of horses at a price below the usual rate; but it is very doubtful whether the owner of those horses consults his own interest by entering into such an arrangement. The charge is generally from thirtysix shillings to two guineas per week, for the keep of each horse and boy ; shoeing, medicine, and travelling expenses not included. This may appear to yield a considerable profit, especially when hay, corn, and provisions are at a low price (and so, unquestionably, it does); yet there are a few little items which deserve notice. - In the first place, the hay and corn must be of the very best quality, if the animals which partake of it are to be brought out in a state fit to run. The rental of appropriate stabling is another consideration; to which must be added the keep of the boy: and lastly, an experienced trainer is entitled to a compensation for his skill, over and above the profit he may make upon his hay and corn. The management of race-horses is a trust of considcrable 
magnitude, and when conducted with integrity merits reward. When a man undertakes to train horses at a reduced price, he calculates upon making up the deficiency in some other way. He argues with himself that the charge per week ought to be two guineas; but having agreed to take $30 s$., he considers how the difference can be balanced: thus inferior provender is provided, or a system of betting put into operation. The difference between two guineas and $30 s$. per week, for each horse, amounts to $27 l .6 s$. in the vear; therefore, if one horse wins only one extra stake of 50l., he pays the difference for himself and nearly that of a companion. Some abatement may probably be expected, and very reasonably so, in conformity with the times; and if I were about to enter into an arrangement with a public trainer to take charge of a lot of horses, my conditions would be somewhat in this fashion. Charge me a fair, but not an exorbitant, price for each of my horses, and let them have the best of every thing they require; but you must undertake not to bet upon any event whatever in which they may be engaged. When we have good reasons for backing any, I will get the money on for you, and I will give you five per cent. upon the amount of every stake I win. Such an arrangement would give the trainer a pecuniary interest over and above that of the reputation which he gains by bringing the horses entrusted to his care well to the post. It may be said, that if so disposed, he can bet without his employers' knowledge : per- 
haps he can, and it is not impossible he may be found out. But a man who is not worthy of confidence for the fulfilment of a specific contract, is not worthy of trust under any circumstances; and there is no occupation in which a greater share of confidence must of necessity be reposed than the one now under consideration.

It is not a very unusual custom to enter into a sort of partnership with a trainer, especially with persons who have but one or two horses. This is generally done in order to avoid any charge for keep and training, and also to give the trainer a positive interest in the horse's success. The terms are necessarily regulated by the merits or supposed merits of the animal. Take a promising untried two year old as an example: the trainer would in all probability require an actual half share in the colt, charge nothing for keep, pay half the stakes, a similar portion of jockey's fees, travelling and such like expenses, and be entitled to receive half the stakes. These arrangements are open to some objections, inasmuch as the original owner parts with half his property without any positive recompense, and unquestionably resigns all control over his horse. That such terms have been satisfactory in many instances I will not pretend to deny; at the same time, people must have very great reliance on each other to enter into such compacts.

In "Bell's Life" of recent date there are nearly ninety trainers enumerated, about a third of whom 
are privately engaged: it is unnecessary, therefore, to mention them; but as the services of public trainers may be required by some of my readers, a list of these is subjoined, and a few added whose names do not appear in the above-named authority.

\section{PUBLIC TRAINERS.}

At Newmarket.

Arnull, William.

Bell, Henry.

Boyce, Richard.

Edwards, William.

Goodwin, William.

Perren, John.

Cooper, Richard.

Pettit, Robert, jun.

Rayner, Charles.

Rogers, Joseph.

Smith, William.

Daley, John.

Stephenson, 一, sen.

\section{IN The Countri.}

Armstrong, James, Malton.

Balchin, W. and C., Sutton,

Surrey.

Clark, James, Newton.

Cunningham, T., Highfield, Malton.

Dallimore, J., Westbury, Wilts.

Day, J. B. and Son, Danebury, Stockbridge.

Day, W., Woodyates, Salisbury.

Dawson, T., Middleham.

Dawson, J., Middleham.

Death, J., Ascot.

Dickens, S., Northampton.

Dilly, W., Littleton, Winchester. Dockery, George, Epsom.

Fowler, W., Aintree, Liverpool. Flintoff, T., Hednesford, Cannock. Fryer, M., Haxby, York. Gill, John, Richmond, Yorkshire.
Halliwell, J., Mayday Cottage, Gullane.

Hesseltine, Robert, Hambleton.

Hopwood, J., Holcombe Hill, Bury, Lancashire.

Hornsby, Charles, Barham, Canterbury.

I'Anson, W., Malton.

Jones, E., Rockley, Marlborough. King, Young, Stockbridge.

Lord, S., Hednesford, Cannock.

Marson, J., Beverley.

Martin, R., Delamere Forest, Cheshire.

Nelson, R., Thicklands, Huddersfield.

Noble, George, Beverley.

Oates, George, Middleham.

Olliver, Thomas, Prestbury, Cheltenham. 
Oseland, R., Richards Castle; Scott, John, Whitewall, Malton. Lindlow.

Osborne, J., Middleham.

Parlby, J., Berry Hill.

Peck, Charles, Malton.

Scott, William, Prestbury, Cheltenham.

Shepherd, J., Malton.

Thompson, W., Middleham.

Percy, H., Pimperne, Blandford. Thorp, C. L., Bennethorpe, DonPeace, J., Delamere Forest, Tarporley.

caster.

Turner, Thomas, Chester.

Price, T., Cheddington, Ayles- Wadlow, Henry, Stanton, Shifbury.

nal.

Rutherford, W., Bogside, Ayr- Wilkins, J., Aintree, Liverpool. shire.

Saddler, Wm, Houghton Down, Stockbridge.

Winteringham, J. and C., Richmond, Yorkshire.

Woolcot, Isaac, Stockbridge.

Saunders, William, Hednesford, Wycherley, H., Epsom.

Cannock. 


\section{CHAP. IV.}

HEAD LADS AND STABLE-BOYS.

Employment of Head Lads. — The Title. - Avocation. - Necessary Qualities. - Temptations. — Tact. - Anecdote. - Discretion. Advantages of Light Weights. - Regularity. - Correction of Boys. - Obedience. - Number of Boys required. - Selection of Boys. Terms of Engagement. - First Employments. - Horsemanship. Degrees of Superiority. - Anatomical Proportions. - Confidence. - Instruction to Boys in the Art of Riding. - Seat. - Nianagement of the Reins. - Error of inexperienced Riders. - The Power of Horsemen accounted for.- Hands, and their Position. - Neglect of teaching Boys properly. — Tricks played, by Stable-boys. Mischief occasioned.

IT is scarcely possible to conduct the management even of a small training establishment, whether private or public, without the assistance of a head lad, who is generally promoted from the ranks of stable-boys. Somewhat akin to the post-boys of the olden time, these functionaries retain the title of juvenility, although they may be advanced in years; it is a distinction applied to the occupation, and being one in which considerable trust is reposed, there is no inconsistency in selecting one of mature age. A trainer, or superintendent, must, of necessity, be now and then away from home, and then the charge of the stable department devolves on the head lad. He is also required to maintain a subordinate command 
over the boys; and therefore, to be worthy of the appointment, he must possess many good qualities, of which implicit obedience to orders is one of the first. Unless he strictly sets the example of obedience, he will not be able to exact it from those who are under him. In every case where it can be conveniently practised, it will be found a good plan to issue directions to the boys, through the head lad, as it will accustom them to obey his instructions. Without exercising tyranny, he must exact compliance, and to that end should, on his promotion, cease from familiarities with his late associates. To create respect, he must demean himself respectably. That he should be a good horseman is of the utmost importance; for he will not only have to ride the most difficult horses, but he will have to instruct the boys in the art of equestrianism. For this and other reasons, he must be good tempered. Cleanliness in his own person, with a perfect regard to order, punctuality, and neatness in every department over which he has any control, are essential habits; and unless he is gifted with discretion in not making unnecessary and improper communications, he is not fit for his place. As he will often be tempted to betray the interests of his employer, he requires the combined merits of integrity and firmness. When questions are put to him relative to any horses or affairs connected with the stable, he should possess the tact, without incivility or direct falsehood, of evading those questions.

A very trustworthy lad, whom I had in my em- 
ployment several years, possessed this faculty in great perfection. On one occasion, when on the road to Bath races in charge of two horses, he was met by a gentleman, who inquired "Whose horses they were." "If you please, sir, I cannot tell you.' "What races are you going to?" was a sequent question; and that was replied to by a similas answer. Several other unimportant queries met witk precisely the same fate. Two or three days after. wards, when on my way to the races, I met the same gentleman, who was an old acquaintance; and in the course of conversation I mentioned my destination "Oh!" he exclaimed, "were those your horses saw on the road a few days since?" at the same tim giving a description of them: upon which, I sai they were. "A strange sort of lad that of yours who had the care of them," he observed; and relater to me what had passed. "I hope he was not uncivi to you?" I inquired. "No, by no means," he said "the young man was very respectful; but all could get out of him was, 'Sir, I cannot tell you.' "I do not understand," said I to my friend, "tha my servant has told you any untruth, or acted in an: way improperly. On the contrary, had he gives direct answers to any stranger, he would have don so in defiance of general orders. His having replier ' he could not tell,' implied that some definite cir cumstance controlled him." As the gentleman is question was not in any way connected with racing it would not have signified in the slightest degre if he had received the most explicit replies to th 
questions which he put, unless he might have inidvertently given the information he had received to thers who might have made a bad use of it. For nstance, supposing the horses had been intended to :un for stakes which had not closed, and the inquiry made what races they were going to run for: the inswer, being given, would not have been of the least importance to the inquirer, but he might meet with another friend en route to the same meeting, to whom he might mention that certain horses were gone to Bath to run for certain stakes; and thus if the latter person happened to have any of inferior merit, he would be deterred from entering them. Such a question being once replied to, it is impossible to know where the news may circulate; and on the eve of race meetings there are invariably numbers of inquisitive persons about, endeavouring to collect all possible intelligence for all possible purposes. To all inquiries of a similar nature, head lads, and all other lads, should have the answer ready, _ " If you please, sir, I cannot tell you."

It is desirable, although not a sine quâ non, that a head lad should be a light weight, as in that case he is the most proper person to lead gallops, ride trials and sweats, and may be occasionally put up to ride races; the latter profession, however, if the indi vidual possesses sufficient ability, usually gives rise $t_{1}$ ambitious notions incompatible with the duties 0 this service.

No colony enjoys internal peace and order, unless it be governed by well digested regulations. Where 
there are so many youthful tempers to be dealt with: as there must necessarily be where a number of boys are employed, as is the case in racing stables: a steady eye is necessary to direct them, and laws once established should never be permitted to be infringed with impunity. Disobedience of any rule or order once overlooked, will assuredly create disregard and disrespect for others. The necessity for severe punishment will be avoided by slight punishment for trivial offences, if there be a thorough understanding that the amount of punishment will: on all occasions, be commensurate with the degree of misconduct. There is no class of servants in whom obedience is of greater importance, than those who are employed in the care of race-horses; and when it is remembered that the giddy mind of youth may frustrate the hopes of years, and destroy the chance of gaining thousands, by one act of disobedience, it cannot be necessary to urge another word on the importance of strict discipline.

The number of boys required to attend to a certain number of horses, may be decreased in ratio as the number of horses increases. Paradoxical as the assertion appears, it will be clear on explanation. Thus, if there be only three or four horses in work, an equal number of boys are required; but if there be eight or ten horses, five or six boys will be sufficient, as it will seldom, if ever, be necessary to send all the horses out to exercise at the same time.

In making engagements with boys for this pur- 
pose, it is desirable to select those who are of small stature. Whether that property descends from their jarents, is not in all cases a matter of certainty, ieither is it possible to determine whether a youngster it twelve years of age, although diminutive, may tot rapidly increase during the succeeding six or ight years, and become a lusty man; nevertheless, he best criterion is the actual growth of the urchin. The respectability of the parents is an important consideration; for though it appears hard to visit the ins of the fathers on the children, yet, unless boys lave been taught obedience and propriety of conduct, hey are sure to create much trouble ere they are lrilled into good behaviour. The usual custom is 0 engage novices for a term of years; and this is necessary one, for during the first twelve months hey are seldom of much use; and to get well-conlucted boys from other training stables, after having earnt their duties, is not very easy. Owners of corses and trainers do not like to part with them; $\mathrm{n}$ fact, having engaged them upon such conditions, hey cannot consistently do so. Of young scamps here are plenty; but their society is dangerous at once to their comrades, and to the horses entrusted o their care.

Rubbing legs, rolling bandages, cleaning bridles ind saddles, carrying water, and such like suborlinate employments, are the preliminary lessons of he novice, until by degrees he becomes familiar vith such operations, and, in course of time, ascends o higher occupations. The art of horsemanship is 
an acquirement indispensable in the stable-boy, and it is one in which there are many degrees of superiority. Some attain it very quickly, -in them it appears as a gift; others require much tuition; and many never become proficients, with every advantage of the most patient instructors. Now, these degrees arise from divers causes, which may be single or collective. The formation of the human frame is various in its adaptation to equestrian exercises. The youth with short thighs, with knees having an unsymmetrical affinity for each other, can scarcely be expected to accomplish the first most essential acquirement, a good seat; but he whose thighs are lengthy, with knees a trifle bowed outwards, appears as if nature had. formed him for the purpose, the moment he is placed in the saddle Confidence is a qualification without which neither man or boy can ever ride with effect; however large and physically powerful the frame may be, if the individual is timid and nervous, he is a useless in. cumbrance on the animal he bestrides. The first. named quality, that is, the formation of the limbs cannot be controlled; the latter may be so, to a very considerable extent, by means of instruction. If ar unpractised rider be placed on an unsteady horse, it is very probable they may quickly dissolve partnership; and if in doing so, the partner who aspires tc be at the head of the firm, receive an injury by the prostration, he will very probably be reluctant ir again attempting an experiment; and although the fear of chastisement from a superior, and of derisior 
from his companions, may stimulate the fallen aspirant to another essay, it will not be accompanied with confidence.

The most successful method of giving preliminary instruction to boys in the art of riding, is very simple. To begin, I place a saddle on the stand provided for the purpose of cleaning the stable appointments upon; this is done previously to placing the youngster on the back of a horse. Having put the boy on the saddle, and adjusted the stirrup leathers to the right length, he is shown the proper position for his legs, - instructing him to keep them somewhat forward, with the foot bearing well down on the stirrup iron, and the toes pointed a trifle upwards, to avoid the iron pressing on the instep, by which bad habit a very insecure seat is contracted. Having given the necessary directions as to seat and upright carriage of the body, and thoroughly inculcated the propriety of keeping the shoulders well down in the back, the position of the hands and arms is the next point. A single rein is then given to him, and the manner of using it described. The instructor, standing in front of the pupil, takes the bit in his hands, holding it in a position similar to that in which a horse carries his head when that member is in a good place. The most minute instructions may thus be given, when raising the bit to the height where it would be in the event of a horse carrying his head very high: the boy is informed of the intention, and is desired to apply a remedy; this he naturally does by lowering his own 
hands. At the same time he must be ordered to sit well back in the saddle. The example of a horse getting his head below its proper bearing, is illustrated by a contrary disposition of the bit; to obviate which, the hands must be elevated with a sort of rotatory motion, and the bit simultaneously drawn across the mouth: this will afford an opportunity of cautioning the boy not to allow himself to be pulled over a horse's shoulders, in case he should attempt to get his head down, and at the same moment stretch out his neck with a kind of jerk, which will pull an inexperienced rider out of his saddle. This will be a fitting opportunity for illustrating the advantages attendant upon keeping the shoulders in a proper position. If they be shrugged up, not only will a great portion of power be lost, but the animal will very probably pull the rider out of his seat. To prevent this, the feet also require to be placed more forward than usual; sitting well down in the saddle, by putting the hands down on each side of the withers, the intentions of horses so disposed are frustrated. The advantages of these preliminary lessons are very clear. The novice receives his instructions without excitement or fear of being thrown; he consequently attends to them. Take, for example, the illustration of a horse carrying his head too high. If an inexperienced rider be on such an animal, his hands are invariably in a parallel line with the horse's mouth. If the pace be a gallop, in all probability the animal breaks away; but as the saddle stand is not guilty of such indiscretions, the 
pupil is capable of being instructed at a time when his thoughts are undisturbed, and his movements under calm control; thus, an important point is gained towards inculcating confidence. This quality successfully introduced, the physical accomplishments follow in succession. The power of a horsemar is most intimately connected with confidence, practice, seat, and hands; if these four requisites are combined, although the individual possessing them may be of small stature and light weight, they will render him far more capable of managing a determined horse, than one of considerably greater bulk, in whom any one of them is deficient. The great importance of a firm, secure, and steady seat, must not be overlooked; it may be termed the basis of good horsemanship, and boys should be taught to support themselves entirely by it, without any recourse to the bridle; by that means, in course of time, they may acquire good hands, but withont it they never will. When riding up a gallop, it is too frequently the case that boys, as well as more matured riders, depend much on their hands, or more properly their arms, to keep them steady, and by thus hanging at their horses' heads, dead, insensible mouths are formed. So much depends upon the place in which a horse carries his head as to the position of the hands, that considerable practice is requisite to attain this important accomplishment in the art of riding. With a nice steady smooth-going horse, the hands should be laid one on each side of the upper part of the shoulder just below the 
withers, from whence they need scarcely be moved, unless to regulate the pace or to make a turn. In any case they should be kept as still as possible. The flexibility arising from the wrist should be studiously preserved by the position of the hand: as by this the delicacy of touch can only be produced. For this purpose, the thumbs are to be kept upwards, and pointing in a direct line to each other, so that the knuckles of the hand stand forward: this causes the wrists to be slightly bent, and by that means the lightness or flexibility is preserved. But if the hands are held with the knuckles upwards, and the little finger outwards, with a straight wrist, the only elasticity that can be afforded is from the elbow; and in these circumstances the hand cannot regulate or cultivate a lively delicate mouth so thoroughly dependent upon the person whose duty it is to ride the animal at his daily exercise.

Unfortunately for boys, and I may add for the horses which they ride, very little pains is taken, in a general way, to teach them the art of riding. They are left very much to themselves to learn how they can, by imitating their elders; hence, if the latter have acquired bad habits, the juveniles will, most probably, fall into similar errors. If a boy rides very badly, the trainer most probably tells him so, probably chastises him; but, in telling him of his fault, he does not always explain the way by which the error is to be counteracted. In large establishments, where there are a great many horses in work, the trainer has too many other things to engross his 
attention, to permit him to devote his time, as riding master, to every inexperienced boy in his employment; but it is a duty in those cases which should be attended to by the head lad, or some other competent individual.

The mischievous tricks which boys are prone to play upon the horses under their care-plaguing and tormenting them - require constant attention; and whenever a case of the kind is discorered, the offender should be punished, not only to deter him from repeating his misconduct, but as an example to his companions. Some boys commit these faults from ignorance, others from thorough badness of disposition; but, whatever may be the motive, the results are similar. The dangerous custom of striking horses on their legs with the side of the brush, or other hard substance, when they do not stand quietly or conveniently, is to be guarded against. Whenever a horse's legs are observed to fill, or show symptoms of blows, the cause should be carefully ascertained. The silly, absurd, and dangerous propensity of lashing out with one hind leg, - a habit which many horses acquire, - is usually the result of provocation by the boys tickling them on the inside of the thigh. Whenever a horse performs these pranks, the best way to cure him is to punish the boy who looks after him. 
CHAP. V.

HUNTING-GROOMS AND HELPERS.

Comparative Duties of Trainers and Hunting-Grooms. - Gradations. - Gentlemen Grooms. - Single-handed Grooms. - Occasional Assistance. - Inexperienced Servants. - Anecdote of a Gentleman Groom. - The Use of Drugs restricted.-A Veterinary Education for Hunting-Grooms deprecated. - Helpers and their Duties. Covert Lads. - Second Horse Lads.

Compared with those of triners, the duties of hunting-grooms are light and easy. The former must necessarily have a vast weight of responsibility on their shoulders, not only as regards the value of the animals under their care, but also the large sums of money frequently dependent on their success. The last are events from which hunting-grooms are totally free, unless they may be employed in preparing horses for steeple-chasing, in which case their positions are very similar.

Whoever keeps a large stud of valuable hunters must necessarily employ a competent person to superintend them; and when, descending in the scale, we consider the requirements of those who are under the necessity of limiting their desires to one or two horses, the dignified title of hunting-groom appears inapplicable to the functionaries who have the care 
of them. At the same time, there are many degrees in this class of servants; from those whose duty it is only to superintend the stable department, to those who take a share in the work, and others who do the whole. The first can only be necessary when the stud is very numerous and valuable. For my own part, I have a great objection to gentlemen grooms; and for this, if for no other, reason, that they have not sufficient employment to occupy their time. Many hunting men, who only keep three or four horses, are burdened with these superfluities, but I do not find their horses are in better condition than those of others who require their head groom to perform his share of the labour. It generally happens, that a man whose means only permit him to keep a couple of hunters, takes some pleasure in superintending the management of them himself, and one servant is of course sufficient to do the work; but there is more difficulty in meeting with one for this purpose, who is in every respect calculated for it, than there is in selecting any other kind of domestic servant. Many of those who are really competent, generally aspire to what they consider higher employment; they want a menial under them, - in fact, do not like to work single-handed. In this they are to a certain extent correct, if their motive be to do justice to the horse; because when a hunter returns home after his day's work, two persons ought to be in attendance to dress him with the expedition so essential on those occasions. At such times a boy, a gardener, or any super- 
numerary, who is at other times differently employed, may be brought into the stable with advantage. A rough unsophisticated rustic is one of the greatest torments that can be introduced into a stable. He must be constantly looked after, otherwise he leaves the sweat on the horse's ears, or between his legs, or the saddle stains are not got out, the legs and feet are carelessly washed, besides neglecting many other little items essential to the comfort of the horse; and then when he brings the nag out for his master to ride, some of the appointments are imperfectly cleaned, - an event which usually happens when time will not permit of his being sent back to reclean them; in short, their habits are such that they cannot comprehend the necessity for that nicety which is inseparable from the requirements of the horse, if he is to be fit in condition and appearance to carry a gentleman.

Whenever I happen to meet with one of the order of gentlemen grooms, it forcibly reminds me of a circumstance which occurred some years since. A friend of mine who had been hunting in Northamptonshire, attended the Warwick Spring Meeting en route homewards, with his horses in attendance; and although his stud only consisted of six, they were first-rate hunters. While sojourning at Leamington he took a mutual acquaintance, an excellent judge, into the stable, and asked his opinion relative to the treatment which would be most beneficial for the cure of certain injuries which some of the horses had 
sustained; and which opinion was frankly and judiciously given. This, however, did not please the scrupulous jealousy of so important a personage as the master of the horse, who replied to observations made by our friend in very laconic, disrespectful, terms; whereupon, the master of the horses thought fit to remonstrate with his servant, at the same time telling him, that he expected every gentleman whom he brought into the stable to be treated with civility. The reply was, "When a gentleman comes into my stable and behaves as sich, I treats him as one; but when he comes in as a groom to give his opinions, I treats him as a groom." This impertinence led to his discharge; and in less than two years from that time, I saw him in Tattersalls' yard in a state of great poverty. He was too idle to work, and, having lost his character, could not obtain a situation similar to the one which he had so ridiculously lost.

Unless a groom is thoroughly competent, it is a dangerous practice to allow him to give any kind of medicine without his master's knowledge : this, of course, only applies to those cases where the proprietor takes an interest in the management of his stable, and consequently directs the details himself. The owner of a large stud, who is in all probability engaged in other pursuits, must necessarily confide such matters to his groom. It is therefore important to him that he employs a servant capable of directing such minutix. But those who enjoy the means of keeping large establishments are few in number 
compared with those who are obliged to content themselves with two or three, perchance only one hunter. The kind of groom whom the latter engages is seldom sufficiently experienced to give medicine ad libitum. In such hands the veterinary art is a very dangerous plaything. 'The incongruous mixtures which persons unacquainted with chemistry will frequently combine together, are calculated to produce very serious consequences; and as there is a certain class of stable servants, who conceive by giving alteratives, cordials, fever-balls, and such like inconsistencies mixed together for the purpose, as they imagine, of making the horses look well with less trouble to themselves, the safer plan is, to lay an injunction against the use of any medicine without a proper sanction. It sometimes happens, that hunting-grooms who aspire to the management of large studs, consider it a great recommendation to have passed their examination at the Veterinary College ; but with this opinion I am not prepared to agree. A really clever man will be certain to succeed by the practice of the profession. A dunce will derive no useful knowledge by attending the College, but will most probably get his brains conglomerated with technical terms which he does not comprehend; and, like one of these geziuses with whom I was in conversation a short time since, recommend the use of Peter Oleum (petroleum he meant) for thrushes; and although, as it happened, the remedy was proper for the occasion, it would have been better if he had stuck to the comprehensive word, "tar." The 
practice, although the stud may be large as a private one, is never sufficiently extensive to maintain, much less to mature, a college education, unless a varicty of unnecessary operations are performed to keep the practitioner's hand in,-proceedings which few owners of extensive and valuable studs are at all disposed to encourage.

The next order of servants required in huntingstables, are helpers, whose duties are simply to dress the horses of which they have the care, take them out to exercise, and clean the appointments. Three horses are generally assigned to each man, with which he is certainly fully employed if he does his duty. Men who are afraid of labour should never be engaged in such services. They must frequently be at work by five o'clock in the morning; indeed, in many hunting establishments, that is the regular hour during the season. But as no hounds ever meet before half-past ten, it appears rather unnecessary, in a general way, to disturb the horses so early, unless they have a great distance to go to covert. Nevertheless, helpers must not be scrupulous about their time; they must work early and late if required; and that being the case, their wages are generally liberal. A steady lad, whose services are required to take the hunters to covert, is almost essential, unless the head groom performs that duty; to which there are objections, inasmuch as during his absence the horses must necessarily be left to the discretion of persons not always to be depended upon. It is better that he should remain at home 
and attend to the dressing, feeding, and stable duties required by those horses which are not at work, than to delegate those trusts to any other person. Good second horse lads are not very numerous; they require many qualifications. Superior horsemanship is indispensable, combined with great steadiness and discretion; otherwise, the horses which they ride will not be fresher than those which have been ridden with the hounds. Knowledge of country is likervise a very important consideration; for although most of the second horses usually take the same line with an experienced leader as a guide, if by any chance the pilot is lost sight of, those who are unacquainted with the country will often be much at a loss what course to steer. For this service men of light weight are far preferable to boys, although their wages may be higher. 


\section{CHAP. VI.}

BREAKING.

Effects of : Education. - A Comparison. - Progressive Tuition of " Race-horses. - Young Hunters. - Reference to tho "Stud Farm." - Good Horsemen essential on young Horses.-Alarm to be avoided with young Race-horses when at Exercise. - Pace proportioned to the Advancement in Condition. - Importance of a good Mouth. - Improvement of Action. - Effected by appropriate Bridles judiciously handled. - One-sided Mouths. Disadvantages which ensue. - Remedies-Teaching IIorses to leap. - May be done without Hounds. - Confidence necessary to make good Fencers. - Falls to be avoided. - Leading over a Bar or Fence. - Impropriety of Hurry or Confusion. - Riding at Fences. - Horses ought not to be taken repeatedly over the same Fence. - Accomplished Hunters from Stables of eminent Dealers. - Distinct Characters of Riders to Hounds. - Difficulty in procuring first-rate Hacks. - Reason why they are found in the Stables of the Affluent. - Time requisite to cultivate Perfections.-Temper. Proper Age to endure Work. - Ladies' Horses, and the Accomplishments requisite in Hacks. - Shying. - Alternatives. — Objects which Horses encounter in Towns. - Starting. - Young Horses should be accustomed to various Objects. - Harness Horses. Breaking to Harness. - Putting Horses to Carriages. - A precaultionary Method and its Advantages. - Reasons why some Horses are refractory. - The Duties of an Assistant. - Carts deprecated. - Vicious Horses. - Effects of mild Treatment illustrated. — On Bridles. - Mouths. - Hands. - Severe Bits, Objections to. Snaffles. - Pelhams. - Curb Bits. - Nose-bands. — Choice of Bits. - Bridles for Pleasure Horses. $-A$ Change recommended. Exercise Bridles.

MaNkind are strongly inarked by education, and every individual carries the stamp of the place of his instruction upon him through life. The bearing of 
an Etonian is readily distinguished from the comparatively rude manners of the youth who receives his instructions at an ordinary school. A similar distinction is discernible in the education of the horse: one that has received the finishing polish of tuition from an experienced and accomplished rider, is an infinitely more agreeable servant and companion than a rough animal from the hands of a provincial colt breaker, or the usually unsophisticated guidance of a hard-riding farmer. The trainer can seldom expect to have colts placed under his care, which do not require some tutelage under his hands; if they have been sufficiently broken as to ride quietly, that is all he can expect. To follow other horses up gallops, and perform the requisite accomplishments during the successive courses of preparation, will, in most instances, come uncler the supervision of the trainer; and, indeed, on many occasions he will have to direct the entire breaking or tuition of young stock entrusted to his care. Those who follow hounds are frequently in a similar position: whether the duty is undertaken by the master, or devolves upon the groom, it is a task of greater difficulty than that which falls to the lot of the trainer; because there are so many more accomplishments required in the experienced hunter than the race horse. In fact, the lessons which the latter goes through daily when at exercise, nearly qualify him for his duties on the course.

In the pages of the "Stud Farm" I have noticed the degrees of tuition to which young horses ought 
o be subjectert, so long as they may be considered is inmates of the breeding establishment. It now jecomes necessary to add some additional remarks upplicable to race-horses, hunters, and carriage orses, when they arrive at a more advanced stage luring the course of preparation for "actual service."

Concluding a colt to be so far advanced in his education that he will ride quietly, the next process s to teach him to canter; and in the first probations $t$ is far more rational to put up a man of tolerably ight weight, or boy of moderate proportions with power and experience, who can ride well, than incapable urchins with whom it is a matter of great chance if the colt does not contract some bad habit, which will not easily be corrected. It is to be remembered, at this stage of training, the colt is not required to go at a fast pace; it would not be proper, either as regards his education, or his condition. To promote these intentions, a steady horse of more mature age is requisite to lead the work. On all occasions it is a consideration of moment to avoid alarming a horse; and although this applies to every hour of his life, it is of greater consequence with young than with aged horses; that is to say, young ones will be alarmed at trifling objects, which at a future age they would not notice. Exercise grounds will frequently be in such order, that the preceding horse will throw the dirt upon the one which follows: with young ones this should be carefully prevented, by keeping at such a distance as to escape the disagreeable salutation. It will be time 
enough to lay up and accustom the young animal to this unpleasantness, as he becomes more and, more advanced in his preparation and has gained confidence, at which period it is highly advisable he should be occasionally accustomed to the unceremonious proceeding, that it may not be new to him on being brought to the post to run, when he will at times be subject to the annoyance.

As the first preparation advances, an increase of pace will be occasionally necessary; but this must be adopted with discretion, for there can be nc doubt that more young animals are ruined by in. judiciously hurrying them in their work, both with reference to breaking, and the endeavour to promote their condition, than by any other single circum. stance. Improvement, in whatever way it is courted must be acquired by slow degrees; and whoever attempts to assail the handiworks of nature, by violent or precipitate measures, is certain to bc foiled in the attempt.

At this stage in the operation of breaking, it is presumed that the ordeal of lounging has been completed; when the condition of the mouth becomes an object of paramount attention. The contro] which we acquire over the horse depends upon the mouth, and likewise a vast proportion of the agreeable or disagreeable associations which render exercise on horseback pleasant or toilsome. A good mouth is the medium by which any improvement in the natural carriage of an animal is to be accomplished. When going at a slow pace, the way in 
which a horse carries himself may, to a very coniderable extent, be controlled; but when at speed, or even when nearly approximating that pace, his inrestrained action must prevail. By habit in the low paces, improvement in the faster ones may be lightly obtained; but that must be brought about y very moderate attempts, otherwise the action of he animal, far from being corrected, will inevitably ve rendered worse. A horse that bends himself aicely, is, undoubtedly, more pleasant to ride than one which runs with his nose down to his knees; or he reverse, with his head in rivalry with that of his ider; and such defects are, in most cases, capable of correction if properly treated in juvenile days; out too much constraint is adverse to pace, both for acing and hunting. When a horse carries his head oo high, it may, in many instances, be remedied by using a curb bit without any port, but with rather ong cheeks, and the curb chain hung quite loose. Accompanied with good hands, this often produces in excellent effect, especially with young horses, which are disposed to contend against the control of martingale. It may appear as a contradiction; out when a horse carries his head too low, a curb oridle will often be found the best remedy; and the contradiction is cleared up by the remark, that it is by the way of adjusting and using the curb, that the difference of effect is produced. For the latter purpose, a short cheeked bit, when judiciously used, will with many subjects be found effectual; and, in order to render it so, the hands must be raised higher 
than usual at the precise instant when the anima endeavours to drop his head; by this means the curb is brought into action, but should be agair released when the proper position of the head is obtrined. This should be particularly attended to for such horses are very subject to hang on the bit - an imperfection likely to increase with age if no counteracted. Although I so far advocate the usi of double rein or curb bridles for certain purposes let me not be misunderstood as recommending then for general use, - quite the reverse. A horse with: good mouth, carrying his head in the true position never goes so freely and pleasantly to himself, a with a snaffle bridle; but it is to teach the hors how to carry himself, that the curb is in many case of great utility.

Colts that have been carelessly treated frequentl: acquire a habit of getting the snaffe on one side 0 their mouths; thus they become less sensitive on on side than the other, and eventually the same in convenience is discovered when a curb is used This not only renders them very unpleasant to ride but in racing frustrates in a great measure th jockey's efforts to make the turns with precision, anc also in straight running occasions difficulty in keep ing them in the course. With such defects it is im possible to make the most of a horse. With hunters independently of the unpleasantness to their riders they cannot be ridden so nicely at their fence: when they possess one-sided mouths; moreover, ir severe runs with hounds, contention must have the 
effect of producing fatigue, as much as similar proceedings affect the race-horse. To aroid this propensity, it is important that due attention should be observed during the progress of tuition; for it is much easier to remedy a defect than to correct a bad habit. Now it must be obvious to every person possessing the slightest practice, that constantly pulling at that side of the horse's mouth which is the least sensitive, will, in course of time, render it still worse; and the most effectual method of correcting this bad habit, is by keeping the bit as even as possible, when such animals are being ridden, and frequently to indulge them with the company of the dumb jockey, to which a straight-mouthed bit is applied. The trick of taking the cheek of the curb between the teeth, very frequently arises from the cause just named, but that can readily be obviated by means of a chin strap.

On a former occasion we suggested the propriety of teaching young horses to leap small fences while under the surveillance of the breaking tackle, but as in many instances that will have been neglected, it here becomes necessary to introduce some observations on the treatment of those whose future employment is destined to be in the hunting field. Much more can be accomplished in teaching horses to fence, if properly conducted, without hounds than with them. In the first case, there is nothing to attract the animal's notice except the performance which he is called upon to accomplish; but when out with hounds, there are constantly new objects to 
occasion excitement: thus high-mettled horses will frequently contract a habit of rushing wildly at the fences, and, by so doing, experience many unnecessary falls. I have often heard, with surprise, good sportsmen express themselves in terms of satisfaction at their young horses having had falls. I must confess I would rather mine did so as seldom as possible. The first step towards making a good hunter is to establish confidence. Can that be accomplished by occasioning alarm, often injury, and sometimes pain? Horses frequently fall from want of confidence in themselves, and impatience, not always free from timidity, in their riders. A horse, with a naturally high spirit, when roused and excited, will often go up to a fence, and fall from the consequences of alarm and injudicious treatment-being hurried; not knowing where to take off, he probably runs into the ditch, if it lie on the near side, and comes down a burster; or if the squire trap be on the further side, by taking off too soon, drops into the snare. These dilemmas may, to a material extent, be avoided by practice, previously to taking them out with hounds; and I imagine there are but few persons who would not prefer that mode of treatment which will render a hunter equally accomplished and perfect at his business, with the fewest number of falls, and, consequently, with the least amount of risk.

The first endeavour to teach a horse to leap should be with a leading rein at a low bar, if such a convenience be at hand, or over a low fence that will not yield; low walls and stiles, open drains and 
ditches, small brooks, - in fact, every description of fence the country affords should be presented in succession as the animal evinces ability to perform the task. When leading a horse over a fence, the person having the rein should carefully avoid looking the pupil in the face, - a very prevalent, but injudicious custom. All animals are abashed at the stern gaze of a man's eye; hence when it is desired to encourage them to follow, a moment's reflection must dictate the propriety of attending to this hint. It is also a very mistaken plan to give any horse a long run at a fence, but particularly those minor fences chosen for exercise or tuition. Four or five lengths is quite sufficient. Hurry and confusion is to be avoided, for it is impossible an animal can measure his stride, and adapt it to the proper place for rising or taking off if he be bustled and alarmed at the moment of making the attempt. After a fer lessons with the leading rein, it becomes necessary for the horse to be ridden over some fences, and for this purpose a steady horseman with good hands should be selected. Without entering minutely into the subject of equestrianism, it may be necessary to make a passing remark on the very prevalent custom of riding horses at fences with the reins in one hand, in which case, if the animal has any inclination to refuse, the rider has but little power to keep him straight; whereas, with the reins divided, any such disposition may be checked, especially if accompanied by the judicious persuasion of the spurs. The very unwise application of the 
whip, at the moment a horse is about to take his spring, cannot be too seriously condemned; that implement raised at such a moment, often causes horses to swerve, and when once a horse has been struck, he naturally expects a similar salutation when he approaches a succeeding fence; he therefore rushes wildly at it, and a fall is in all probability the result.

Here it is necessary to introduce a caution, not to take a horse too often over the same place. Old and experienced hunters frequently repudiate such engagements. I have often seen very superior animals ridden repeatedly over the same flight of hurdles, till at last they would scarcely jump them at all. Such treatment is calculated to teach careless and bad habits. When a young horse has cleared a particular fence neatly and cleverly once or twice, he should not be required to try it again; that should terminate his lesson, or he should be taken to a fence of a different character. When weary, horses become careless, and from that cause it is very injudicious to go on with young ones after hounds when they begin to show the slightest symptoms of distress. Young horses, and many of those out of the stables of farmers, will have to undergo these probationary lessons, unless their owners are content to rough it when following the hounds. Hunters from the emporiums of a very few of the first-rate dealers will not require such drilling, from the simple cause that they do not attempt to recommend them, unless they are certain the animals know their business; and as they generally employ an artiste of 
superior ability to ascertain their qualifications, they are never very far out in their judgment. In this I am alluding only to dealers of the highest repute.

Among first-rate men with hounds, two distinct characters may be noticed; those who will go in front upon any horse endowed with the faculty of going, so that they can fence, stay, and go the pace, no matter how difficult or disagreeable they may be to ride; the others are men who go well on certain kinds of horses, thoroughly made, with good mouths, fine tempers, and with action suited to their taste and peculiarity of seat. Of the two, the first-named have much less difficulty in finding horses to suit them than the latter.

A really good hack is a creature difficult to procure. Not that there is a great scarcity of the "raw material," but, unfortunately, it is only the raw material that can, in many instances, be obtained; this arises principally from want of care in breaking. It is presumptuous in people to suppose, and subjects them to ridicule when they assert that they can complete the education of a colt as well in three weeks as in three years; but there may be some few who do not appreciate a nicely-trained hack, and it is a great pity when such an animal happens to get into their possession. In my jurenile days I was forcibly struck with the prevailing fact, that hacks, when sold in consequence of imperative events, out of the studs of noblemen, and others of wealth, realised such great prices, while equally good-looking animals at fairs, or in the possession of persons of less note, 
were purchasable at very reduced figures; but the cause may be readily explained. Those who have the means, only purchase such horses as are thoroughly educated, or they employ men of experience to break, and cultivate the accomplishments of the horses which they either breed or buy. Of course they only select those of goodly appearance, with superior action; and no one need despair of making them agreeable to ride, if they will unite patience with discretion. Such animals will always realise a good price; but it requires time to render them perfect. To suppose that a horse can be educated, so as to carry his rider with comfort and pleasure, in three weeks, or even three months, is ridiculous. An animal may be ridden in a very few.days after he is taken in hand; but it is not assumed that a gentleman will undertake the duties of a rough rider, and until horses are quite tractable, handy, and accomplished, they are not marketable at high prices.

Good temper is an attribute more frequently the result of treatment than innate propensities: the best dispositions may be spoiled by ruffianly usage, - or the reverse, pusillanimous timidity. Highcouraged horses will become intractable by abuse, and sluggish ones will turn sulky. It is of some importance to ascertain the tendency of an animal's temper, in order to facilitate the progress of tuition. Some horses appear to possess much more retentive memories than others, and, when this is the case, they are in every respect gifted with greater sagacity, and will, when properly managed, usually be- 
come the most docile; but if their memories are retentive of good deeds, they are equally so of injuries.

Hacks are not usually selected for active service until they have attained their fifth year, neither are they calculated for hard work till that period; but if they have not been judiciously treated, they will very often by that time have contracted many unpleasant if not bad habits, which entail more time and trouble to correct, than would be required to teach them their duties from the first. To carry a lady as she ought to be carried, we should be most scrupulously nice in the selection of the palfrey, and in the course of his education; to carry either a lady or a gentleman it is not necessary to recapitulate the worn-out, threadbare description of what constitutes the good qualifications; it will be sufficient to mention how they are to be fostered. To stand quietly while being mounted, and to walk well, are necessary accomplishments. As in the different paces some are faster than others, the slow walker when in company, in order to keep up, is frequently forced into a shuffle, - a most unpleasant, and it may be added ungentlemanly, inelegant kind of action. The virtue, patience, must be taxed sometimes pretty considerably to prevent this; and so long as the tuition of the animal is in progress, it is far more advisable to allow a companion to walk away, if his rider have not the consideration and politeness to restrain his nag, than to allow a young horse to habituate himself to such an objectionable pace. 
When a horse is required to accelerate his speed from the walk to the trot or canter, the indications should be distinct, and thoroughly inculcated; for it does not add to a horseman's gracefulness if, when he proposes to put his horse in a canter, the brute runs off in a trot, which many will do, from want of proper teaching.

The habit of shying - for it ought not to be termed a vice in the way of passing censure on the equine race - generally arises from improper and unkind treatment. No horse ever contracts this fault from any cause but fear in the first instance, and that fear may be produced by a variety of causes; but what is the course too frequently adopted to allay that fear? - chastisement. A train on a railway, a gipsy's encampment, clothes hanging on a hedge, wheelbarrows, carts drawn by dogs, stones and timber by the wayside, carriages of divers descriptions stationary and in motion, and many other objects with which the list may be increased, are monstrosities which a young horse may never have seen before. His instinct dictates that they may be productive of pain or danger. In the hands of a ruffian the first impulse is verified: roughly handling the reins, he drives his spurs into the sides of the poor frightened victim, and forces him past the object, and not unfrequently beats him afterwards - on every similar occasion the like treatment is observed. Fear having been excited, it matters not whether the object of alarm inflicts pain, or whether it is the thoughtless rider, the same effect 
is produced; the animal has anticipated an injury, and the anticipation is realised. But instead of this, if, on evincing symptoms of alarm, the young creature is very quietly and patiently coaxed to within a short distance of the strange phenomenon, he soon finds that nothing causes lim pain, and in a short time ceases to notice any objects that may present themselves. Starting at strange sights that unexpectedly and abruptly offer themselves to view re very similar in their consequences, and call forth the same sort of kind usage. Horses that have never been accustomed to see anything but what they meet with on country roads are naturally shy and timid when they encounter the confusion in the streets of London and other large cities, where omnibuses and such like gigantic machines come oouring along the streets in a continuous stream: by ind treatment they very soon become accustomed ;o such sights, and it is astonishing how soon they secome reconciled to them.

Young horses should be accustomed in their tuteage to all sorts of objects. If intended for the turf, hey should be ridden or led on to race-courses, wiere they may see and hear what on a future day hey must encounter: if this be neglected, when hey are required to run for, perhaps, a valuable take, they may probably become so greatly alarmed is to sustain defeat. They should also be taken to laces where they will meet carriages and vehicles of 11 kinds, and if taken to the covert side occasionally hey will be better accustomed to varieties. Hunters, 
and all other classes of horses should be taken when young to those places where they will meet with divers strange novelties.

There are very few horses that cannot be made to go in harness, and that safely, when driven by persons of experience; but a more dangerous animal cannot exist, than one which has not been thoroughly broken, or is in any way uncertain, in the hands of a novice.

The routine of breaking for harness, if properly conducted, is so efficacious that few disappointments arise, unless a horse has been rendered vicious by il' treatment, or alarmed by an accident. To gc through every event that may happen, and sugges a remedy for each in order, to reclaim badly managec or frightened animals is unnecessary. No persor would, if endowed with moderate prudence, attemp. to drive such horses unless thoroughly skilled ir these matters, and to them it is unnecessary to offe] advice.

Every horse intended for harness work, it is to be presumed, has already gone through the ordinary forms of breaking, has a good mouth, is tractable and has been ridden. Before a horse is attached to any vehicle, the harness should be allowed to remair on him in the stable several hours during two os three consecutive days; he should be led out, sc that he may become thoroughly accustomed to the trappings, and a cord six or seven feet in lengtl should be fastened to each trace. With this the horse is quietly led about, one man performing that 
duty while another follows holding the aforesaid cords, which as the animal moves forward are to be strained, so that he feels a slight pressure of the collar on his shoulders. The intention of this treatment must be obvious; if the horse is alarmed by the effect of the collar, the man holding the cords which are affixed to the traces can instantly relax them; and again, when he finds his pupil is reconciled, he may renew a moderate strain, and finally as much resistance as he has the power to create. By this means the most timid horses will gain confidence, and hy perseverance the most refractory may be overcome. A horse when first encumbered with harness, if immediately attached to a vehicle, is astonished when required to move, at find-ing a pressure on his shoulders which he has never previously experienced. He discovers other novel apparatus of confinement; he is, in fact, trammelled and endeavours to escape; probably he plunges, kicks, or rears, and becomes difficult to manage; but by the simple process just recommended, all that is obviated; and when he is found to be reconciled to that kind of exercise, he may be put to a carriage without risk; and it is quite immaterial whether it be a single or a double break, provided it be light of draught. When putting to, great care should be observed not to run the shafts, pole, or bars, against the animal's sides or quarters; it should be done with the most perfect quietness, yet promptness. During the first two or threc essays an assistant is necessary, and it is highly important that he and 
the driver or breaksman perfectly understand each other, and the signal of the latter should be the only medium of giving directions. An expert assistant is of value; it is his business to keep the horse in the road, in case he will not answer to the bit, and also to reconcile and encourage the animal when such treatment is seen to be necessary. 'The custom of putting beginners to heavy jumbling carts is more calculated to make them restive than promote the object of tuition. The weight is improper, and in their cases all unnecessary noise should be aroided. The rattle of wheels over néw laid broken stones or gravel will occasion alarm to many horses, till they become accustomed to them. A little patience only is necessary, and all these trifling difficulties anc dangers will be overcome.

The subjugation of vicious horses is an experimen which can scarcely be recommended; they may br ridden or driven by persons gifted with nerve temper, and experience, but with all others they art dangerous. With an unpractised individual, some. thing may necur to excite a badly-disposed creature to a renewal of his malicious propensities; hence they require constant watching and precautions to guari against their tricks. In justice to the equine tribe: it must be observed, that there are very few natu. rally vicious, though many are rendered dangerous by ill treatment or bad management. I have had two that were pronounced incorrigible, and, as ] found means to render them otherwise, it may not be out of place to relate the measures which rendered 
hem tractable. The first was a most determined icker in harness, and as that was the only service 1e was calculated for, I set about to correct his vice. This I did by attaching him to a very strong but ight roller, such as is commonly used for rolling arley; and by means of kicking-straps, and such ike derices, prevented his getting his legs over the hafts. A powerful, steady horse was put before im. The scene of action selected, a fallow field. In this he was kept moving from an early hour in the norning till dark. He kicked the roller repeatedly, out it hurt his legs, and, in the course of time, he ound he got the worst of it, and left off. I then out him to a gig, but he showed no desire to kick, and I drove him more than twelve months, during vhich time he never attempted to renew his former conduct. Afterwards I sold him at a remunerative price. The other horse would rear on being put to, ind, if persevered with, fell backwards. By adopting he plan already advocated, of fastening a cord to ach trace, with a little patience he gained sufficient onfidence to go up to his collirr. Having succeeded n teaching him to bear the pressure on his shoulders, - put him to a gig, with which he was not disposed o move. With an assistant on each side on foot eady in case of necessity, I sat in the gig a coniderable time; at length he proceeded a step or two, ind again stopped; for this he was encouraged, not vhipped; for an act of that kind would have defeated ny intentions. After a further lapse of time he went in a few steps further, for which he was amply 
fondled; and he ras kept in the middle of the road by the men gently guiding the shafts. Eventually he walked away as quietly as possible; and without attempting to urge him to a faster pace, I kept him at that about an hour. On the following day I renewed the same plan, and never afterwards experienced the least difficulty with him.

So much of the comfort, both of the rider and the horse, depends upon the bridle made use of, that nc person having regard to his own ease and that of the animal will pass over it lightly. The very great difference which exists in the mouths of horses, the various positions in which their heads are placed, the formation of their shoulders, their action, and dis. positions, all tend to augment the varieties of bridles which are called in aid to accomplish the desirec object. The hands of different riders also vary and if the equine race had the gift of comparing anc making known the result, I think we should learn that they experience as much difference as we car distinguish in the style of men's autographs. It is therefore necessary to select bridles suitable to horst and rider ; and from these causes it is not astonishing that such a diversity has been invented. To enu. merate and describe them all would be a difficul task. But as many of them are only conspicuous for their absurdity, I will content myself with noticing those which are best calculated for the purpose, re marking, as a general principle, that any which have the effect of keeping the mouth in a sensitive state without sererity, are the vest; and that any lind 0 : 
it having a fixed position, must be objectionable, beause it occasions a deadening of the part to which it ; so fixed. For a horse with a light mouth, having his ead naturally in a good place, with good shoulders, nd nice action, the plain snaffle bridle; the thickness $\mathrm{f}$ which is proportioned to the size and breeding of he animal, is doubtless entitled to take precedence $f$ all others; and those made with a ring in the entre may be mentioned as the most easy. Various egrees of twist will increase the severity, if the lain snaftle is not sufficient. Those which are traight from the joint to the rings are still sharper han such as are formed with a curre, which latter the general shape. Such as are made with two houth-pieces and two joints of unequal length cannot e too strongly condemned.

A snaffle without a joint, that is, a straight piece f metal suspended by a ring on each side, to which he head-piece is attached, and with two rings, indeendent of those to receive the reins, if made suffiiently wide, is an excellent device for some horses. $t$ has a more powerful effect than the ordinary snaffle, nd may be recommended for horses that are too ritable in their tempers to submit to a curb.

In the "Stud Farm" I have already intimated ome of the objections to which the Pelham bit, aving a joint in the mouth-piece, is subject; and I vill now add some others. This bit may be decribed as a snaffle, with the lower portion of the heek longer from the mouth-piece than the upper. Co the lower end is attached a ring to receive the 
reins; to the upper part, which is formed into an eye, the curb chain is attached, also the head-piece. When the reins are pulled, the width of the bit is contracted like a snaffle, consequently the curb has little or no effect; unless it be exceedingly short, in which case it maintains the bit in its contracted form. In the former case, it has the effect of causing horses to lean or hang on the bit; in the latter, it deadens the mouth from the fixed position in which it is kept by the curb chain. Some Pelhams are made without any joint in the mouth-piece, which is either straight or has a port. These are less objectionable than the first named; they operate like a curb, and, although there is a snaffle rein fastened to rings parallel with the mouth-picee; the width from cheek to cheek cannot be made sufficient to allow of a change of position; it does not act satisfactorily: and thus the sensitive condition of the mouth is impaired.

The curb bit when required should be apportioned in its dimensions to the size of the animal, his style of going, and the amount of power necessary to hold him. This being, in point of fact, a lever, its efficacy depends upon the length of that portion of the cheek from the mouth-piece to the eye whereon the head-piece is fixed, compared with the lower branch which receives the reins. Thus, the shorter the upper part the greater the leverage. A high port likewise adds to the severity of the bit. As an adjunct, a noseband is in many cases a very useful companion to the bridle, especially for hun- 
ters and hacks, many of which by opening their jaws, and at the same time extending their heads, relieve themselves from the principal power of whatever bridle may be made use of. A noseband buckled sufficiently tight prevents this; at the same time, unless placed unreasonably low, so as to press upon the cartilaginous portion of the nostrils, it cannot have the effect of interrupting respiration. The ordinary noseband is simply a strap sufficiently long to pass round the jaws, and is suspended either to the head-piece of the bridle, or by an independent arrangement, which latter is preferable. The advantages derived from this apparatus, have led to the invention of varieties, which are unquestionably adapted for certain horses; and one which, in my opinion, is of great utility, is made by Mr. Heavens, of South Molton Street. All these auxiliaries require hands, and some discrimination in adjusting them, otherwise they are ineffective; and such things are often condemned as useless, because they are not properly brought into action.

There are two essential objects to be consulted in selecting bits for race-horses and hunters, - those in which they will go most pleasantly, and, at the same time, by which the greatest amount of their physical powers can be obtained. If a bridle be put upon a race-horse not sufficiently efficacious to enable the jockey to hold him, the animal's powers are evidently expended by an excess of pace. Again, if the bits made use of are too severe, and the horse will not face them, it causes him to go high and short in his 
stride, - as it is technically expressed, he "fights in his action;" and the powers of endurance are exhausted from that cause. Similar considerations apply to hunters, - with this distinction; that more regard may be observed to the bridles in which they ride most agreeably, than those which are only calculated to call forth their utmost powers; because, in a race, a jockey will willingly submit to some personal inconvenience to make the best use of his horse, which few persons would carry to an extreme in the hunting field.

The bridles which will be preferred for pleasure horses, whether under the saddle or in harness, will, doubtless, be those most conducive to a perfect command. It is desirable to try a variety of bridles on horses, not merely for the purpose of discovering which is most suitable, but a change has a good effect. The casuist may exclaim against this, and say, if you have found out the bridle in which your horse goes well, keep to that; but such an argument, however good it may be in theory, is not so in practice. A change refreshes the animal's mouth; in other words, a different bridle bearing upon a different part of the mouth, is a relief to the animal; and, even if he does not go quite so well in it,presuming that it is not calculated to produce any permanent bad habit, - it is desirable to use the change for a short period, and, upon returning to the favourite bridle, the horse will very probably go better in it than he had done previously.

For the purpose of exercise, snaffle bridles are 
generally in use. Intrusted to the majority of grooms or helpers, any other kind of bit would be quite out of character. With hands as heavy as a blacksmith's anvil, they would spoil the mouths of the best tempered creatures in the world, if they were to use anything else. The bits with which the late Lord George Bentinck was accustomed to ride, would be destructive to the mouths and tempers of most horses, unless guided by a gentle touch; and in a general way, as servants are not ordered to go when at exercise faster than a walk or trot of some six or seven miles in the hour, a snaffle bridle answers that purpose. When hunters require faster work, which they do prior to the commencement of the hunting season, a sportsman who studies his future comfort and satisfaction, will prefer riding such horses himself as are at all difficult to manage, unless he has a competent groom, rather than allow a mutton-fisted lout to render a really good animal very unmanageable. Race-horses requiring curbs, are generally ridden by boys who have had some practice, and are, therefore, capable of using such tackle; moreover, they are generally better horsemen than those who are employed in hunting stables, as strappers. 


\section{CHAP. VII.}

\section{STABLE DISCIPLINE.}

Comments. - System. - Importance of minor Observances. - Ap. plicable alike in Racing and Hunting Stables. - Advantages of Regularity. - Time of commencing Stable-work. - Routine Duties. - Preparing for Exercise. - Going to Exercise. - Dressing after Exercise. - Feeding. - Afternoon Performances. - Washing Hunters. - Two Helpers employed. - Quietude.

IF the management of horses is not acknowledged to be a science, at all events it is capable of being reduced to a system. In no occupation can it be more necessary to lay down certain rules, and scrupulously to attend to them, than in the direction of racing or hunting establishments. However convenient the construction of the building may be, however good the horses may be which are the occupants of those buildings, their powers can never be thoroughly developed without the strictest attention to their wants, their propensities, and their constitutions.

The great importance connected with the internal management of the stable, especially the operation of dressing the horses, must be my apology for entering here very minutely into details; and as the observances in racing stables, with very few exceptions, resemble those of hunting establishments, it is unnecessary to introduce many distinctions. Two 
important objects are accomplished by punctilious observance of these minor events, - the comfort of the animals, and the facility afforded of ascertaining if any operation has been neglected. No boy or helper can tell the precise moment when his superior will enter the stable; and as it is impossible for a trainer, hunting groom, or other superintendent, to be present and see each horse dressed, by strict observance of regularity, that is, of insisting that erery act is performed in due rotation, there can be no difficulty in detecting any negligence or omission.

During the spring, the autumn, and the winter, six o'clock in the morning is the regular hour for commencing operations. When very hot weather prevails in summer, an earlier time may be advisable for the sake of getting race-horses through their work while the atmosphere is cool; and in this variable climate, throughout all seasons of the year, the time of going to exercise must be occasionally controlled by the elements.

The first duties to be performed when the stable doors are opened will be, to rack each horse's head up, throw their respective hoods over their loins, wash out their mouths with three or four go-downs of water, and present them each with a feed of corn, taking care that the mangers are quite clean, and if any hay be left of the past night's portion, that it be gathered up and deposited in a conspicuous place to be seen by the trainer, superintendent, or head lad, when either may go round to inspect the horses. The boys then proceed to gather up the dung into 
a basket, shake up the litter, and throw it into the corners of the boxes, carefully selecting and removing that which is wet and damaged; the paving is then swept quite clean, and a thin coat of litter spread over it. The thighs and hocks of the horses are then to be brushed over and wisped; and should there be any stains, they must be thoroughly eradicated, and the hair laid smooth with a damp sponge. The clothing in which they are to take their exercise must then be put on, the quantity of which will be regulated by the weather, and the work they are to perform. If it be mild, and they are to gallop, the quarter pieces, hoods, and breast clothes are sufficient, unless it may be thought proper to throw a rug over all, to be removed for the purpose of galloping in the event of having to encounter cold, bleak weather. When walking exercise only is to be exacted, the rugs will be placed under the quarter pieces, still consulting the weather as a guide. The saddles being put on, and the girths drawn slack, to be tightened before leaving the stables, the legs and feet claim the next attention. Any dirt which may be lodged between the shoes must be picked out, the legs well brushed, a damp sponge drawn down them, and finished with the rubber; after which the boots or bandages, if either are required, will be put on, the mangers examined to ascertain if any corn be left, in which case it must be removed when the boys go to their breakfasts.

The morning meal being discussed, they return to their duties, turn their horses' heads round, put on 
the bridles and hoods, and finally draw up the girths. The trainer or head lad should then go round to ascertain if everything is in proper order; when the boys are put up, and the horses kept walking in the yard, or some convenient place, till they are all marshalled in their ranks, which is usually regulated by age upon the maxim of seniores priores. The head lad, if he be riding a horse in work, brings up the rear, so that he may be able to detect any tricks which either boys or horses may be tempted to practise; or if he be riding a hack, he takes such a position as to be able to see what is going on in front. This, however, is an office which the trainer usually reserves to himself. In this manner they proceed to the exercise ground, where, having walked the necessary time, they take their canters, gallops, sweats, or such work as their condition requires. On returning to the stable, the hoods and bridles having been removed, and the girths slackened, the horses have their heads, necks, and manes brushed, well wisped, and finished with a rubber, during which process a lock of hay should be given; the legs and feet are then washed, observing that every particle of grit and dirt is removed from the frogs, as also between the web of the shoe and sole of the foot; the legs may either be bandaged or rubbed dry. To prevent the necessity of keeping the animals stripped longer than is absolutely necessary, if the weather be cold, the clothing may be thrown forward for the purpose of brushing the quarters, the inside of the thighs, and the hocks: that being concluded, the water is

$$
\text { F } 4
$$


given, and they are immediately stripped; when they should be dressed with vigour, at the same time without violence or abuse, which to irritable, highcouraged horses is very annoying; often occasioning them to break out, and very frequently causing them to become vicious. Those which have thin, delicate skins, can scarcely endure the friction of the brush, unless it be a very soft one. The damp wisp should be used freely to all. The operation of dressing being concluded, and the clothing adjusted, the legs are to be finished; if they have been bandaged, that apparatus is to be removed, and in either case the legs require to be thoroughly brushed and handrubbed. The feet next claim attention in the way of stopping, and the occasional application of the tar ointment. The succeeding ceremony is that of feeding; when those horses which consume their first allowance with a good appetite, may have a similar portion repeated. During the time they are feeding, the boxes or stalls are set fair, and if any should reject their corn, it is to be removed; after which their hay is to be given, and the doors closed till five o'clock, when the same routine of dressing, watering, and feeding is renewed. At eight o'clock they are fed again, have their portion of hay for the night, and are then shut up.

This course of discipline is applicable alike to racing and hunting stables; but in the latter the custom of washing the horses after they return from the chase is very frequently adopted, and certainly, when properly conducted, with good effect. It cleanses 
1e coat and skin more perfectly than any other leans, and is much more expeditiously performed-a reat desideratum, especially when the animals are tigued. The necessity of a stall box, or conveient apartment for the purpose, must be apparent, 3 it would be very improper to wash horses in the alls or boxes wherein they are to remain. To erform this effectually, two helpers are necessary, that it may be done quickly. In fact, under any rcumstances, there should always be two persons nployed to dress each horse after hunting. Having ashed the horses with warm water and soft soap, othing more is requisite than to scrape them as dry ; possible, and immediately cover them with a full it of clothing kept for the purpose; at the same me the leg's must be bandaged ; thus they are congned to their. usual stalls or boxes, and a bran lash is given, half a bucket of linseed, oatmeal, or our gruel having been offered before the process of ashing commences, and during which a lock of hay ould be placed within their reach. In the course $f$ an hour it will be found that all or nearly all the 1oisture which could not be removed by scraping is bsorbed in the clothing, which is then to be reloved; they are then wisped over, which two men ill perform in ten minutes, dry clothing substituted, ad the legs attended to. They are fed, and shut p for the night.

It is an object of considerable importance, both ith race-horses and hunters, that they should not e unnecessarily disturbed during the day-time be- 
tween stable hours; that is, from the period whi the doors are closed after the morning's routine $h$ been performed, till the afternoon operations cor mence. Most trainers are very particular in tl respect, and properly so ; neither is there any reas why the same practice should not be observed wi hunters. After horses have been working hard, th will, if undisturbed, generally lie down during $t$ day; and it is a wanton piece of thoughtlessness interrupt them unnecessarily. With hunters it is great object, after a severe chase, to restore the from their fatigues as quickly as possible, whi cannot be effected unless they are permitted to enj their repose. 


\section{CHAP. VIII.}

TRAINING AT TWO YEARS OLD.

versity of Opinions. - Events which determine the Propriety of early Racing. - Overgrown Stock. - Undersized Stock. - Effects of early Racing on overgrown Colts. - Distinction between the Work necessary for present and future Engagements.-Large Horses require much Time for Training. - Reasons why small Horses are capable of ruming at an earlier Age than large Ones. - Weedy Stock: - Consequences of Procrastination. - Opinions formed from extreme Cases. - Circumstances calculated to determine the Propriety of running at Two Years old.-Action.-Change of Action. - Causes thereof. - Action in some Cases restored by Rest. Management of a Candilate for a fortheoming Derby. - Moderate Work recommended at Two Years old. - Paramount Object. Betting Adventures. - Comparison of Work between young and old Horses and between Boys and Men. - Customs of Trainers.State of young Stock. - Their Nutrition, Growth, and Work considered. - Reference to the "Stud Farm." - Time when Yearlings should become Inmates of the Training Stables. - Gradual Preparation. - Increase of Work. - Successful Treatment in certain Stables. - Owners of Horses. - Patronage. - Two Years old Stakes.

'HE treatment of horses at the tender age of two ears is a subject which has produced much diversity f opinion. The chief points to be kept in view are te effects which early training for the purpose of rcing has upon young animals, distinguishing beween that kind of preparation necessary for immeiate appearance in public, and that which is re- 
quired for future engagements. The inducemen held forth by the existing customs of the turf in tl value of stakes open for competition by two yea old stock, and the desire to ascertain as early possible the relative qualites and action of every is dividual, are ostensible motives.

The growth and proportions of particular anima are points not to be overlooked. A large overgron colt, with long striding action, is certainly not $t$ kind to be selected for racing at an early age ; indee they are sometimes not fit at three years old. Mar such creatures have been brought out and condemn at that early age, - perchance, have not gained respe the succeeding year, - but after attaining greater $\mathrm{m}$ turity have become superior horses. On the oth hand, small, symmetrically formed jureniles, wi quick action, have attained high honours at two yea old, but could never accomplish any great fe afterwards. With respect to the first descriptio the opponents of early training will urge, that if $t]$ animals had not been worked so soon, they wou have evinced greater superiority when more advance in years. That, however, depends entirely upon tl treatment which they receive. If large, weakl. loose-made colts, while they are rapidly growin: undergo strong preparations, no doubt the effects wi have prejudicial infiuences upon their constitution and their limbs. The texture of their muscles, sinew and bones not being sufficiently matured, the weake parts fail ; but it does not follow that because they al inmates of the training stables, they must be prepare 
race, or that they should be subjected to a greater oportion of work than is conducive to their welfare. here is a marked distinction between the ordeal reaired for immediate racing, and that which promotes e capabilities of enduring future preparations. Of all kinds of horses, such as those now alluded require the most time to get them quite up to e mark; and although it may not be prudent to $n$ them, it is quite necessary to keep them in ntle work. With those which are undersized, the ducements to run them at an early age are more ar; they are better able to bear the prepara$\mathrm{n}$, because they are in a more forward state of marity ; their natural powers being more concentrated, ey are mechanically or comparatively stronger. In is class I do not mean to include little, worthless, eedy creatures, that are not worth training at any e, but the small, well-shaped ones whose muscular wers have assumed a precocious development. If e opportunity of winning with them be deferred, e chances may be very problematical at a future riod. These two extremes have led many persons the conclusion that early racing is the bane of ung stock; with respect to overgrown colts it is nerally correct, with the undersized ones it is oubtful.

The object with every owner of race-horses is uniestionably to make the best and most profitable use the stud; therefore, the respective properties of each aimal must guide the determination, whether they ould run at two years old or not. Similar arguments 
will apply to those of intermediate size ; the propriet of running them will depend very considerably upo their constitutions. Young horses are reared wit so much attention to the early development of the: powers, and the system has been so much improve upon within the last forty years, that the two yer olds are quite as capable of running three quartes of a mile in August and September as the three yes olds of former days were to run their accustome distances, and the juveniles are quite as able to ber their preparations.

It is a subject of some importance to ascertai the style of going of young stock, as well as to for some opinion of their racing properties as early : possible, and for this purpose it is very common 1 prepare and try them as yearlings, but it is not very satisfactory probation. Many will alter in the action very materially when put to work; some wi improve, others will deteriorate; but it may $k$ relied upon as an almost invariable criterion, that bad goer at two years old will never make a sup rior race-horse. Disproportioned limbs or natur: weakness in some parts, either from accident or ni tural imperfections, are the usual causes of ba action, and it is very seldom they are overcom There are many with action sufficiently good to pai muster, with whom it will go off for a time, whe they again recover it. This must be ascribed $t$ indisposition, or too much work; when the faculty restored by rest.

If I were fortunate enough to possess a very prc 
rising colt engaged in a Derby, I should certainly efer bringing him out once or twice at two years $d$, providing he would bear a preparation which could be moderate, if it were only for the purpose of customing him to appear in public; but I would t work him severely, although his chance of win.ung might be lessened by the indulgence. In such case I should consider the object of securing the ue ribbon of the turf as paramount, without any ference to the position the colt might occupy in the tting, consequent upon his winning his two years l engagements.

There is as much impropriety in giving young cimals an amount of work they cannot be expected bear, as there is in allowing them to be absolutely e. It is equally unreasonable to suppose that colts ly two years old should endure the same labour as tose a year older, as it is to expect a boy at fifteen n undergo as much fatigue as a man at five-andtenty; supposing of course that the respective subits are each of them in health, and endowed with teir ordinary faculties. The treatment of yearlings is already been noticed in the "Stud Farm," that is, I the time arrives when the training stables become most appropriate asylums for them, which ought t to be postponed later than the month of July or ugust. They will then be brought imperceptibly rough the finishing process of tuition, and become adually prepared for such work as their constituons can safely bear, and their engagements require. he period of the year when it is intended they 
should make their debut in public, conjoined wit their respective constitutions, must regulate the tim when it becomes necessary that their work should 1 increased; but it should be borne in mind that th hardiest, most robust, and powerful require th longest and strongest preparation. Some traine: insist upon the necessity of sweating the youngste: under heavy clothing, and of going nearly or qui the same distances as older horses. Others the are who never sweat them at all. If one of tl two extremes be imperative, the latter appears 1 be the most rational; but the constitution and cor dition of every individual is the safest and best guid An over-abundance of fat is a great hindrance commence with, for it must be reduced; and if that 1 effected prematurely, in all probability it will be dor at the expense of some important faculty. Your creatures in that state can scarcely be expected to be: work sufficient to enable them to run without injus to their legs or constitutions, unless a great length . time is allowed for the gradual reduction. It mu be remembered they are at this period in a growir state, when nature requires a certain portion of nutr tion to support increase of bulk, and to develc various functions; if, therefore, animals are deprive of that nourishment by excessive labour, debilit and emaciation succeed, the consequences of whic may probably never be overcome.

Some few owners of race-horses have been for series of years particularly successful with the young stock; and although I do not consider myse 
at liberty to specify the stables to which I allude, I know the treatment adopted in them lias been similar to that which I have recommended.

There is yet another circumstance worthy of notice. Unless gentlemen who breed and train horses considered such engagements conducive to their interests, they would not subscribe the large sums they frequently do to stakes for colts and fillies at two years old, more especially when it is remembered that the attraction in the addition of public money is not generally offered in an equal ratio as it is to stakes for older horses. The economy and policy of such matters are determined by the proprietors of horses; hence, whatever views may be held by persons who are merely lookers on, must be erroneous if opposed to practice. 


\section{CHAP. IX.}

FIRST AND SECOND PREFARATIONS.

Physic. - Indications. - Cooling Lotions. - The Tendons. - The Hocks. - Concussion. - Over-exertion, its Effects. - Rest. Diuretics. - Increase of Work. - Trainer's or Groom's Judgment. — Objects to be gained. - Healthy State of the Blood.-Disorders produced. - Faculties of Animals. - Increased Power of sustaining Work. - Duration of daily Exercise. - First Preparation connected with Breaking. - Period required. - Circumstances which denote the Necessity of Physic. - Distinction between First and Second Preparations. - Sweating. - All Horses cannot bear the same Quantity of Exercise.-Trials.

When the colt has completed his education sufficiently to justify his being put into gentle work, it will generally be advisable to give him a couple of doses of physic. A variety of circumstances may occur to indicate the propriety of this course. Slight effusions in the legs, in consequence of the indolent state of the absorbent vessels connected with those parts, also heat more or less about the fetlock joints and hocks, will be the most prevailing symptoms, which should be minutely investigated. It may, in many cases, be prudent to apply a cooling lotion to some of the joints. Numerous curbs are thrown out, and inflammation in the sheath of the tendons, naturally predisposed to relaxation, terminates in incurable lameness, by hurrying young horses in their work, 
which physic, and a week or two of rest, would correct. Nothing can be more injudicious than working a horse when incipient inflammation is detected in the hocks. On its first appearance it may be only seated in the secreting vessels, but, if neglected, it extends to the arterial and venous circulation, from which it is sympathetically communicated to the sinews, about which a deposit ensues, and their action is thereby impeded. There is an impression that work will rouse the absorbent vessels, and thus reduce the enlargement; but this is an experiment too hazardous to be justified.

The fore legs are subject to similar affections, with the additional inconvenience arising from concussion, which alone will not only produce this disordered state of the limbs, but is certain, if the animal be worked, to maintain the inflammatory condition where it has once commenced. It must be borne in mind that these evils had their origin from an amount of exertion beyond what the frame was capable of sustaining: this is more frequently the case with young than aged horses; and it is irrational to conceive that the event which caused the malady, should restore the parts to their natural state, and effect a cure. Without temporary rest nothing can avail, and that should be assisted with gentle doses of physic by way of alteratives.

Diuretics, very sparingly and judiciously administered, will frequently promote a cure; but the utmost caution is necessary not to exhibit strong doses, or persist in their continuance during any 
length of time, lest the coats of the stomach be incurably injured.

After having put a horse to moderate exercise, if no unfavourable symptoms occur, his work may be gradually increased. In this the discretion and judgment of the trainer or groom will proclaim much of his capacity and knowledge of his business. An inexperienced, headstrong person will force his charge through work when totally unfit to endure it, and probably by so doing ruin the animal for ever. A juvenile trainer with a Pharmacopœia of nostrums is the most dangerous character that can be engaged to direct the management of horses: he will always be trying, at the same time that he is giving them work, to patch up defects, which nothing but rest, and simple cooling remedies, can effect.

The principal objects to be gained by the first preparation, - whether it be a young animal that never has been trained, or one of more mature age, which from accident, or some other cause, has been thrown out of work, - are to accustom the limbs to exertion by such moderate and almost imperceptible degrees as they are capable of bearing without injury, and tc bring the blood to such a state of perfection, that the circulation may be free, vigorous, and healthy. Wher it is remarked that the respiratory organs are in : great measure influeneed by the state of the blood that the renewal of the muscular system is deriver entirely from the blood, it seems scarcely necessary to urge any other reasons as to the importance of thi strictest attention to its healthy state. During : 
protracted period of inactivity, and most especially with good and nourishing food, the blood acquires a plethoric condition, in which state it is quite unfit to pass through the various channels when excited by rapid motion. This is readily distinguished by the excessive action of the lungs; and thus inflammation of those delicate and important organs, ruptured blood-vessels, swelled legs, colds, inflamed eyes, and other serious affections, have their origin, if the animal is caused to undergo exertions without a rational preparation. It is by gradually increasing the amount of labour conformably with the capabilities of his constitution, and the power of his limbs, that we may reasonably expect to obtain the maximum of a horse's physical force and endurance.

In regulating the work which a horse should perform, circumstances must be our guide. From one to two hours' walking exercise daily, and a canter of half a mile, occasionally increased to a mile, twice or three times a week, is as much as some light-constitutioned, weakly creatures can conveniently bear; while those which are robust and hardy will adrantageously accomplish three hours' walking exercise, and a canter approximating to half speed every day. At this crisis an opinion may be formed of the temper and constitution which will materially guide future operations.

The first preparation of young stock includes a certain proportion of the process of breaking. It is a step of advancement in the life of the animal, and the duration of this preliminary ordeal will in a 
great measure be determined by the progress that has heretofore been made in his education. In general, unless some accident intervenes, from six to eight weeks will be the average term; when arrangements are made for the second preparation, prior to which two doses more of mild physic are usually necessary. I make use of the term usually, in distinction to that of invariably, as there may be instances in which it is not only unnecessary but injudicious to give physic, as it would be prejudicial to the promotion of condition. If the animal be already too light of flesh, of a weakly constitution, and free from all indications bespeaking the necessity for medicine, I should by no means recommend it.

The difference between the first and second preparation consists in the quantity of work, and the manner of giving it. The process of sweating is now generally introduced; a subject which will be found discussed in a separate chapter. In this place it is only necessary to observe with reference to that operation, that the pace should be moderate, and the distance conformable to the strength and state of the subject; three miles, or three miles and a half, is quite enough for the first essay.

One of the errors that may be occasionally noticed in training stables, is that of all the horses being kept out the saine length of time, arising often from the fact, that it is not safe to trust boys to take home their horses by themselves, or to dress them till the trainer or head lad can return; but as some horses require much more exercise than their companions, 
and particular horses more on some days than others, it is highly important that such arrangements be made as will permit the practice of apportioning each animal's work to his temporary capabilities rather than make the duration of exercise subservient to personal convenience.

Towards the conclusion of the second preparation it may be considered advisable to give young horses something of a trial, or, as it is technically called, " $a$ spin." Two motives present themselves for this suggestion, the one being to ascertain something of their pretensions to favour, and the other to teach them something of racing. Whether they be tried or not, they should be occasionally accustomed to work stripped, in order that they may not be alarmed when running divested of their clothing. 


\section{CHAP. X.}

\section{FINAL PREPARATION.}

Work to be regulated by Circumstances. - Symptoms denoting the requisite Quantity of Work. - When insufficient. - When properly apportioned. - When too severe. - Venial Error. - Comparison between old and young Horses. - Daily Exercise. Walking. - State of the Evacuations. - Irritability of the Bowels. - Sometimes produced by Cold. - Remedy. - Cantering. - Position for the Trainer. - Examination after pulling up. - To be brought Home cool, but not suffered to become chilled.-Time when the strongest Work is recommended. - Sweats preferable to rattling Gallops. - Notes of Preparation. - The final Gallop. Indications of Fitness to run.- Treatment on the Day prior to running. - Necessary Examinations. - The Muzzle. - Alternatives with irritable Horses. - Examples. - Quietude of Stables desirable. — Treatment on the Morning of running. - Leading out. - Treatment oll returning. - Exercise distinguished from Work. - Circumstances under which Exercise is proper. - Difference of Constitution. - Stout, muscular Horses. - Delicate Horses. - Every Horse has his Distance. - Hunters. - Exercise during the Hunting Season. - Analogy between Hunters and Race-horses. - Steeplechase Horses.

THE exact amount of work that a race-horse requires to enable him to run, or that will qualify a hunter to follow hounds, varies so considerably in different subjects that it is impossible to state precisely what may be necessary. The only alternative, in this case, is to explain the symptoms which indicate the necessity for extra work, those which proclaim that 
the animal is going on satisfactorily, and the appearances which claim indulgence. To regulate the nice point - the maximum proportion of exercise a horse can bear, so that he will come to the post in the best possible condition - requires great attention on the part of the trainer; it is one of his most difficult and important duties. At the same time no man ought to be disheartened in the attempt, if he will only call to his aid, assiduity, observation, and common sense.

In the chapter on Sweating, the reasons for adopting that process, and the effects produced on the horse, are fully explained. I will now confine inyself to those symptoms to which the trainer's attention must be particularly directed. A horse whose work has been insufficient will give eviclence in the action of the lungs; when pulled up after a moderate gallop, his flanks will heave with considerable violence, and it will be some time before they regain their ordinary quietude. This must not, however, be mistaken or confounded with any affection arising from cold, roaring, or temporary indisposition immediately comnected with the respiratory organs. The quantity and appearance of the perspiration will afford a very significant criterion; when too copious, and of a soapy character, it proclaims the existence of a superabundance of fat and an inspissated condition of the blood. The eyes, after a strong gallop or sweat, will sometimes exhibit more than an ordinary degree of redness, or fulness of the blood-vessels. The ribs also give proof of the presence of too much fat; 
the animal generally looks too lusty without a sufficient development of muscle, and with his daily exercise he appears to be gaining more fat than muscle. A few additional sweats, judiciously managed, will in general produce the desired results.

When the work is duly commensurate with the constitution, the lungs will act with freedom, and very soon after the horse has performed his gallop the flanks will recover their usual regularity of action. The perspiration flows freely, is clear, and quickly dries after exertion without leaving a quantity of frothy stains. The eyes, although showing a greater degree of redness after sweating than wher the circulation of the blood is not excited, do not exhibit that extreme fulness of blood previously noticed. The nostrils, which will become distendec by a smart gallop, are soon restored to their natura condition after the horse has been pulled up. Wher the hand is passed along the ribs they should fee firm, clean to the touch, free from adipose deposit: their bareness will, however, depend much upon the make of the animal, and, to a certain degree, upor the length of time he has been in work. The coat should feel silky, and possess a blooming, glossy appearance, than which there is not a more expressive criterion of health; for it may be regarded as a general principle, that so long as a horse looks particularly brilliant in his skin there cannot be any constitutional infirmity. He will, under favourable circumstances, increase in muscular development, his 
iction will be free and elastic, and his appetite good. If, with all these happy indications, the legs are cool and the sinews clearly defined, with the feet in good order, he may be pronounced as advancing towards a fit state to contend for an approaching Derby.

In the event of too much work having been exacted, the lungs will not unfrequently exhibit a similar condition to that noticed when the exercise has been insufficient, but proceeding from a different cause. In this case a debilitated condition of the system calls forth greater efforts to perform the ordinary share of labour, and the lungs are distressed from the effects of exhaustion. The perspiration will flow too profusely; at times the horse will break out from exhaustion and a deficiency of oxygen in the atmosphere of the stable, which, under these circumstances, the animal requires in greater quantities than usual. The appetite will fail, and the sufferer will give unequivocal tokens of weakness, emaciation, lowness of spirits, and loss of flesh; the digestive organs being impaired, the evacuations will often become relaxed, and much food will be thrown off in an undigested state. 'The coat sometimes assumes a hollow appearance, and feels chilly even in warm weather, and will look dull, arising possibly from the effects of slight fever brought on by exhaustion. The legs will most probably fill from want of energy in the absorbents or venous circulation. An attentive observer will readily detect any of these symptoms, and vary the work according to circumstances. Apart from illness, 
which may have caused the horse to be incapable 0 bearing his accustomed exercise, the remedy wil usually be obtained by indulgence; this, however, $\mathrm{i}$ is highly important to investigate. Should the ina hility to bear the work have arisen from a sligh cold or any other disorder in its incipient state, tha indisposition must be attended to, and the exercis regulated accordingly. It must also be observer that the work may have occasioned some irregularit? of the system which must be relieved, according $t_{1}$ the symptoms, before any amendment can be reason ably expected.

In these delicate cases the most careful and expe rienced person may occasionally be led into error: $\mathrm{w}$ cannot always tell where to draw the line-in othe words, when to stop; but, over-anxious to improv the power of the horse beyond what nature ha limited to our use, we give him one extra gallop, o one more sweat, and in doing so the bow, whic. has already been strung to its utmost pitch, snap asunder, and the anticipations, hopes, and fears whic have occupied us for months, are frustrated in moment. Physic will, in most cases, be prope between the intervals of the second and final pre paration; but that, as in most other cases, must $b$ indicated by circumstances mentioned in other pages

Young horses will not generally require so mucl work as older ones, although some of the former tak a great deal; and there are instances when the latte can, comparatively, bear but little, and thus eacl will want nearly a similar portion. Three hour 
laily is the usual term for exercise when horses are in strong work. During the first half hour the prerailing custom is to give them walking exercise, unless the morning be chilly, when it is deemed expedient to let them trot for the purpose of increasing the circulation - a practice which has other recommendations ; for it has the effect of bringing muscles into action which are not employed in the other paces; and in the event of their being used at some future time as riding horses, it accustoms them to a style of action that will be required of them.

There is not any indication of health more necessary of observation than the state of the bowels. The freces of each horse should be examined before leaving the stable; and again when at exercise, especially during the first half hour. If they be thrown off at first covered with a slimy mucus, and if after the horse has been walking some time they become relaxed, as if physic had been administered, there is not a more unequivocal sign of irritation of the bowels, which, under injudicious management, may very probably proceed to inflammation or other dangerous results. When such symptoms appear, very little if any thing more than walking exercise is prudent; and it may be necessary to resort to a mild dose of physic; when, if that does not remove the evil, the assistance of professional skill is advisable, as it is evident the system must be in a disordered state. The influence of cold will not unfrequently produce the above-mentioned symptoms, under which the bowels are rery susceptible of in- 
Hammation upon even very slight exertion. A re laxed condition of the bowels is frequently ascribec to nervous irritability. Without attempting to deny that such is the temperament of some horses, ] cannot refrain from observing that it more generally arises from a disordered state of the system. If $\mathrm{i}$ proceeds from nervous excitement, it is very certair the animal must, at some period or other, have expe rienced a severe ordeal, the reminiscences of whicl alarm him when he finds preparations are makins similar to those preceding the event which occasioner his distress. In such cases, the utmost degree 0 tenderness and care is requisite, if possible, to recon cile the affrighted creature, and avoid, as much as car be done, any act that may call to his remembranc the origin of the evil. Old horses that have under gone serere preparations, and have run distressins races, are most susceptible of these consequences Some hunters are equally excitable. These symptom of relaxation sometimes occur from the use of nev oats or hay; but it can scarcely be imagined sucl provender ever finds admission into a well-conducter racing or hunting establishment.

Having considered these subjects, and the hal hour devoted to walking exercise having elapsed preparations for a canter ensue. Should any hors have given signs that it will not be prudent to re quire from him more than walking exercise, order: must be given to the boy who rides him to leave the string, and walk in the most retired, quiet place tha can be found. Or it may be desirable the horse 
hould have one canter only, and after that move off, iway from the others. When the number of horses is considerable, it is most advisable to work them in classes, associating those whose paces are nearest upon in equality; this must, of course, be determined by ircumstances. After the first canter of about half i mile, another half hour's walking exercise should ntervene, when they are to take another canter or a gallop, which must be determined by the judgment of the person who officiates as commanding officer. To state, in print, how many canters or how many gallops horses will require, is an utter impossibility; t must be regulated by those events which a person present can alone decide. Horses vary from day to lay; and for any that do not feed well, much galloping must be improper - yet three or four steady canters may do them good.

At the time the horses are cantering or galloping, n order to observe the action of each horse, it is needful for the trainer to place himself in such a position that he can command a view of them, if possible, throughout the whole distance, but especially he latter portion of the gallop, by which he will be mabled, by signals mutually understood by the boys, to regulate the pace; and, likewise, being near at and when they pull up, will be able to detect any ameness as they fall into the trot, - a custom which should be invariably practised. When they have stood still a few minutes, much information may be gleaned by a careful investigation whether any horse ippears more or less than usually distressed. 
It is scarcely necessary to say that every horse should be perfectly cool before he is taken into the stable; at the same time, he must not be suffered tc become chilled. As much care is necessary to allow the circulation to subside gradually, as in not exciting it too violently at first. On this account a steady canter, as a finale to the morning's exercise, must always be advocated.

With the generality of horses, I consider it the safest and most judicious plan to give them thei strongest work ten days or a fortnight previously t the time of their running, especially with youns ones. It is a custom adopted by some of our mos experienced trainers, yet there are others who wor] them severely up to the day. By this recommenda tion I do not mean to advise the interval of tim just named to be devoted to idleness, or such in dulgence as may be calculated to permit the subjec to accumulate internal fat, which may be prevente by gentle sweats; but I would avoid rattling gallops which are liable to produce staleness, and subdue th spirits, infinitely more than properly regulated sweat: It must be remembered, that on the day prior $t$ a race, the horse has to undergo several little pre liminary forms. Fasting, or, as it is technicall styled, setting, is not the least significant; and horss frequently accustomed to it recognise it as a note c preparation, in some instances so decidedly as $t$ render it a performance "more honoured in the breac than the observance."

Whether a horse should take his last gallop on th 
day prior to his race, or on the morning previous to that, should be decided by his health, constitution, and temper. In general, the latter period is to be preferred. The principal object of the final gallop is to keep the respiratory organs and the muscles in their utmost state of activity. They must have been brought into this condition beforehand; if they are in good order on Monday they will not lose their tone on Wednesday, more particularly when the ani$\mathrm{mal}$ is restricted in the allowance of hay and water, unless some indisposition should unfortunately intervene. But we will assume that the race takes place on Wednesday, and it is decided, from the plethoric condition of the horse, to be absolutely necessary to sweat him on the Sunday; he will, in the usual routine, walk on Monday, and require a gallop on Tuesday; however, there are few cases where such a severe ordeal can be recommended. Calculating, therefore, that he sweats on Friday or Saturday, a good steady gallop on Monday will usually be found the best practice. Gross, indolent horses require sweating nearer to the day of running than light-fleshed and irritable ones; indeed, if a horse is found to accumulate flesh, which some do very quickly, whilst others will fall away, it may be necessary to sweat the day but one before running. A gentle sweat, properly conducted, only one clear day before a race, is the means of bringing many horses fresher and lighter to the post than an extra share of galloping. The great art at this crisis is to have a horse light in himself, full of 
muscle, fresh on his legs, and his courage unsubdued by unnecessary fatigue. Having declared this, and pointed out the way in which it is to be accomplished, under various circumstances, the discretion of the trainer must be exercised to determine the course most advantageous to his horse.

After the exercise, on the day prior to that of running, a reduction in the usual quantity of hay and water takes place. From thirty-five to forty go-downs of water should be the limit, unless an uncommon degree of thirst prevails. A doublehandful of hay will be sufficient when the horse is shut up, but the allowance of corn will not vary from the accustomed proportions. At evening stable time from twenty-three to twenty-five go-downs of water is the extent of fluid to be given; and after the last feed of corn has been consumed, a very small portion of hay can be allowed, the general appearance and fulness of the body being the principal guide. An examination of the horse should not be omitted at this period, by feeling the pulse, and noticing the pulsations of the heart; also the state of the mouth, the appearance of the eyes, and the condition of the legs. The calm working of the flanks will indicate the action of the lungs, unles: some particular cause of excitement exists, - which may readily be distinguished, because under those circumstances the horses will usually break out, or sweat more or less. Any unfavourable symptoms existing, such courses must be adopted as are mos likely to alleviate them. Similar examinations shoulc 
be minutely observed after strong gallops and sweats.

As it is necessary to diminish the quantity of hay when the time for running approaches, that precaution would be unavailing, in the majority of cases, without the aid of the setting-muzzle. Much mystery was associated with this ceremony in former days, and it was supposed that a very select few were adepts in this art. It was almost considered an act of necromancy, and that such persons only as were gifted with the profound secret could determine the precise moment when the performance of adjusting the muzzle would operate as a charm and insure the victory. Apart from all notions bordering on superstition, a very few words will suffice to expose the absurdity of such nonsense as the supposition that any difference could be made in a horse's powers by being set half an hour or an hour earlier or later. In those days when this impression prevailed it was not known to an hour or two at what time a race would take place; it is therefore ridiculous to suppose that any man could calculate the precise number of hours and minutes that should transpire between the time a horse ought to be set and that of the race taking place; nevertheless there are circumstances which regulate the propriety of early setting, late setting, and, in some cases, of not setting at all, which I will endeavour to explain.

The most rational guide as to the time when the setting-muzzle should be put on with the generality of horses, is as soon as they have consumed the little 
bit of hay given to them after the last feed of corn on the evening preceding the race; but horses of a greedy disposition, who will distend themselves by eating the litter from under them, may sometimes require to have a muzzle on as soon as the morning stable work is concluded. The use of this apparatus is simply to prevent horses from eating their straw, and therefore their individual propensities will on all occasions influence the propriety of adopting it. To say the least of it, it is an annoying appendage, and therefore the less its aid is called into requisition the better. Hence, so long as a horse has no inclination to consume more than the food which is given to him, setting may be advantageously deferred till his appetite induces him to transgress; and thus an early hour on the morning of the race, especially if the engagement is fixed to come off late in the day, is with many horses quite soon enough. Observation is on these occasions a valuable monitor, because horses differ so exceedingly in the powers of abstinence, - indeed as much so as in their tempers. It frequently happens that horses have to run on two consecutive days, or sometimes with one intervening, and it is found that some run better on the second than the first occasion; again, there are others with which that order will be reversed. In the first case, one of the causes will arise from the fact that the animal can run most advantageously when set very sharp; in the latter, that so long an abstinence is projudicial. As a rule, it may be regarded that hearty feeders require sharper setting than delicate 
ones; but that is by no means invariably the case, because the digestion of the former being the strongest, and usually the quickest, the food is got rid of, in many instances, quite as rapidly as in others. That the stomach and intestines should be free from an unnecessary quantity of food is perfectly consistent with reason; but they must not be thoroughly empty, and what little is contained should be of a nutritive character.

In the foregoing cases it is presumed that the subjects are of a perfectly placid temper, and that the exhibition of the muzzle does not occasion alarm and irritability, which with some horses it will do to a very prejudicial extent. Some of those which have frequently gone through this ordeal will break out most profusely the moment they are aware of the proceedings about to take place. To set them on the over-night would entirely destroy every hope of their running successfully. A little tact is necessary with such creatures, and those things which indicate the note of preparation must be carefully kept away. The muzzle is with them the most prominent item; therefore when it is found to be repugnant to the notions of these acute observers, other alternatives must be adopted. In most cases these animals, being irritable, are light feeders, and therefore restrictions are not so urgent; the expedient of not letting them have fresh straw under them to tempt their appetites may be resorted to with propriety, and they must be kept with their heads racked up as much as possible. An extra half hour or an hour's walking exercise on 
the morning of running will assist in relieving them of plenitude, and, in many instances, a canter may be desirable.

With cunning old horses some variations in the observances up to the last moment of going to the post may be necessary so as to avoid excitement, but the principles should be adhered to as nearly as possible. Different horses evince their caprices in various ways; some will be perfectly reconciled, unless a particular event takes place; and others are so sensitive as not to allow the most trivial circumstance to escape their notice. I knew one horse, an animal of repute, who could not endure having his mane plaited; and I had a mare in my own possession who would calmly undergo every act of preparation but that of being led on to the course : the moment she found where she was going to she would break out in a profuse sweat, and all chance of her beating a donkey was at an end; but by saddling her in the stable, and leading her direct to the starting-post at the precise moment, and without any preparatory canter let her go, she would run respectably.

The noise and confusion in the vicinity of a racecourse on the eve of the day of running is most especially calculated to disturb the repose of horse usually accustomed to the utmost quietude; and after a few repetitions, it is not surprising that it shoulc operate as a warning of what is about to follow. It is therefore highly desirable to procure accommoda. tion where the least possible disturbance exists.

The eeremonies of adjusting the plates and plait. 
ing the manes are frequently performed on the afternoon of the day before running with good effect, as it aroids the necessity for disturbing the horses at a period of time when quietude is important. This may, however, be postponed till the morning to suit convenience. An early hour should be appointed for going to stable on the day of running, when the horses are only permitted to take a quantity of water just sufficient to wash their mouths preparatory to a feed of corn. They must then be walked out for an hour, or more, according to circumstances, and when brought back to the stables half a dozen go-downs only of water can be sanctioned. After the usual routine of dressing, they are fed again, but no more hay is allowed; the muzzle is adjusted, the stable door closed, and they are suffered to lie down. About three hours prior to the time appointed for their respective races to come off they are once more visited, their heads racked up, finally wisped over, and a double handful of corn presented to them. About an hour before the races come off is the usual time for leading out, dependent in all cases upon whether it may be necessary to leave the stable earlier, as in the event of late setting, or such causes as may indicate the propriety of additional time for evacuations. The treatment to be observed on returning to the stable after running, is precisely similar to that after sweating.

Apart from what may be emphatically termed work, there is a modification which should more 
strictly be denominated exercise, and, whether applied to race-horses or hunters, ought to be understood as signifying just that quantity of daily labour which will keep them in health, and preserve the condition to which they have been brought by judicious work and training:-for example, during the first two or three days following a race, horses seldom require more than walking exercise. Much of a trainer's attention and ability is put to the test to get horses perfectly fit on the day of running; but if those horses have subsequent engagements near at hand, his care and judgment are still required to keep his charges in the same state. When horses are once thoroughly prepared, that class of work which may with propriety be termed exercise, with most animals will be best adapted for the purpose. Some horses are only up to the highest pitch of their excellence when they are full of muscular development, others only when they are very light in their appearance; and it may be regarded as a general, though by no means an universal principle, that those which are constitutionally disposed to carry an abundance of muscle will perform best when they appear lusty to the eye, and those which are constitutionally light, when drawn fine. Here, however, it is necessary to observe the great distinction between the indications of muscle and the deceptive accumulation of external fat. Animals which deposit a vast quantity of fat internally, - that is about the region of the heart and the lungs, such as are commonly described as thick winded,-require to be sweated frequently with a vast 
deal of work on intermediate days. With them a sweat every fifth or sixth day is necessary, and in some cases it is desirable to sweat them within three days of their running. The great difficulty is in giving them the necessary amount of work without injuxing their legs ; especially if the ground be hard. For this reason it s better to sweat them frequently at a rery steady pace, than encounter the great risk of breaking them down by repeated rattling gallops. As a contrast to these are light delicate creatures, generally mares, that can scarcely ever bear to be sweated; and when that process is deemed indispensable, they should not be encumbered with any clothing whatever, but merely allowed to go the distance for the purpose of enabling them to stay their course. The same priniple holds good with hunters; and whatever prejulices some of the old school may entertain against the practice, horses will be got into better wind with nuch less injury to their legs, and will acquire a greater proportion of muscular power, by a few gentle iweats than by frequent gallops. But there are many persons who follow hounds possessing but an imperect idea of the value of condition, from the simple act that they never have their hunters in that cnviable state.

With reference to hunters the distinction between work and exercise is even more striking. Their reatment during the summer months, since Nimrod escued them from the miseries, dangers, and dimiished value, accompanied with the olden custom of urning them like bullocks into the open fields to 
graze, renders the preparation of them for the chase in November a work of easy attainment. To have hunters in high condition no green food should be given, and if it is not considered convenient or expedient to give them exercise in the summer, - a practice decidedly conducive to their welfare,-they must be accommodated with sufficient room in loose boxes with outlets or yards. I am aware there are persons who still advocate the ancient practice of giving hunters green food in the summer, but practical experience proves that the acme of condition cannot be attained by that plan. The quality of the blood consequently the circulation, the vessels connectec therewith, the muscular system, and all those import. ant functions of the body which depend upon thr state of the blood, are so completely changed by suc culent diet, that the time which intervenes betweer summer and winter is insufficient to allow the part to be restored to that state which is absolutely ne cessary to the acquirement of high condition. Th middle of August is the period for commencin? their preparations with physic; and when it is ob served that the pace at which they will be requires to go, taking into consideration the fences they hav to clear, fully equals in point of exertion the effort of race-horses, it is quite evident their conditior should be equally good, and similar means adoptec to produce that result. Hunters do not generally require to be so frequently sweated as race-horses because it is not desirable to draw them so fine 
neither should their gallops be, comparatively with their speed, at so fast a pace; but, with those distinctions, no difference should be made in their treatment. The same observances with regard to feeding and stable discipline are perfectly applicable. When the hunting season commences, if regularly ridden with hounds, very little more than walking exercise is necessary to keep them in order. There are of course exceptions to this rule with some, and in the event of a horse by any chance missing his day with hounds, a good striding gallop or two will be advisable to keep him in wind.

The general treatment of steeple-chase horses is in a few crses only different from that of race-horses. As they are required to run greater distances, their work should be apportioned and their pace slower. Practising them at fences is likewise an observance not to be forgotten, and taking them out with hounds as a portion of their training is decidedly the best method of rendering them perfect; but at the same time they should be ridden by a good horseman, who makes the horse's training his motive for hunting, and not the pleasures of the chase.

Every horse has his distance; some can only excel in half mile races, others are best at the end of a mile, a mile and a half, or two miles, and often evince their superiority at the end of three miles. These faculties it is very essential to ascertain, not only for the purpose of placing them, but of regulating their work. Horses with great speed, may, 
as they gain maturity, with a long and very judicious preparation, be brought out to run favourably, a little beyond their distance; but they never will exceed it greatly, and the fact of their being successful in such cases must generally be attributed to the inferior capabilities of their antagonists over the length of course on which they happen to run. 


\section{CHAP. XI.}

SWEATIXG.

Teneral Knowledge of the Term. - Necessity for the Process. Distinction between fat and muscular Horses. - Fat and its Use described. - Phenomenon of the Blood. - Congestion of the Lungs. - Nourishment from Fat. - Parts where Fat is deposited. Importance of Fat. - Effects of severe Sweating. - Young Horses deposit Fat more constantly than old Ones. - Importance of maintaining the Condition of old Horses. - The muscular System considered. - The Action of the Muscles. - Muscular Derelopment. _ Process of Sweating. - The proper Adaptation of Clothing. - Material. - Distance. - Preparations. - Objection to the Muzzle. - The Canter. - The Sweat. - Kind of Ground to be selected. - Pace. - Idle Horses. - Caution against destroying the Courage. - Rubbing-house or Place for Scraping. - Scraping out of Doors. - Objection to Sweating in windy Weather. Observances at the Time of Scraping. - Scraping._- Gallop after sweating. - Routine of the Stable. - Expedition in Dressing. Danger from taking Cold. - Dry Hay preferable to Wet. - Temperature of the Stable. - Breaking ont. — Practice at Afternoon Stable Time.-Causes of Horses breaking out. - Exercise on the Day after Sweating. - Interrals between Sweats. - Varicties of Constitutions. - Sweating Hunters.

EVERY stable-boy knows that sweating has the effect of reducing the quantity of fat, or, to use his own nore familiar expression, that it makes the horse ighter; but how and why the fat should be diminished $t$ is necessary to explain.

The object to be gained by sweating is to unburden the system of all superfluous fat, both that 
which is contained in the internal parts of the body, and that which is deposited among the interstices of the muscles and the cellular membranes more immediately in contact with the surface or outer skin; the overabundance of which interferes with the action of the muscles. A horse may appear to the eye full of flesh without being muscular, that is, without the muscles being clearly defined and in that full force 0 development which they are capable of acquiring from nutritious food and judicious exercise. Unless theJ are in that state the animal is not equal to the per formance of great efforts of speed and endurance.

Fat may be denominated the superfluous and oil: portions of the blood, which being deposited in certail cells or reservoirs, and conveyed there by vessel adapted to that office from the extremities of th arteries, is intended for the purpose of lubricating th adjacent parts; hence a reason why the state of th blood is so intimately connected with the condition $c$ the animal. The study of physiology teaches us that if the blood be too viscid and its particles sepa rate with difficulty, the circulation ceases, becaus blood in that state cannot pass through the lungs being thus obstructed, it is effused into the substanc of that organ. Hence congestion of the lungs is ofte: produced, and frequently becomes chronic. This is condition to which hunters and race-horses are ver. susceptible; and, as it must have a prejudicial effec upon the respiratory functions, the necessity of pre caution becomes manifest. ' Superficial observers ar 
00 anpt to disregard this fact; they are not in reality wware of the injuries produced by improper food, uch as an abundance of green succulent herbage, ;iven in the juvenile days of the horse, or when at est, and which, not being eradicated from the system prior to work, occasions this and many other evils. Jolds will produce a similar inconvenience. The body vidently derives much nourishment from the fat which it contains, for long fasting decreases the juantity very considerably. This substance is found $n$ the region of the stomach, about the kidncys, at he basis of the heart, and in the interstices of the nuscles, and if deposited in too great abundance it pbstructs the freedom of those particular organs.

The ordinary uses of these oily humours are undertood to be the faculty of supplying moisture to the surrounding parts. In moderate quantities it is essential ; it facilitates the action of the muscles, and lefends them from attrition, or, more familiarly speak$\mathrm{ng}$, from friction. Thus it will be observed, that llthough it is necessary to reduce the quantity within the bounds of moderation, it would not be consistent to carry on that reduction to excess. It is one of the ordinations of nature, that a certain portion of fat should remain in the body, as it is constantly being renewed by absorption, and a faculty of depositing itself in those situations where it is required. It is, therefore, very certain, that that power of constant renewal would not have been ordained if the presence of the substance were not essentially necessary. 
Sweating, if practised too extensively, having reduced a great portion of the fat by exhausting the system, likewise reduces the muscles. The ability to deposit fat does not exist so vigorously with old as with young or middle-aged horses, and for this reason the latter should never on any account be suffered to lose their condition, unless illness be the unavoidable cause. Having to a certain extent lost this faculty. a similar failing of the power to regenerate muscle ensues; this remark is more applicable to hunters of steeple-chasers than race-horses, as the latter seldon continue in training to an age at which this reductior of the system has established itself. The reasoning powers of man must co-operate with the decrees 0 nature to accomplish his desire of inproving the phy sical powers of the horse, in order to gain the benefi of his services.

So much of the superiority of the horse depend upon the state of the muscular system, that the con struction and functions of the muscles require to bi briefly explained. The muscles being the means b? which all the movements of the body are performed anything which tends to diminish their powers mus of necessity produce an equivalent difficulty of action The fibres of which the muscles are composed art placed in different directions; as, for instance, som run parallel with the tendons, others lie in an obliqu direction, and some have the fibres running across ol intersecting each other. That which we call flesl may be denominated the body of the muscle, the ex tremities of which, contracting into a finer substance. 
are named tendons. The muscles are supplied with an infinite number of blood-ressels and nerves, and are also enveloped in a very delicate tissue or skin, the interstices, as already observed, being places where fat is deposited. They possess a striking and unaccountable difference in their means of action; some having a voluntary motion, the origin of which it is beyond the power of man to trace.

Although increase of bulk does not always denote increase of power, - that is, does not add to the limb made up of muscle, - yet the muscles, by constant use, will become more thoroughly developed. A healthy man or horse, who is least disposed to be fat, appears generally most muscular, and indeed is usually possessed of stronger and finer muscles than those who are fat.

Having thus explained the inconveniences and disadvantages arising from a superabundance of fat, and at the same time the injurious results of excessive reductions, we proceed to show how the practice of sweating is to be carried into effect. Clothing - the quantity of which must be regulated by the weather, the condition and also the constitution of the animal, - is to be put on, a greater portion being applied to those parts which are most loaded, if any such irregularity exists; for example, if the neck and shoulders be gross and heavy, which is frequently the case with stallions, an extra quantity of clothing is required on those parts; or, if the neck be light, as often happens with mares and geldings, it may be prudent not to use even a 
single hood. For this purpose the best description is that which is made of rugs, which will be more minutely described in the chapter on Clothing. The motives for selecting that material are its lightness, warmth, non-absorbing qualities, - in consequence of which latter property, a great portion of the perspiration, as it escapes from the horse, evaporates, and the ease with which it is subsequently dried. The distance of ground to be gone over will vary. If it be the first or second sweat, three miles or three miles and a half will be quite sufficient, after which four or even, sometimes, five miles may be the extent of the performance. The night before sweating it is advisable to diminish the allowance of hay; in fact, some greedy horses require the muzzle, but this should be avoided if possible, as the frequent use of that apparatus previously to any fatiguing exercise, is very likely to cause restlessness and great inconvenience when the animal is set, preparatory to a race. After leaving the stable, half an hour's walking exercise renders the horse in a fit state to take a canter; and at the termination of a similar period, he may commence the sweat. Level ground, or that which is nearly so, should be chosen for the purpose. Ascending hills is too distressing, and descending them shakes the fore legs. The pace at starting should be slow, and gradually increased, but not to exceed half speed. Some horses become so cunning and idle, that great difficulty is experienced in getting them along, and it becomes necessary to have another to lead them, and at times to run head 
and head with them; but it is a custom that should be avoided if possible, as nothing tends more to depress the courage than bullying them when in the least distressed by pace. If thus harassed, when other horses come to run against them, the moment they are, as it is technically called, "collered," and begin to tire in a race, they will very probably "shut up," calculating, as no doubt they do, upon severe distress, similar to what they have previously experienced. It must thus appear evident how essentially necessary it is to avoid any act that will have that effect.

A suitable place must be appointed for scraping in: if the exercise ground be at a distance from the stables, a rubbing-house is usually erected convenient to the spot; but if the stables be near at hand, and are made use of for this purpose, an unoccupied box or stall should be selected in preference to the apartment in which the horse is kept, because the steam which arises will render the place damp, and, for a time, unwholesome. In fine warm weather there is no objection to scraning in the open air, but in a sheltered situation; indeed, I think it is preferable, because the animal is less likely to experience faintness, which will sometimes occur in a confined building. It must not be understood that I would sanction a horse being scraped out of doors during a shower of rain, or when the wind blows keenly from the east; in fact, if it can possibly be avoided, horses should never be sweated in windy weather, for then 
they never sweat kindly, and are very apt to break out after they are shut up. Unless the necessity be urgent, it is far better to postpone the operation till the following or even the second day. Indeed, of the two I would rather sweat a horse during mild rain than when the wind is very boisterous.

The horse having gone the required distance, and been pulled up, will be allowed to stand a few minutes, and then taken quickly, in order that the perspiration may not subside, to the place where he is to be scraped. Having arrived there, additional clothing should be thrown over him, to increase the perspiration till it runs freely down the legs: during this period he may be refreshed by washing his mouth with water from a bottle, and having his lips and nostrils cleaned with a sponge. The clothing is then to be thrown forward from his quarters, which are to be scraped. The implement with which this operation is performed should be used lightly, to avoid irritating the temper. The girths are then to be slackened, and the hoods removed. The person who holds the horse's head rubs that part with a dry rubber, while another commences scraping the neck on the near side. That being accomplished, a boy rubs the neck with dry wisps of hay, and the neck on the off side is scraped, the mane having been struck over by the scraper, as it is held up with the fingers, - all hands being at work to get the head, ears, and neck dry as quickly as possible. When that is done, and the mane combed, a dry hood may be put on, or not, according to the state of the animal 
and the weather. The saddle and the remainder of the clothing must then be removed, and the body scraped, and made dry as expeditiously as possible with wisps and rubbers, after which the ordinary dry clothing is to be put on, the mouth washed, and the horse led about till he is fit to take a steady gallop; after which, being walked till sufficiently cool, he returns to his stable, where the regular routine of dressing is to be performed. The legs should be fomented with warm water, and bandaged. Then follow gruel of linseed, wheat flour, or oatmeal, a bran mash, a small portion of hay, and the horse should be shut up for five hours.

The importance of having a horse dressed expeditiously and vigorously after he returns home from sweating must not be overlooked, and two competent persons should be employed for the purpose. Considerable danger arises if the animal becomes chilled: colds, inflammation of the lungs, swelled legs, and a long list of catastrophes are to be apprehended. During the time the head and neck are being dressed a lock of sweet dry hay should be given : many persons give it wet, which is objectionable for the following reason:- The horse at this time being naturally thirsty, and probably hungry, gives the wet hay two or three twists in his mouth and swallows it, by which means it passes into the stomach like a little wisp; whereas, when given dry, he is compelled to masticate it, which excites a flow of saliva and more effectually moistens the mouth than the wet hay. A 
ferw go-downs of gruel may be given to facilitate the object. Similar treatment should be observed with a horse on his return to the stable after a race or after hunting.

The temperature of the stable demands particular attention when shut up.' If it be too cold, inconvenience will ensue from the animal becoming chilled; and if there be not a sufficient quantity of fresh air, it will be the cause of his breaking out. More oxygen is required after severe exertions than on ordinary occasions. Considerable nicety is therefore indispensable in regulating the ventilation, so as to avoid either extremes of heat or cold.

It is not customary to strip and dress a horse in the afternoon of the day on which he has been sweating; nevertheless the legs should be well brushed, sponged, and hand-rubbed, and the usual routine punctually followed. But in the event of the horse having "broken out," it will be advisable to wisp him over. At this crisis it is excecdingly important not to allow him to become chilled. There are three principal causes for horses "breaking out" after work: the first may be ascribed to irritability of temper, the second to an impure condition of the blood, and the third to being shut up in an over hot stable, without a sufficiency of oxygen being admitted. The first is the most difficult to contend against, and can only be overcome by great care, kind treatment, the most scrupulous avoidance of any disturbance, noise, or event which may tend to alarm the animal, 
and so regulating the pace and distance when the sweat is performed as not to occasion distress. The second not unfrequently arises from the injudicious use of diuretics, which not operating on the kidneys, as intended, act as sudorifics. Many persons give nitre in the gruel or mash on these occasions, with an idea of cooling the system ; but it is a very mistaken practice. Spirit of nitric ather, or, as it is also called, sweet spirits of nitre, is open to similar objections. If anything appears necessary as a diuretic, Epsom salts, in quantity from four to six ounces, may be given; as a corrective also of the secretions in the alimentary tube its effects are often salutary. But it must be remembered that after sweating the discharge of urine will of necessity be less copious than usual, so great a quantity of the fluid contained in the body being oarried off by perspiration. The impropriety, therefore, must be apparent of forcing certain organs with medicine when there is a deficiency of material for them to act upon. The third cause may be aroided by giving more air, unless the stable is badly contrived, or the weather be intensely hot, in which case it may be desirable to reduce the quantity of clothing.

On the day after sweating, little, if anything, more than walking exercise is necessary; and the process will most probably require to be repeated with racehorses at the termination of five, six, or seven days. Some horses may require it more frequently, while others cannot bear it so often ; and many require very 
little or no clothing. These are circumstances which can only be determined by observation, combined with some study of "cause and effect." If the art of training could be simplified by mathematical demonstration, like a rule-of-three sum, or any other operation in arithmetic, every village schoolmaster would be capable of superintending the performance. All horses cannot be trained alike; that is, they cannot all bear the same proportion of work to bring them to the post in the best condition their respective constitutions are capable of attaining. A horse may come to the post very fit to run, although trained by an ignorant and inexperienced person, but that is the effect of chance. The ability of the trainer is determined by the generally good condition in which every horse comes out.

These rules and observances relative to sweating are equally applicable to hunters and race-horses; but the former do not usually require so many sweats as the latter. From four to six, commencing early in September, will render most hunters quite fit to go with hounds when the season commences. They are not required to be drawn so fine as for racing; yet, considering the pace at which hounds run, the condition of hunters should not be lightly treated. If a hunter is overburdened with fat internally, or the interstices of the muscles are overcharged, he will not be able, from want of wind and muscular freedom, to undergo the exertions frequently required from him. The functions of the lungs, the kidneys, 
ad the heart, being interrupted by an overabundace, the horse is in constant danger when the system highly excited by exertion; neither will the circution recover its accustomed tranquillity in a reasonble time after a severe day's hunting. - Hence arises ongestion of the lungs (so prevalent with old unters), obstructions of the kidneys, palpitations, ad other affections of the heart. 


\section{CHAP. XII.}

\section{TRIALS.}

Importance of Trials. - Causes of Mistakes. - Participation Trainers and Jockies. - Indifference respecting Trials. - Erro of Judgment. - Comparison between Trials and public Races. Sceptical Opinions concerning Trials. - Touts. - Circumspectic necessary. - Trying Two Year Olds. - Preparation requisite. Placing Horses. - Qualification's. - Weights. - Reference Handicaps. - False Conclusions. - Speed of aged Horses. - Pac - Boys not eligible to ride Trial Horses. - Sagacity of old Horse - Contradictory Results. - Flat and hilly Courses. - Inference Work, but actual Trials necessary. - Case of Prejudice. - Cautic against Touts. - Trial Saddles. - Caution with Boys. - Place finishing Trial. - Skill of Touts. - Indiscretion. - Anecdote.

To ascertain a horse's qualifications before he brought out to run in public is a subject of conside: able importance, whether it be a young one that he never raced, or one of more mature age that has. I the first case it is necessary to know the young one pretensions to favour; in the second to discover whe ther the horse has improved, retrograded, or remair in his original form; and by the opinions thus $\mathrm{de}$ rived of their respective powers, the propriety c paying forfeit or starting will be decided, as well s the propriety of backing him for a larger amount.

It must be remarked that the most extraordinar mistakes are at times made in trials, arising frol a variety of circumstances. A sanguine hope that 
roung animal which a man has reared, which he as daily and hourly watched with the utmost assiluity and attention, which becomes frequently the larling of his heart and the pet of his imagination, - such a creature, in his ardent imagination, must, ie conceives, possess, if not every perfection, at east very superior powers. These feelings are znown to exist, both by the trainer, the jockey, and he stable-boy, and each, desirous to gratify their imployer, uses every means to show off the pet to the rest advantage. I will not even hint that anything $s$ done hy either of the above-named persons for the surpose of deception, but from a laudable endeavour o please: thus the capabilities of the young animal ire set forth in the most flattering terms, and the swner, if he be not thoroughly experienced, deceives aimself. These facts lead many persons to regard orivate trials with considerable indifference, but that feeling must arise from the circumstance of their uaving been injudisiously conducted, and the numerous events connected therewith not being thoroughly scrutinised. To hold a principle cheap which is good in itself, although capable of misconstruction from bad management, is an error of judgment. If well conducted, trials are as certain tests of a horse's powers to those who have the management of them as public races. The health of animals influences the result as much in one case as in the other, and there are contingencies calculated to enable a horse to run better on one day than another, and applicable equally to public races and private trials; hence pro- 
prietors of race-horses ought not to hold the latter is contempt because the sequel on all occasions does no turn out agreeably to their preconceived notions an their wishes.

The public have infinitely more reason to enter tain doubtful opinions of trials from a combination 0 events; but the public have no right to any advan tage that may arise from private trials. When the: do obtain any knowledge of a horse's superiority 0 inferiority, it must be gained "second hand," an generally unfairly. Therefore at best they have $t$ contend against any little mistakes that may have oc curred in the trial, the representation given, the sourc from whence the representation is derived; in othe words, the motive of the informant; and consider ing, in ninety-nine cases in a hundred, that the resul of the trial is surreptitiously acquired, and therefor not to be depended upon, with a host of other circum stances likely to lead them into errors, it is not sur prising that the most experienced portion of the racin public should entertain sceptical notions of wha reaches their ears relative to private trials. Th legion of touts which has of late years sprung ur and who advertise their services in the sportin journals, to give intelligence relative to race-horse for "certain considerations," no doubt endeavour $t$ obtain information concerning trials for their ow] benefit ; but an owner of horses, or a trainer, must b an especial flat if he ever allows one of these geniuse to obtain any knowledge that is correct. Even is their presence, there are means of conducting trial 
$y$ which the most cunning would never discover the secret." This may be accomplished without ractising any deception which the strictest moralist ould impugn. I will presently explain how this can $\mathrm{e}$ done. There is a marked distinction between wilully misleading a person by a falsehood, and cirumspection in guarding the management of a trial so hat intrusive bystanders, or concealed touts, cannot orm a conclusion as to the result. When it is conrary to a man's interest to make it publicly known hat he has a horse of great pretensions, there is no ww, moral or legal, that can render it imperative for im to do so.

The two years olds, in the progress of their work, nay have a trial as an initiatory proceeding, which, lthough it may afford some idea of their speed, canot be relied upon. To be satisfactory, every horse hould be as carefully prepared as if he is intended 0 run. There cannot be greater folly than for a an to allow himself to be deceived by flattering rials; by making excuses that the animals which are ried are not fit. If they are in a fit state to run nd are defeated, it is generally a conclusire proof hat they are not good, in which case the only pruent course is, to place them in company of a iediocre quality, or part with them without incuring additional expenses; unless, indeed, they may e engaged in produce stakes, where they may meet thers worse than themselves, or by chance have the ood fortune to walk over.

Before it is possible to form a just estimate of the 
merits of young horses, three or four trials must tak place, and the important fact established whethe speed or stoutness be the forte of the respective can didates for favour. The relative proportion of weight at which horses of different ages ought to be trie must necessarily depend on the time of the year, an may readily be determined by reference to the Racin Calendar. The best criterion will be formed by th weight which the trial horse may have carried in popular handicap, or which may be appointed $\mathrm{fc}$ him to carry; taking that as a standard, and regt lating the weights on the young ones in proportion.

Notwithstanding there may be many other caust which lead to false conclusions respecting trials, th following may be considered the most general, ar should be enumerated in order to be avoided. I the first place, it frequently happens that the tri: horse has lost his speed. It is a very common cas that aged horses, as they improve in stoutnes lose their speed, and thus, single-handed, do ni furnish trials for young ones. Neglecting to mak the pace sufficiently strong is another event calcr lated to give the jureniles a chance. Having a ba pace to commence with, a moderate young one wi beat a tolerably good old one. It not unfrequentl happens that a boy is put up to ride the trial hors and that jockies are employed to ride the youn ones; this is just reversing the proper order, the bo being engaged to perform a duty which requires th most experience, - that of making "the running. Independently of this, many old horses will $\mathrm{nc}$ 
in kindly on the ground whereon they take their sercise.

As an example of the mistakes which are occaonally made in trials, I may state that some years nce, a trainer, of some notoriety at. Newmarket, ied three two years old fillies three times, with a ifferent result each time. When they came out to in (for they all started in the same race), the one hich was held in the least estimation proved to be te winner, and her subsequent running proved her be the best of the lot.

The nature of the course on which a horse can run the greatest advantage is a point which ought to e ascertained, as there are many that can run sereral ounds better on a flat than on a hilly course, and ice versâ. It is impossible to know how to place iem most satisfactorily without having established ais point. Some little judgment may be formed in ze common routine of exercise, but that is not to be alied upon. A trainer may have an idea of the terits of an animal in his work, which will assist im greatly, if he makes proper use of his opinion, hen he comes to try that animal; but it should lways be held imperative to ascertain by actual ials, unbiassed and unprejudiced, what are the most artain points on which a horse will run most sucessfully. Owners of race-horses and trainers are equently satisfied if the result of a trial leads them suppose that a horse has some running about him, ithout inrestigating enough to decide what his best ndowments may be. Many years ago I purchased 
a five years old horse, and left him in the care of th trainer who had had the management of him from th. time he was a two years old. The horse's runnin had been very moderate; he had frequently bee second, but very seldom first. Shortly after I becan possessed of him I rode him myself, and, accordir to my trainer's advice, waited with him, when he w: beaten easily; but fortunately the race was heats, ar at the second attempt I made running with, hir which changed the result; for the third heat I $r$ peated the running, and won that still more easi than the second. This misconception of the train arose from two causes: he tried the horse when th years old, but never afterwards, and the result of $t]$ trial led him to suppose that the speed of the cc was his forte. Being a prejudiced man he nev changed his opinion. In the second place, the hor no doubt improved in stamina and stoutness as 1 gained maturity; and had it not been for the heat which enabled me to try a different way of runnir from what had ever been adopted before, I should, all probability, have remained in ignorance how $\mathrm{n}$ horse could be made use of to the best advantage.

In order to avoid letting touts or bystanders in the secrets of trials, there are two ways of manag ment. The saddles employed for the purpose mu be made to vary very considerably in their respecti weights, and a small one, having the appearance of three or four pounds saddle should be made to weig a stone or upwards; a seven pounds saddle-cloth wi assist in the artifice. A large saddle, made as light: 
possible, will not exceed five pounds, although it will have the appearance of weighing fourteen. By this means even the jockies who may be engaged, are, if necessary, kept in ignorance of the weights they ride, by weighing them without their saddles; and with boys, if they are put up, it is a ruse invariably to be adopted, for they must be far more discreet than such jureniles usually are, if they do not confide the secret to some of their companions, when, by the agency of telegraphic information, it is a miracle if the intelligence is not spread half over the kingdom in a few hours. The inquisitive intentions of strangers will also be frustrated, by directing the jockies, or boys, to gallop on some distance beyond the point where the trial actually terminates, over which ground the winner should not be allowed to go first. Touts and watchers of horses are of course "down to every move ;" they are most of them very skilful in their calling, and for that reason every change of tactics that can be devised must be brought into play. If the true result of a trial does gain publicity, it arises from some indiscretion or mismanagement on the part of the person who conducts it.

Apropos of indiscretion, a certain trainer of much celebrity, in whose stables many great favourites for various Derbys and St. Legers have been tutored, formed an acquaintance with a lady in the gay metropolis. Being desirous of winning and maintaining her good graces, he was wont to inform her confidentially - never dreaming that such intelligence 
would be turned to account-upon which of the horses under his care she could most safely bet her dozen pairs of gloves. It happened, however, that a young gentleman who frequented Tattersalls' also became acquainted with the fair innamorata; and observing that her delicate hands were unusually well provided with unsullied kids, upon inquiry discovered she had won a great number by betting on horses whose names she mentioned. This was too favourable a chance not to be turned to good account; and, through the medium of the unconscious enslaver of the hearts of men, the future secrets of the stable were elicited from the unguarded trainer, when, on several occasions, it was discovered some person had got his money on before the stable, and, of course, at a better price. This scheme prospered wonderfully, but at length it was discovered. The trap, which had already been well baited, was set; that is, the office was given to back the wrong horse, and bet against the right one; the event came off satisfactorily to the trainer, and the hero of the ladies' boudoir has never since visited Tattersalls'.

Writhout intending to invest the practice of timing horses with more importance than it deserves, if accurately notel, it may be made use of in trials with good effect. I use the expression accurately noted adrisedly, from having more than once heard of horses running trials, specified distances, in much less time than they ever afterwards ran in public. By such mistakes grave disappointments are likely to ensue. The utility of this measure is to ascertain if 
the pace has been true throughout; and to do so satisfactorily, the exact measurement of the ground must be known, not guessed at, and which latter problematical question, I apprehend, led to the errors already mentioned. The state of the turf must also be taken into consideration.

The following table will afford a criterion of the time occupied by horses, of fair repute, in running the respective distances with the turf in good order. I have confined it to the accounts taken of races at Newmarket, because the respective lengths of the courses there are more accurately known than any others, although I must observe there is some doubt as to the exact measurement of some of those. Reference to the average rate of speed per second will show that timing trials unaccompanied by the test of horses running against each other cannot be relied upon. Unless a race, or trial, be very accurately timed, it leads to much disappointment; a mistake of only two seconds will occasion a deviation varying from twenty-seven to thirtyfive yards, - nine to twelve lengths, - much too great a distance when a conclusive opinion is to be formed of a horse's qualifications. Furthermore, it must be observed, that if two or three persons attempt to time a race, there will frequently occur a discrepancy in their calculations; it follows that errors are likely to prevail if the persons who attempt it are not exceedingly well practised in the duty.

The reports that Eclipse and Flying Childers ran a mile in a minute are unworthy of credence, for it is 
nearly double the pace that horses of the present day can go, and they are now bred more for speed than they were in the ages of the aforesaid worthies. The mistake must have originated in an attempt to time them over a short distance of ground, and coming to a conclusion that, according to their supposed rate of going that short distance, by continuing at the same pace it would equal a mile in a minute.

TIME TABLE AT NEWMARKET.

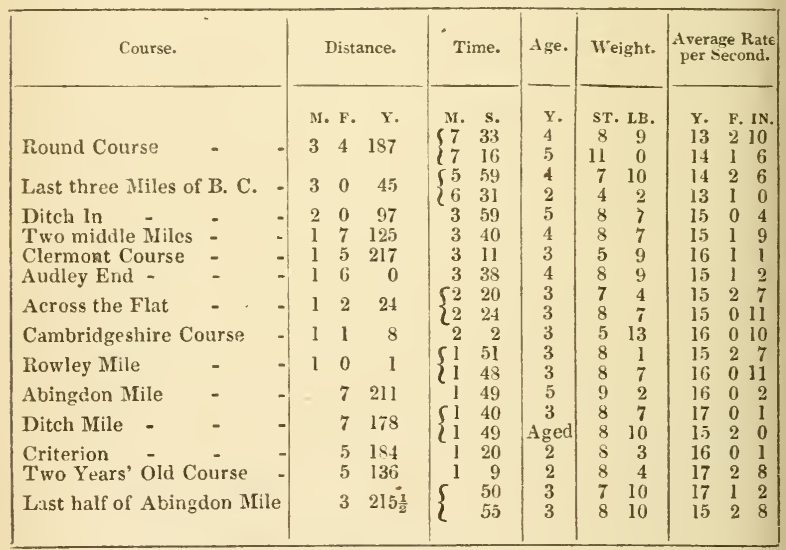

Thus it will be seen that the average rate of speed per second, over courses varying in distance from 3 miles 4 furlongs and 187 yards, to 3 furlongs $215 \frac{1}{2}$ yards, is 15 yards 2 feet 2 inches and a fraction. 


\section{CHAP. XIII.}

\section{MAXAGEMENT OF THE LEGS AXD FEET.}

Difficulty of training Horses with bad Legs and Feet. - Hunters. Causes, Remedies, and restorative Measures. - The back Sinews, and Treatment of them. - Caution. - Injurious Effects of hard Ground. - Alternative. - Comparison between Race-horses and Hunters. - Remedy. - Rest sometimes imperative. - Treatment after the Sinews have given way. - Recipe. - Sore Shins. - Relief. -Cooling Applications, and Mode of applying them.-Arnaca. - Keeping Horses at Work. - Stimulants. - Biniodide of Mercury. - Injuries to which Hunters are liable. - Fomentations. Bandages. - Blows. - Thorns. - Poultices. - Stubs. - Cold Water. - Orer-reaches. - The Pastern Joints. - Synovia, its Use. - The Hind Legs. - Cracked Heels._ Ointments.- Recipe for cracked Heels. - Prerentive Agency of Food and Exercise. Case in point. - Bruises of the Soles. - No Protection afforded to the Soles of the Feet by Plates. - Fomenting the Feet. - Tar Ointment. - Precantion. - Plating. - Texture of the Feet, and Treatment._Bad Feet. - Good Fect. - Consequences of Neglect. - Observances after Removal of Shoes. - Caution to Smiths.

There is no portion of the frame that occasions the trainer so much perplexity as the legs and feet of certain horses. Such is their peculiar formation, that when put to work they will baffle the care and judgment of the most experienced; in defiance of every precaution they will give way. This is the more vexatious, as it happens very frequently with horses endowed in other respects with uncommon powers. The state of the legs is a source of daily anxiety and attention. Some horses evince symptoms of brealing 
down in the back sinews, others of sore shins; and with many, the form of the limbs is such that they constantly hit the inside of one leg with the opposite foot so violently as to produce inflammation. Neither is the hunting groom free from these troubles, although they generally arise from different causes. It is not a very common occurrence for hunters to break down, or to have sore shins; but they are subject to injuries from blows inflicted in various ways, and likewise from thorns, stubs, and stakes.

The first consideration to be brought under notice is the cause, with a view, as far as possible, of alleviating it; the second, the remedies best calculated to strengthen the parts, keep them cool, and thereby postpone the catastrophe; the third, the means of restoring the injured parts when the animals are $\mathrm{nc}$ longer capable of performing their work.

Those horses are the most liable to give way in their back sinews when the formation of their legs is such that they stand back on their knees; the only remedy for which is, to keep their heels as strong as can be prudently allowed, - a precaution, howerer, which must not lead to any very sanguine hopes. Moreorer: it must be done with great care and by degrees; for if the heels be allowed to grow too luxuriantly, or the shoe be made thick at the heel, with the intention of relieving the back sinew, it will throw the numerous small bones, joints, and ligaments, of which the foot and pastern is composed, quite out of order, and thereby produce lameness as incurable as the evil which it is intended to avert. Keeping the legs as cool as possible, and using erery means to brace 
them, may be expected to produce some benefit; but with all the care human ingenuity can devise, it is not possible to give those horses which show unmistakeable indications of bad sinews, sufficient work to bring them to the post in the superion form their constitutions would admit of if their limbs were differently formed. When the ground on which horses are worked, or on which they run, becomes very hard, danger is always at hand from the concussion which exists. Thus it will be seen that the evils are not within the control of human influence; the only alternative, therefore, is to give these animals as little work as can be deemed calculated to develop their powers to the utmost extent their legs will bear, taking advantage of those times when the ground is in the most favourable order, and never letting them go too fast, for it is when they are extended that the greatest danger is to be apprehended. In fact, that is the reason why hunters so seldom break down compared with race-horses, because the former are seldom put to the utmost extent of theiv speed - at all events, over any distance of ground; and thus many horses which cannot bear the ordeal of the training stables, with eare will last for years in the hunting field. When the muscles and tendons have been subjected to the utmost degree of extension which their combined elasticity will permit, the tendons become, by so much exertion, so inflamed as often to produce incurable lameness. When the sheath of the tendon is highly inflamed, and appears like a bow standing back from its natural position, 
there is very little hope that the animal will be able to bear sufficient work to enable him to race.

On the first appearance of any inflammation in the sheath of the tendon, temporary rest is imperative, with cooling applications to the part affected; as an auxiliary, and, at the same time, to prevent the animal from becoming too lusty, a dose of physic may be given advantageously. If these remedies do not succeed, there is little chance of the animal's success on the turf; unless a lengthened term of rest restores the limb to a sound condition. Whether the experiment is justifiable must depend on a variety of circumstances which it would be impossible to suggest. A horse or mare descended from good blood, having done some service on the course, may be more valuable in the stud than on the turf, taking into consideration the chances of not being able to win which the malady may entail.

When such an unfortunate erent as a break down has occurred, the first course to be adopted is the immersion of the leg in warm water; for which purpose a fomenting bucket is the most convenient apparatus; but if that is not at hand, an ordinary stable bucket must suffice, and the warm water conveyed to the part by means of sponges, or thick flannels. As the poor animals suffer much pain on these occasions, the greatest care and tenderness is requisite; but the fomentation must be unremittingly persevered with, - in fact, it ought to be continued throughout the first night; but if that is not done, a poultice becomes necessary, - to which there is an 
bjection, from the difficulty experienced in keeping $t$ in the proper place, as the weight of it causes it o slip down. The poultice may be formed with ran made up with warm water, or boiled turnips, which are preferable if the accident occurs at a eason of the year when those esculents are prourable. A dose of physic will materially assist in ubduing the inflammation; and, in some cases, leeding may be recommended. After the operation f the physic has subsided, cooling remedies are to e adopted. In most cases firing is eventually conidered necessary ; but as that operation comes under he immediate practice of the reterinary surgeon, it s unnecessary to introduce any comments upon the erformance or the time when it is proper; but as here are cases in which it may be dispensed with, y repeated applications of blisters, especially of hose which are composed of biniodide of mercury, very effort of that kind must be tried before the evere and disfiguring agency of the iron is resorted o. The following formula will be found serviceable n such cases :-

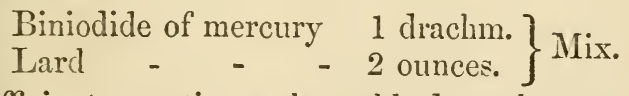

$\left.\begin{array}{l}\text { Biniodide of mercury } 1 \text { drachm. } \\ \text { Lard - } \quad 2 \text { ounces. }\end{array}\right\}$ Mix.

1 sufficient quantity to be rubbed on the part once day, and repeated till a scurf appears. This must iever be applied till every symptom of inflammation as been reduced; a caution to be observed with all inds of blisters.

As the formation of the leg already described has tendency. to cause horses to give way in their back 
sinews, the reverse - that is, those which stand ove at their knees-are most subject to the perplexin: torment known as sore shins. Not, let me remark but that some horses with the most perfectly forme legs will occasionally be affected with either malady particularly if the ground on which they take thei work is dry and hard. In those cases, concussio will produce the inconvenience now under con sideration. Peculiarity of action is another canse also frequently galloping against a severe hill. sore shin is occasioned by inflammation of the siner which passes down the front part of the cannon bon - the office of which is to lift and extend the foot from its proximity to the bone itselr, the inflan mation extends sympathetically to the periosteum, delicate and extremely sensitive membrane, supplie with remarkably minute vessels, which, on that ar count, when they are once disordered, generall create much trouble in restoring them to their prope tone and action. Some relief may be obtained b lowering the heels, so that the sinew in question ma be subject to the least possible amount of extension and, like the contrary measure proposed for wea back sinews, may be termed a mechanical alternatir which cannot be relied upon as the only remed: Rest, as in all other cases when inflammation pr vails, is the grand panacea; but as that is frequentl impossible, the only good practice, under such circun stances, is to introduce such means of relief as al calculated to allay the violence of the inflammation The pressure arising from bandages increases th 
MANAGEMENT OF TIE LEGS AND FEET. 139

vil; they must not, therefore, be used as agents for he application of any of the cooling lotions which nay be selected. A linen cloth or rubber, folded to convenient size, and tied on above the knee, so as o fall loosely down the front of the leg, constantly aturated with a cooling mixture, is the most effiacious means of reducing the inflammation. The incture of arnaca, in the proportion of one ounce to ight of water, may be used advantageously as a otion; in which case, the shin should be bathed vith it twice a day, having a linen cloth, which has een dipped in cold water, kept constantly on the art, as before recommended. By this mode of reatment, horses may sometimes be kept on in their rork so as to enable them to run out an engagement. But it will depend upon the proximity of the ime when a horse is required to run, and that of the ore shin making its appearance, whether it is most dvisable to keep him on in work or indulge him till he malady is overcome. In either case, as soon as he inflammation is subdued, the use of stimulants secomes necessary, in order to disperse the effusion which has taken place in the periosteum; because if hat be neglected, the part will eventually become ssified, from which state it can never be restored. Co promote this cure, mild stimulants are the most atisfactory, as they admit of frequent repetitions. A small quantity of the oil, or the vinegar of canharides, may be employed; at the same time, for all such purposes, the biniodide of mercury appears to be the most effectual. If made in the proportion of 
one drachm of biniodide of mercury to three ounce: of lard, a small quantity being rubbed on daily til a scurf has arisen, it will generally be followed by beneficial results; after the scurf comes off it mar be repeated in case the enlargement is not reduced This, it will be seen, is the same preparation as th one recommended at page 137 ., but rendered milde by an additional proportion of lard.

The suspensory ligaments which pass down bot] sides of the legs, are also subject to inflammation Two predisposing causes may be named, one occa sioned by blows, the other arises from the formatios of the leg, the first of which may be obviated by th use of boots or bandages to be worn at exercise; fo the second there is no alternative; beyond the rer. trivial one which may be expected from a moderat thickening of the shoe on the side on which the evi appears. The utmost caution is necessary to kee the part as cool as possible, and the remedies alread. recommended for weak sinews and sore shins are ap plicable.

The injuries to which the legs and feet of hunter are most subject, are occasioned by bruises, stubs thorns, and over-reaches. Hunters experience man: blows by striking against stakes, timber, stone walls and such like obstructions, although their riders d, not always discover the accidents at the time the happen. The excitement which prevails, and the higl courage of the animals, very often prevents thei: giving any evidence of such catastrophes, but unmis. takeable symptoms will be discovered when they re. 
irn to the stables, if not on their road home. Wounds om stubs, thorns, and over-reaches oceur under milar circumstances. The most advisable and the sually adopted practice of fomenting the legs in arm water is the best remedy for all these injuries; ad after the legs have been thoroughly cleaned by e ablution, a careful search should be made to asrtain if any, and what, aecident may have taken place. he application of flamnel bandages very generally ad very properly follows the fomentation, in which ise they should be put on quite loose, that they may ot have the effect of foreing any thorns deeper into e part; their intention is merely to keep up the rculation, and absorb the moisture during the time dressing, when they should be taken off. Any juries will then most probably give evidence of heir existence if they have not been previously disvered. Blows or bruises require continued fomentions, which are advantageously succeeded by poulces, and subsequently by cooling remedies. If tere be any thorns, they should if possible be carelly extracted with a pair of tweezers. It is imritant that the points of the thorns be examined , ascertain if they be broken off, or if any of te bark or other particles of the intruding subances remain behind; in which cases, as also in ose where the thorns cannot be removed, poulces are necessary. Not unfrequently it happens at the parts swell, by which the heads of thorns come so buried that it is impossible to remove 
them until the enlargement is reduced; and thorn will often remain in without occasioning any incon venience. The legs of old hunters when examine after death will frequently be found to have man thorns in them. Stubs in general occasion more ex tensive lacerated wounds. It is necessary to ascertair as soon as possible, if any portion of a stub remain in the wound; in which case, it must be removed $b$ operative means, if possible; otherwise recourse mus be had to poultices. In these cases, great benef will be found from the use of cold water very fr quently applied with a sponge, and this will gent rally effect a cure without the assistance of any othe measures. The contusion which usually accompani an over-reach occasions much inflammation, and cons quent soreness. There is, very often, a portion of $t$ skin torn, the remainder of which requires to be $\mathrm{cr}$ away, as it is perfectly certain it will not reunite. Tl treatment recommended for other injuries, name. fomentations, may be adopted in the first instance but on the following day the refrigerating effects cold water will materially facilitate a restoration soundness.

Much heat, generally accompanied with enlarg ment, is sometimes found to exist in the pastes joints, when horses have been doing a considerab portion of work, especially if the ground be har These joints, like all others, are supplied with syn via, an oily kind of fluid, intended to lubricate tl parts, and prevent attrition. In these cases, $t$ l synovia is not secreted in sufficient quantities; or, 
ther words, it is not equivalent to the attrition ccasioned by the work; and as the secretion of arious fluids is not similarly abundant in all animals, will readily be understood why they cannot all adure the same proportion of work without evincing 1ese symptoms. Horses, more particularly aged nes, after having performed much labour when thus Hicted, generally give unequivocal notice of this eficiency, by a stiffness of action most observable hen first brought out of the stable. Sometimes it ill go off when the circulation is excited; in some ises, they will continue to go short in their gallop. othing without rest will restore the limbs to their rimitive freedom; and even that cannot be reasonoly expected after a great excess of work. Nature, these cases, demands a sacrifice; and if not timely fered, the animals so affected will soon become usess, - at least, for racing purposes. With rest must e combined cooling remedies, and eventually stimunts, to rouse the absorbent vessels to increased tion.

With the exception of the hocks, the hind legs are ss susceptible of injury than the fore ones. Spavins ad curbs are so universally known as to require no inute description; the former, however, are somemes so trifling in size as to require much discrimiation to decide upon their existence, although the aimal gives unequivocal tokens of lameness. In their fant state they may, perhaps, be cured by repeated listers, composed of cantharides or the biniodide of ercury, previously recommended. These failing, 
the actual cautery is the only alternative, and eves that is not in all cases successful.

Many horses suffer seriously from cracked heel: and appear to be most susceptible during the las preparation, just when they are in a fit state to rur Various causes can be assigned for their appear ance; one of which is, the highly excited state c the body, when the superabundant humours, flowin into the legs, must have a medium of escape. Th perspiration lodging in the heels, without bein carefully cleansed, will also produce them. The will often break out in the heels of hunters an other horses used for ordinary work, from the hai being cut away. Carefully washing them wit warm water and soap, and the application of a coo ing emollient ointment, generally effects a cur There are many ointments adapted for this purposi each of which has its advocates; as, for exampl camphorated spermaceti ointment, mercurial oint ment, and white lead ointment, - the latter of whic has an additional property over the others, from it power of shielding the part from dirt. Poultices ar sornetimes required to assist the cure; but when th heels get into that condition, it may generally $b$ inferred that due care has not been observed to pre vent it, unless the horse is in a rery foul state c body, and in want of physic. The following appli cation I have found very effective; it combines th advantages of a poultice with ingredients calculate to promote a cure, and will serve as a dressing thre or four times : - 
For Cracked Heels. $\left.\begin{array}{l}\text { Oatmeal } \frac{1}{2} \text { pint. } \\ \text { Honey and lard (each) } \frac{1}{4} \mathrm{lb} . \\ \text { Altum } 2 \text { ounces. }\end{array}\right\} \begin{aligned} & \text { To be made into a cataplasm, and fas- } \\ & \text { tened on the heel with a piece of linen. } \\ & \text { This is sufticient for two heels. }\end{aligned}$

This is sufficient for two heels.

Having noticed the different parts of the legs which are most susceptible of inflammatory ailments, and enumerated individually the relative causes which superinduce certain parts to become disordered, it is here necessary to introduce a few words on the general treatment conducive to the prevention of such serious defects. I have, in the "Stud Farm" and other parts of this work, endeavoured to impress my readers with the advantages arising from strict attention to the selection of those kinds of food, for young stock, which have a tendency to produce the firmest texture of muscle and sinew, as that will, in a great measure, operate in averting many of the evils which have been treated upon in this chapter; and as food has precisely the same effect upon the ligaments, tendons, and muscles in one part of the body as another, the importance to be attached to this hint will be clearly understood. Every person who has watched the condition of horses when they are fed and worked with green food in the summer, must be aware of the effect it has upon them, by the effusions which are invariably visible in the legs. This is occasioned by the peculiar quality of the food, which forms an overabundant supply of bad blood. Surely a moment's reflection will operate as a warning to refrain from giving green, succulent food to horses 
when they are required to perform active labour. At the same time, it must be remembered that food alone will not accomplish these favourable results, unless it be assisted with exercise proportioned to the age and strength of the animals. I have known some breeders of racing stock keep their yearlings and two year olds on the very best kinds of food, without giving them any exercise whatever beyond the precincts of a loose box and a very small yard. These animals scarcely bore the process of breaking; and, when put into training, gave way in some part or parts most essential to their physical powers. An advocate of the principle which I must strongly condemn, told me several years since, that he should not rest contented until he had won a Derby with a colt treated according to his views. He has, since then, bred a great many, most of which have been trained, but not one of them has been able to win the most insignificant weight for age stake.

Horses, when taking their exercise, but more frequently when running, are liable to bruise the soles of their feet, particularly when the ground is hard, or a stone happens to be in their path. The plates used for racing present no protection whatever in the way of cover to the soles of the feet; and the ordinary shoes, unless made wider in the web and heavier than is desirable, leave a great portion of the soles uncovered. The effect of a bruise on the foot, unless it be severe, will not always occasion perceptible lameness, though it will create a degree of soreness and heat, which generally increases, unless proper remedies are made use of to counteract 
the mischief; and there is frequently a difficulty in determining immediately when such accidents have occurred, until a repetition has taken place, or the inflammatory action produces unequivocal evidence. When there is reason to imagine that the foot has been bruised, fomentations of warm water must be frequently made use of; and a light shoe, with as much covering as can be conveniently used, will be a means of protecting the part from a repetition of the injury. For the sake of rendering the sole more tough, and to promote its growth, the tar ointment, for which a recipe is given at page 92 . of the "Stud Farm," should be applied daily, or every alternate day. The softest ground should, in such cases, be selected for exercise, and great care taken to remove the dirt from between the web of the shoe and the sole of the foot when the animal returns to the stable, - a precaution which should at all times be taken, but more especially under these circumstances. When horses are observed to go tenderly upon their feet, as if they were treading upon hot bricks, there is reason to suspect that repeated bruises or concussion has occasioned inflammation, or, probably, the shoes may be nailed on too firmly; but, whatever the cause may be, it is highly necessary to institute an investigation, remove the evil, and apply a remedy suitable to the case.

The necessity for substituting plates in the place of the ordinary shoes, when horses are about to run, entails a vast amount of wear and tear to the feet of race-horses, which, unfortunately, are usually of a 
delicate texture. This circumstance renders it the more imperative to adopt every means of keeping them in the best order their respective properties admit. The nature or texture of the feet varies so essentially in different horses, that the treatment applicable in some cases would be very detrimental in others. For example, those feet, the soles and hoofs of which are very thin, require but little if any moisture, because they are already too soft; these soles are not sufficiently strong to protect the sensitive part of the foot. The frequent use of the tar ointment, and stopping with pads of dry tow, will preserve such feet in the best order. On the other hand, those feet which secrete a great proportion of sole and crust demand the assistance of moisture: which is most conveniently supplied to the soles with pads of tow saturated with water, to which a smal quantity of salt may be added with good effect. The shoes should be frequently removed in order to pare away so much of the soles as to admit of pliability and if the crust or hoof is overabundant, it is some. times advisable to reduce it moderately with the rasp but this operation is to be performed with caution In this respect, likewise, the two kinds of feet demani opposite modes of treatment. The first-named car scarcely have their shoes removed too seldom; anc neither the sole nor the crust can bear any reduction beyond that of clearing away the ragged portions The feet already mentioned may be denominated bac feet, possessing opposite characters; and good fee are the happy medium between the two extremes the healthy condition of which will generally be 
maintained by treatment equivalent to that medium. Hence, when new shoes are applied, old ones removed, or plates put on, the soles require only to be reduced to a moderate extent,- the crust or quarters seldom if ever demanding the use of the rasp,-and occasional dressing with the tar ointment, not forgetting, however, the advantages which will be derived from stopping with tow, especially after sweating or strong galloping exercise. Hunters should invariably have their feet stopped on the night after hunting. In all cases, frequent inspections of the feet should be made, when their appearance will indicate the treatment they require. The best feet will soon get out of order if neglected; while those which are naturally very indifferent, may be kept fit for service by proper attention. After the shoes have been removed, the feet should be immediately immersed in water, - to the depth of about two inches, - whereby a slight incrustation of rust is produced between the nails and the holes in the shoes, in case there is any space for such an action to take place, by which means the nails become more firmly attached to the shoe, and therefore less liable to cause the crust to break away. It is also very requisite to caution the smith not to drive the nails too hard, - a custom which many country workmen adopt with hunters, in order, as they fancy, to prevent the shoes from being pulled off; an effect which it may have in some cases : but it more frequently produces a more serious result that of laming the animal so treated. 


\section{CHAP. XIV.}

\section{SHOEING。}

The Importance of good Shoeing. - Perceptible Improvement in the Art. - Navicular Lameness less fiequent. - Canses. - Heary Shoes deprecated. - Effects of Horses slipping. - Casualties in the Hunting Field from slipping. - Descriptions of Shoes calculated to prevent Horses from slipping. - Shoes for the hind Feet. - Remarks on Shoes. - Corns. - Racing Plates. - Plating Steeplechasers. - Light Shoes recommended.

THE very great importance of the healthy condition of the feet, in their connection with the shoes, renders it necessary for every person concerned in the management of horses, or interested in the use of them, to devote some attention to this subject. The soundest and the strongest feet may be easily injured by bad shoeing; but it speaks well for the march of improvement that has taken place within the last quarter of a century, that there are now so few horses in any class afflicted with painful and incurable lameness from affections of the navicular bone. There are several causes to which the alleriation of the disorder may be attributed; namely, the improvement of the roads, a better method of treating the feet generally, and a considerable advancement in the art of shoeing. Many horses become lame in their feet when they are put to work, from causes which have their origin in 
neglect at an earlier period of their lives, when incipient disorganisation is established; but not being so extensive as to render them lame at the time, no notice is taken of it till work produces unequivocal testimony of its presence.

An unnecessary weight of metal is an incumbrance from which all horses ought to be exonerated; racehorses and hunters more especially. A heavy shoe is frequently the cause of a blow on the leg from the opposite foot. Horses in training, as they seldom move far except on the turf, cannot require such unnecessary appendages. Any description of shoe which will prevent horses from slipping in their gallop is to be recommended. Every person gifted with ordinary observation, who has been accustomed to ride horses at a fast pace, whether it be in racing, hunting, or training, must have experienced the exertions made by them to avoid slipping, or rather to recover themselves after such a casualty has happened. The racing plate is as well adapted to prevent this as I imagine any form or construction of equal lightness can be; nevertheless, on some kinds of soil, after a certain quantity of rain, horses must encounter that difficulty, because a portion of the earth adheres to the feet. A similar consequence takes place in the hunting field, but the land is not always in that state; and such are the varieties of soil, that you may ride a given distance over a country where it is in such a greasy state that your horse can scarcely maintain his foothold, and in the next field find it perfectly sound and secure. The same argument is good 
with horses at exercise. A superior horseman may, to a limited extent, by holding his horse well together, assist the animal when in the act of slipping; but as race-horses are usually ridden, at their exercise, by boys, who do not possess the knowledge or power to afford them any assistance, the danger arising from such casualties is more extensive. What can exceed the anxiety of a trainer, when he has a horse engaged in an important race, during the time he is performing his last sweats and gallops, fearful that every stride the animal makes he may lame himself, - an accident which frequently occurs from slipping. Not only are the feet in constant danger of sustaining injuries, but every muscle and sinew connected with the horse's action is in constant jeopardy. Somè horses are much more liable to slip, when galloping, than others; of course that is in consequence of peculiarity in their action; and many such are exceedingly nervous and timid. They indicate their fear by breaking out into profuse perspiration the moment they come in sight of the place where they are accustomed to do their work; - not but there are other causes which render horses timid, but this is one of them, and a very prevalent one.

In the hunting field, nine falls in ten are caused by horses slipping at their fences when about to effect their spring: sometimes it arises from the state of the ground, as already noticed, and from banks giving way, which no system of shoeing can prevent; but these accidents are most frequently to be traced to the insecure footing which horses experience from 
icir shoes. Every man who has had experience in ding to hounds is aware of the great exertions hich horses frequently make when fences preent themselves, in order to avoid slipping, as they ise to leap those fences; the danger is greatly icreased if uneven or sloping surfaces receive them $\mathrm{n}$ the further side; and they often fall from such auses. When a wide blind ditch obstructs the rogress, though scarcely ever perceptible till the nimal is taking his spring to clear it, how frequently, hen making a great effort to do so, does the exertion ause the feet to slip, when a fall is inevitable. Brook umping is even more subject to this inconvenience, ecause, from the nature of the banks, - they being sually wet, if not boggy,-horses are very liable to e disappointed when taking their spring; and as here is no chance of clearing a wide brook without he impetus acquired by the speed at which the mpediment is encountered, every aid should be fforded to the animal, unless the rider delights in hose little amphibious exhibitions, which occasion ast amusement to more successful rivals. There is lso another circumstance, which must not pass unoticed. When horses which are ridden across the ountry are slipping and sprawling about, indeendent of the danger to themselves and their riders, hey tire so much sooner than those which go ollectedly; and this is one reason why some animals vince such vast superiority in point of endurance ver others. There are many that will go brilliantly n a burst of fifteen minutes, but cannot go longer; 
not from any want of judgment on the part of thei riders, but from the very cause now under notice,they are so addicted to slipping as they gallop, tha they tire from the extra labour called into requisition to prevent falling.

Several forms of shoes have been devised to pre vent horses from slipping; but there are only four that I am aware of, applicable to race-horses an hunters. The first, as they deserve the precedenc in every respect, are those made by patented ma chinery, the invention of Mr. Rodway, of Birming ham. They are made of wrought iron, the only mate rial hitherto discovered applicable for the purpose 0 shoeing horses. By means of machinery they ar formed into moulds, in which state they are sent ou to be finished and fitted to the feet. The foot sur faces are precisely of the form which all well-shape shoes ought to be : the ground surfaces are hollowe or grooved out, which produces the great desideratur of preventing horses from slipping, as much as a sho can be the means of preventing such casualties. An other merit which they possess, is that of bein; lighter than the common shoes. It must be remem bered, however, they are not well adapted for th hind feet, for which the shoes require to be essentiall. different from those suitable for the fore feet. Th next to these are the concave shoes; but they are no adapted for horses with thin soles, or wide flat feet neither do they afford as much security from slippin! as the first mentioned. They are similar to th common shoes, except that they cannot be made witl 
much seating; hence one reason why they are not pplicable for thin soles and flat feet: and they differ om the former in having the ground surface of ie web bevelled down; but that should not be connued further than about the last half inch towards he heel, so that it may form a kind of stop or resistnce when a horse is in the act of slipping. The same ray of finishing the heels of Rodway's shoes is likeise to be recommended. The concave shoes are nly suitable for race-horses with good feet, and unters in a grass country. Another form of shoes - but they are not very commonly known, alhough I saw them made by a country smith, in Shropshire, thirty years ago - will be most readily lescribed by comparing them to a very thin shoe of he ordinary kind, with a racing plate forged on the uter rim. They are rather difficult to make with ccuracy, as they require a tool or instrument vherewith the rim is forged. Their effect in preenting horses from slipping is satisfactory; but I lo not think they are superior in that respect to Rodway's; and as the latter are lighter and less exensive, they certainly claim a preference. The other onstruction of shoe, calculated to prevent slipping, s the ordinary one, with the outer heel very slightly urned up, in a similar manner to a racing plate. They appear, however, to possess an imperfection in he possibility that they might occasion a twist or vrench, from the circumstance of the outer heel only being turned up; on the other hand, as I used hem for many years, till Rodway's invention came 
out, without experiencing any inconvenience, they must not be condemned on that account.

As I have previously remarked, the hind shoe: require to be made of a very different form from those which are suitable to the fore feet. They are mucl narrower in the web, and have usually a cawking 0 : turning up on the outer heel; a construction, how ever, which I am not prepared to recommend on al occasions; and if that projection is formed, the inne: heel should be made of corresponding thickness The toes should be made straight, and that part 0 the web bevelled down to the sole, for the purpose 0 avoiding an accident by pulling off a fore shoe; anc to prevent over-reaching, the toes of the shoes ough not to extend quite so far as that part of the feet The recommendation for making the toes of the hin shoes straight is obvious, - it affords a wider fulcrum from whence horses take their spring in gallopin and leaping, but more particularly on the latter occa. sion. When leaping, the toes of the hind feet art the last to leave the ground, and, therefore, if the shoes be made round at the toes, there is only a poin from whence the final resistance can be obtained; but if made straight, there is a bearing varying betweer two and three inches.

Whatever construction of shoes may be determined upon, it is of the greatest importance that the foot surface presents a perfectly flat even bearing for the crust to rest upon, as it is that part of the foot which sustains the greater portion of the horse's weight. In 
ct, when standing in the stable, it sustains the hole of the weight, unless the feet be filled with Iv or some such substance. The situation of the ail-holes is likewise a subject demanding attention. one ought, on any account, to be admitted further ack towards the heels than the widest part, or, 1 other words, the centre of the feet; and their roper position in the shoe is in the surface upon hich the crust rests, where they should be punched bliquely outwards, and their distance from the uter edge of the shoes regulated by the thickess of the crust with which the respective feet are urnished, so that when the nails are driven they lay secure a very small portion of the sole. Punch$\mathrm{gg}$ the holes obliquely outwards is of great importnce : with that direction given to the nails they will raw outwards in the crust, without depending enirely upon the pointing of the nails to effect that bject. Thus, by attention to this, the shanks of he nails will be perfectly straight; whereas, if the oles be punched straight into the shoe, there will be slight bend or curve in the shanks of the nails, inless they are brought out very high up in the hoof, - an exceedingly objectionable custom, because that ortion of the boof below where the nails pass is lamaged.

The proper length of the heels is of very great imortance, particularly to hunters ; if the shoes be too ong, they will almost to a certainty be drawn off: he width at the quarters is equally important from 
the same cause. In either case, if the shoes project beyond the corresponding parts of the feet, the slightest over-reach will do the mischief.

Great inconvenience is sustained from corns, whick may be ascribed to two causes - peculiar formation of the feet, and bad shoeing. In either case they art formed by extravasations of blood, which is depo. sited in the corners of the heels: this may be occa. sioned by the form and position of the coffin bone by the nails being placed too far back, and by the shoes pressing on the heels. They will sometime: exist without producing lameness; at other time: they will cause great pain; it is therefore advisable whenever the shoes are removed, to examine the part and if any symptoms appear, cut them away, dres them with tar ointment, and relieve that portion 0 the foot from pressure.

The difficulty of securing racing plates to the feet in consequence of their slender make, frequentl. induces smiths to extend the nails too near thi heels, which causes pain more or less acute, com pelling horses, so treated, to go short, in some in stances, absolutely lame. To obviate this, it is fa better to make the plates stronger; and on all occa sions their substance should be adapted to the size 0 the foot. Nailing them on too tight has also : similar effect. Horses with very thin feet, when thr ground is hard, would run better in light shoes thas plates; but such is the effect of custom, that if : horse were started in that way, and had not the goor fortune to win, the ever suspicious public woul 
ttribute the defeat to design on the part of the wwer or trainer.

For steeple-chasing, plates are in some cases erfectly out of place. Horses with very strong eet, when the country is nearly all grass, will go vell in them; but those which have tender feet reuire more protection than a common racing plate ffords. The very great diversity of country comnonly selected for the avowed purpose of trying the aerits of horses, renders it impossible to calculate what the nature of the ground may be till it is shown. itony fields and hard roads occur in most lines, by eaping on to which horses are liable to bruise their eet considerably, unless they are properly protected. The great exertions which animals are required o make, when engaged in these contests, render it ecessary to afford them every assistance our inenuity can devise. Light shoes on Rodway's priniple, or the common shoes already described, but of ourse much lighter than for hunting, are admirably dapted for steeple-chasing, and are for many kinds $f$ feet superior to plates. The variety of subtances which horses may place their feet in contact ith, when steeple-chasing, must show the propriety $f$ being prepared to encounter such impediments as lay occasion even momentary pain. 


\section{CHAP. XY.}

BANDAGES AND BOOTS.

Prejudiee confuted. - Materials. - Dry Bandages. - Their U'se an Effects after washing the Legs. - Their Use and Effects sul sequently. - Benefits derived from Bandages. - Linen Bandage - Cold Water. - Cooling Lotion. - Mode of applying it. - Col Bandages for Exercise. - Recommended for Hunters. - Trea ment of the Legs of Hunters after severe Work. - Distinction br tween warm Woollen Bandages and cold Linen Ones. - Prop Method of adjusting Bandages. - Bandages or Boots for Exercis - Merits and Demerits of each compared.-Indian Rubber Boor - Objections to them. - A Case in point.-Best description of Boc for Hunters.

THE difference between use and abuse cannot 1 better brought out than in the matter now und consideration. A prejudice exists with many persor against the advantages of bandages for horses' leg arising from an improper or careless mode of apply ing them, or from selecting a material not calculate for the particuiar purpose. Hence, by using thos which are improper as remedies for specific ailment ill effects are produced, and the apparatus condemne without judge or jury. The materials of whic bandages are formed, are woollen serge or flanne linen, and chamois leather; and as these are capab? of producing very lifferent effects, dependent upo the manner in which they are applied, it become 
necessary to consider how they act, and make the selection according to the nature of the case.

Dry woollen bandages are employed for horses' legs when they return to their stables from exercise or work, immediately after the legs have been washed: in this case, they are only suffered to remain on during the time the horse's body is being dressed, and should be put on quite loose. It may or may not be advisable to keep the legs bandaged; but, under any circumstances, they should be taken off after the body is dressed, that the legs may be brushed and well hand-rubbed. Their effect, when used immediately after washing the legs, will be to maintain warmth in the extremities, and to absorb the moisture left by the ablution. When bandages are applied to the legs after they have been made quite dry, it is to prevent their swelling, or - in more familiar stable lingo - filling; the cause of which frequently arises from irregular circulation,that is, the arterial force is more energetic than the venous and absorbent systems; consequently, the arterial blood is thrown out to the extremities more copiously than the veins have the power of returning it, or the absorbents of carrying off their appointed portions. In these cases, the veins become suffused with blood, often to a painful, and, in some instances, to a dangerous, extent, when cracked heels, and such like vexatious nuisances, become the outlets for those superfluities which the absorbents cannot accommodate. As, however, cracked heels arise also from other causes, it is unnecessary to treat of them in 
this chapter, as they are noticed in that which is devoted to the Management of Legs and Feet.

When dry woollen bandages are properly adjusted, they act beneficially in various ways. By their warmth they stimulate the venous system to action, and, by the moderate pressure which they produce, they have a similar effect on the absorbents. This explains the necessity of devoting great care in their application; if irregularly put on, they will have an injurious effect, acting as a ligature to a vein: the bandage will prevent the return of blood in a similar way to that used by a surgeon when he bleeds his patient in the arm, or the pressure on the vein of a horse when he undergoes a similar operation. It must therefore be seen how great is the importance of having bandages firmly and regularly adjusted when they are intended as remedies for swellings of the legs. The best material for woollen bandages is the serge made for the express purpose, as it has a selvedge, which is more even and elastic, at the same time firmer than flannel, which must be sewn over or hemmed.

As the benefits to be derived from the use of a bandage depend entirely upon the way in which it is adjusted, it is necessary to be minute in the directions for putting it on. This cannot be done properly unless it is first carefully rolled up, and in this operation it must be made quite tight and even. It is then to be taken in the right hand, and with the left the end of the bandage is held to the horse's leg, about midway between the knee and the pastern; the 
next turn laps over that end, when the bandage is to be worked up to the knee, great care being taken to keep it quite even; it is then to be gradually carried downwards to the pastern joint, and tied round the pastern. This is not the usual place-for securing it, but I will offer reasons for adopting it. If it be tied round the leg, and the bandage slips from the horse rubbing it, or any other accidental cause, or if the leg fills, the tape becomes a ligature, which it is most important to avoid: being tied round the pastern, that being the lowest and smallest part, such a misadventure cannot occur.

Linen bandages are only serviceable as agents for the application of cooling lotions; and to produce the desired effect, great care is necessary. If wet linen bandage be permitted to become dry $t$ acts as a stimulant, and instead of cooling it inlames the leg, more particularly if saturated with efrigerating lotion, composed of the usual ingredints ; namely, nitre, sal ammoniac, and salt, which, laving expended their powers of evaporation, become timulants. It is for this reason that simple cold vater is often more beneficial than medicated lotions, ot because the water is more powerful in its proerties of evaporation, - in fact, it is not by many egrees so much so,-but because, when it has ceased produce evaporation, it does not act as a stimulant, Ithough it must be remembered that the linen bandre, when it becomes dry, has that effect to a cerin extent, from the heat which it occasions. When 
properly attended to, the best effects will be produced by cooling lotions composed as follows : -

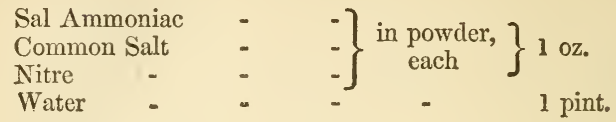

In using this lotion, the mixture should be applied immediately that it is prepared, because it is during solution that the powers of evaporation exist, and it should be renewed as often as the bandage becomes warm. This will necessarily interfere with stable hours, - that is to say, a horse cannot be shut up during the usual periods, otherwise the bandages will not only become warm, but they will become dry, and a stimulating effect will be produced, as already mentioned. When extensive heat or inflammation is to be subdued, it is most advisable to apply the lotion with cloths fastened loosely on the part: and it should also be remembered, that when linen bandages are used for this purpose, they should always be put on quite loose.

I have witnessed great benefit from cold bandages for horses when at exercise, particularly for hunters; the action of which I will endeavour to explain. The ingredients of which the lotion is composed being refrigerant, from the faculty they possess of evaporation, are greatly assisted in their operation by the cooling effect of atmospheric air; consequently, they act more powerfully out of than in the stable. I am not advocating this plan for horses when they are to gallop; but, indeed, when 
they require cold bandages, it is not, in general, prudent to give them much fast work. Hunters, whose legs have been knocked about, and racehorses, on the days they are not required to take galloping exercise, if their legs demand the use of cooling remedies, derive great benefit from the application. Bandages made of chamois leather are admirably adapted for this purpose.

Old hunters, whose joints suffer from stiffness after a hard day's work with hounds, obtain great relief from the application of woollen bandages wrung out of warm water, which are to be left on all night. They are put on after the legs have been well fomented with warm water, and thus operate as a kind of poultice, whereby the vessels are temporarily relaxed. It must be observed, a woollen bandage applied in this manner is essentially different in its effects from a linen one saturated with a refrigerating lotion, which, as I have already stated, after a certain time, becomes stimulative.

For the purpose of affording protection to the legs when at exercise, either boots or bandages are made use of. Many horses absolutely require them, because they scarcely move in some of their paces without striking the foot against the opposite leg at some part or other, between the knee and the fetlock. With them it is almost unnecessary to intimate how soon inflammation will be established, and lameness produced, unless some artificial means of avoiding the injury be introduced. There are various opinions on the question, whether boots or bandages are best 
calculated for the purpose ; it is necessary, therefore, to discuss the merits and demerits of each. The objections to boots are these: they become hard from the frequent exposure to wet and the accumulation of perspiration to which they are subject; and, with all the care that can be bestowed upon them, some dirt will work into the texture of the serge with which they are lined; and when wet, they are not readily dried. Without very frequent inspection, their hardness and, consequently, their inaptitude to save the legs from injury, is not discovered till the legs proclaim the fact; for it would be vain to expect that the boys who daily make use of them will give any intimation that they require fresh lining. While they are new, or when they have been recently lined, if properly padded, they afford the necessary protection; but by a little neglect in thoroughly drying and brushing them, they very soon fall into a state unfit for use. The mode of fastening them on, by means of straps and buckles, is open to objection, because if one strap be drawn too tight, if only by?one hole, it produces an uneven pressure on the part of the limb where it is situated; and unless they are buckled on tolerably tight, they will turn round. With respect to bandages, the chief objection lies in the nicety required in putting them on, and that can only be overcome by strict attention in teaching the boys how to adjust them the eye will readily detect whether the instructions have been followed. Bandages are easily dried, and 
may be thoroughly cleaned with soap and water from all accumulations of perspiration and dirt. They also afford some trifling support to the sinews. Under these circumstances, I think the vote will be given in favour of bandages.

There are many hunters requiring protection to their legs, some because they strike them with their opposite feet, others in consequence of weakness in the back sinews, or the suspensory ligaments. For these purposes, bandages would be unsightly and inconvenient; the question, therefore, ensues, what is the best description of boot? That will be determined in a great measure by the nature of the case. Those horses which hit themselves only on their fetlock joints require that part alone to be protected, which is most neatly and readily accomplished by means of a narrow piece of leather, cut just long enough to surround the joint, having a strap with a buckle on the outside running through four loops, one of which is placed about three quarters of an inch from each end. This need not be buckled on very tight (a great objection), because, if it turns round, it still continues to guard the part. As for speedy cut boots, a horse requiring such apparatus can scarcely be worthy of stable room; and it is, therefore, useless to waste time on the subject. The old fashioned leather boot formerly used for hunters which hit their legs between the knee and the fetlock, or require support to their sinews, is superseded by those of elastic Indian rubber fabric, which are not per- 
fect, from the fact that they contract or collapse with cold, and expand with heat; therefore, when a horse is standing by a covert, half way up to his knees in clay, they will become painfully tight; and when he becomes warm by galloping, and requires the support which the boots are intended to provide, they become relaxed, and for that purpose useless, as I myself have experienced. I had been sitting on mv horse some considerable time in Austey Wood; which all those who have hunted in Warwickshire are aware is intersected with rides of a very wet nature. My horse had on a pair of the Indian rubber boots: at length the fox broke covert, when I found, to my surprise and mortification, that my horse was completely crippled. At first I could not imagine the cause; but a friend who was passing me in my difficulty suggested it was the boots; upon which I immediately dismounted and cut them off, when the poor horse went as well as ever. I have never repeated the experiment.

The most appropriate boots for these purposes are made of kersey, the colour of which may be regulated by that of the legs. They should be nicely lined, and fitted on with laces: if properly cut, they afford a support similar to bandages, and are as little unsightly as such contrivances can be. 


\section{CHAP. XVI.}

CLOTHING.

isplay of Taste. - Colours. - Texture. - Shape. - Material for Sweaters. - Stable Suits. - Precaution against Dampness. Rollers, and thei Adjustment. - Tearing the Clothing. - Preventives. - Example. - Crib-biting. - Remedies. - An incorrigible Crib-biter.

CHIS very necessary portion of the appointments onnected with the stable admits to a considerable xtent a display of taste on the part of the prorietor; nevertheless, there are certain considerations f convenience and utility which fashion and a desire or novelty should not be allowed to overrule. For acing purposes, light tints usually prevail, or-more n keeping with uniformity - those which assimilate vith the colours of the cap and jacket. The latter seection is advantageous to the public, and enables trangers to identify horses by the analogy of their ivery. The light colours, so long as they are fresh and lean, have a superiority in appearance to the dark nes; but when the gloss of newness is worn off, the atter are preferable; nothing looks more slovenly than $\checkmark$ suit of light-coloured clothing soiled with stains vhen a horse is led out in it on a race-course. The texure requires to be adapted to the season of the year, 
or more properly, in this variable climate, to the stat of the atmosphere. In cold weather, a fine ligh kersey will be appropriate; but when the air become hot, something of a thinner texture is required. Tha which is made of serge is preferable to linen for thi purpose, because the perspiration causes the forme to become wet and cold; besides which, not bein? sufficiently elastic, it never fits nicely. The art 0 cutting out clothing is a portion of the saddler' business not always performed with good judgment Quarter pieces require to be cut back at the point 0 the withers, otherwise they rub the mane away, an cause the horse to appear as if he had been in harness From that part they should be sloped forward, s that the shoulders may be well covered. Muc nicety should be observed in the form of the hoods for the appearance of the most symmetrically forme horse is spoiled by clothing cut in bad proportions.

The best material for sweaters, as being th lightest, the warmest, and the most readily dried, $\mathrm{i}$ the common rug. "For the body, the rug should $b$ formed by cutting a piece out in the form of a hal circle, commencing at the point of the withers; thi leaves a portion which admits of being fastene across the chest by means of a strap and buckle, an dispenses with the necessity of a breast cloth. A rui cut down the middle, with the two ends joiner together, forms a breast sweater, occasionally requirer for horses which become loaded about the shoulder and neck.

Rugs are likewise most suitable for horses to wea 
1 their stables. The substance of this material aries considerably; but those which are of medium ickness are preferable: in the first place, very aick ones are too warm for summer use; in the econd, they are not so readily dried; and in the inter, especially in the hunting stables, it is more onvenient to use two of moderate thickness. The isensible perspiration which constantly escapes from orses will render the clothing in which they stand ore or less damp; that dampness will be found on he outer rug when two are made use of, and the nderneath one will be perfectly dry. The outer ne can, therefore, be very easily dried while horses re out at exercise, or being dressed; moreover, the hick rugs, with quarter pieces over them, are two leavy for exercise.

Great inconvenience is occasioned by buckling the ollers, with which the clothing is secured when in he stable, too tight. It is well known the injury vhich the fair sex inflict on their forms by tight acing, and this can scarcely be less injurious. A oller buckled tight round the part where the heart s situated cannot fail to be prejudicial to the action of that very important member, and consequently uffect the circulation. To avoid this, ingenious devices have been introduced in the way of springs and India rubber webbing; but they cannot act satisfaccorily, because when drawn sufficiently tight to keep the clothing in place, the springs or tension of the India rubber fabric must be so nearly expanded as to render either ineffective. The purpose is more 
readily accomplished by means of a breast-girth fixer to the rollers, with which it is impossible for tha apparatus to slip back.

The propensity which many horses evince for mis chief is exemplified in a trick of tearing their clothing - a very expensive amusement, and one which it is is some instances difficult to check. Clothing made 0 horsehair is in some cases made use of, but no with very satisfactory results, for some determine offenders will destroy that; moreover, it is of harsh rough texture, calculated to produce irritatio: of the skin, and, from that cause, promote the habit A side stick - that is, a piece of ash, with a buckl and strap at either end-is the most effectual remedy one end of which is buckled to a loop on the rolles the other to the head collar: this, if made of a prope length, prevents a horse from turning his head suffi ciently to reach the clothing which covers th shoulders or any part behind; but I very recentl. had a horse that was not deterred by that means although I had a stick placed on each side. Bein: curious to ascertain how he contrived to perform hi trick, I watched him from a window when he wa shut up, and discovered that he accomplished it $b$ : throwing up that portion of his rug which was fast ened over his chest with his knees, and catching $i$ with his mouth, tearing it away nearly as far back a the roller. Having carved his clothing to his ow fancy, I allowed him to wear it in that form, as thi only alternative; for if any portion was brought for 
vard sufficiently to enable him to reach it in the nanner described, it was certain to be torn.

Another of the accomplishments to which some corses are prone, that of crib-biting, is generally preented by means of a broad strap round the neck. A nuzzle with bars at the bottom, so that the subject nay feed through that space, is sometimes used, but $s$ no preventive of wind-sucking; in fact, it is rery likely to induce a crib-biter to adopt that habit. A head collar has also been invented for a similar urpose; but I think the broad strap is preferable. t should always be taken off when the horse is lrinking.

This very obnoxious habit is doubtless acquired luring hours of idleness, when a variety of projecions convenient to the animal's purpose are preented; it is, therefore, important that all buildings ccupied by horses be free from inviting objects. There are many degrees of crib-biting; but unless ffectually checked in its infancy, by allowing nothing o remain within reach, the habit usually increases. ndeed some horses are so determined in this proensity, that it is scarcely possible to prevent them ven with the broad strap already named. I rememer a hunter belonging to a master of foxhounds which ould not be deterred from this habit. He stood in stall, the manger of which was guarded with a reolving bar of iron, having little spikes inserted, like chevaux-de-frize. It had not been placed there a reek before the cunning brute set that at defiance, 
by taking up mouthfuls of litter and winding them on the bar, thus forming a nice protecting cushion. Th effective remedy was then adopted, of keeping hin in a loose box, with a small moveable trough for corn but during the time he was feeding, it was necessar. to have a man standing near him, or he would leav off eating, to indulge in his bad propensity. Th trough being removed, there was no kind of projec tion which he could take hold of, and his hay wa thrown down in a corner of the box. 


\section{CHAP. XVII.}

PHXSIC.

nportance of Physic. - Constitution to be consulted. - Circumstances which indicate the Propriety of giving Physic to Racehorses. - Reference to Formula. - Circumstances which indicate the Propriety of giving Physic to Hunters. - On Alteratives. Reference to the "Stud Farm."

HE great importance of physic for race-horses and unters is so generally admitted, that it appears unecessary to enlarge on that topic, more especially as have in the "Stud Farm" introduced the subject ith directions applicable to the management of all orses prior to giving medicine, and during its operaion, together with formulæ for its preparation.

The only caution I shall presume to repeat is, that f not giving physic in strong doses. The first conideration is to proportion the dose to the constiution of the subject. On this head, experience is he only monitor. Hearty-feeding - I may term hem gluttonous - horses are often very readily cted upon by purgative medicines; and on the conrary, horses which are light feeders will sometimes equire the most powerful remedies. With a strange orse whose constitution is not known, the safer plan the first instance is to begin with moderation. 
Horses in training generally require physic be tween each preparation; but whether it is advisabl to give it at other periods must entirely depend upo circumstances. If the very hard state of the groun renders galloping a dangerous exercise, a mild dose ( physic may sometimes stand in the place of a swer with good effect, more especially if the legs git suspicious tokens. Any horse whose appearance ir dicates that with a considerable portion of work he acquiring fat, will in all probability be benefited $b$ a dose of physic. The first symptoms of indispositic will very frequently yield to a dose of physic, mor particularly if the liver be out of order, either as primitive or sympathetic cause. Loss of appetite, fetid odour arising from the evacuations, depressic of spirits, a dry feverish state of the tongue, all ter to show that the biliary secretions are not acting wi regularity. In such cases the introduction of calom may be recommended in combination with aloes, a cording to the formula given at page 154. of tl "Stud Farm."

The general custom of giving hunters physic founded upon such a rational basis that it cannot $k$ safely dispensed with previously to commencing the work. Two doses are usually sufficient during th month of August, and I have found it an exceller plan to give another early in the month of Novembe The process of assuming the winter coat has a ver considerable effect on the constitution: during tl time it is in progress, much lassitude and debilit exist, when it is most prudent to avoid giving purg: 
tive medicines, unless some particular cause renders it imperative. By giving two doses of physic sufficiently early in Angust before the coat has undergone any change, and again in November when it is stationary, the most beneficial result may reasonably be expected. In the event of an accident, it is generally necessary to give medicine to allay inflammation, which with horses highly fed is usually extensive. The old custom of bleeding on all trivial occasions is nearly superseded by the more rational introduction of physic. The setting in of a frost is usually the suggestion to give physic to hunters, and there are several good reasons for so doing. In the first place, it is an auxiliary to the recovery of injuries from blows on the legs to which hunters in all countries are susceptible; also from the inflammation occasioned by thorns. The exuberance of spirit which highly conditioned horses are prone to exhibit, can scarcely be kept within moderate bounds by the exercise obtainable during a protracted frost; and on that account again, unless physic were employed, the animals would become internally fat, in which state danger is always to be apprehended if they are suddenly required to undergo laborious exertions.

The indiscriminate use of alteratives composed of antimonial preparations, prevails in many hunting stables to an injurious extent. "Nimrod" was at one period a great advocate for them ; but from a conversation which I had with him a few years before his death, I found he had changed his opinion. The principal effect that I have observed from them is to 
occasion nausea; consequently, temporary loss of appetite, and debility. It must be admitted they cause horses to look well in their coats; but if they have been properly prepared for their work by mild doses of aloes, they will not require any alteratives, or nostrums denominated "condition balls." By this I do not mean to disparage the merits of tartar emetic in cases of fever or indisposition requiring such a remedy; but those disorders come under the direction of veterinary treatment, which I do not presume to discuss in these pages. Cutaneous diseases may also require diaphoretics.

I offer no apology for the brevity of this chapter, having in the "Stud Farm," with the exception of the few subjects here introduced, explained most of the causes which indicate the propriety of giving physic to horses at all ages; and have likewise, in every case, suggested the occasions when it is required. But I cannot conclude without urging the importance of strict attention to the preliminary management with regard to food, without which the proper effects of purgatives can never be relied upon with satisfaction or regularity. 


\section{CHAP. XVIII.}

TRA VELLING.

An Apostrophe. - Exorbitant Charges made to Owners of Racehorses. - Comparison with other Classes of Trarellers. - Extortions counteracted by Railways.-Economy of Railway Travelling. - Inconveniences of travelling by the Road. - The Time necessarily occupied.-Touts disappointed. - Effects of Road Travelling on the Legs and Feet. - Weather. - Cost per Diem of travelling by the Roal. - Sweating essential afterwards. - Precautions against Alarm and Injury. - Horses to be walked a few Miles after Railway Trarelling. - Impertinent Curiosity defeated. Construction of Vans. - Expense of Posting. - Obserrances when travelling on the Road. - Boys walking with their Horses. Objections thereto. - Road Travelling seldom imperative. - Influence of Railways on Race Meetings.

THex a man sallies forth with race-horses, it would appear that every individual with whom he has pecuniary transactions accosts him with these quaint expressions :-

"I wish thee, Vin, above all wealth, Both bodily and ghostly health;

Not too much wit or wealth come to thee, For much of either might undo thee."

Every innkeeper, and indeed every other person with whom an owner of race-horses comes in contact, aprears to be so wonderfully interested in the moral N 2 
happiness of the latter, that rather than he should suffer the dreadful evils to be apprehended from a plethora of riches, they would singly or collectively encounter the risk of taking all superfluous abundance upon themselves. Why it should be, I never could conceive; but all classes of men connected with racing are charged enormously at most of the hotels or inns to which they are accustomed to resort. The man of pleasure who travels for his amusement, who seeks the enjoyment of the coffee-room at the hotel in the town where he may be sojourning, is charged fairly, and according to the luxuries which he desires. The commercial traveller, when on his route for his own or his employer's profit, is charged moderately; but he who keeps race-horses - who moves himself, his horses, and his servants from one place to another to promote sport by which an influx of company is gathered into the town, whereby the innkeepers are great gainers; and who maintains one of the noblest diversions of the present age ; to which may be added the ambition of still improving that breed of horses as yet unrivalled by any other nation, not only for the honour, but also for the prosperity of this country - is charged extravagantly.

These extortions are in some measure counteracted by the facility of locomotion afforded by railways; and although the charges made by the companies for the transmission of horses and boys are considerable, taking all circumstances into calculation it is a more desirable mode of travelling than by the road. The risk and inconrenience attendant upon change 
of stabling, and the consequent change also of hay and water, must be taken into account. The time occupied when travelling by the road is another very important item, which likewise entails the necessity of making a longer sojourn prior to the meeting at the town where the race takes place, in order that the horse may take a sweat after his journey; an event which affords the touts opportunities of scrutinising his condition, and sometimes of putting more unworthy practices in operation; for they are evil genii, on all occasions to be regarded with great caution. The road never produces beneficial effects upon the legs and feet; on the contrary, it is often productive of much staleness, especially when it is in a very wet state; or the reverse, dry, hard and dusty. Bad weather is likewise a very serious affair; for if the clothing becomes wet with rain, the difficulty of getting it thoroughly dried for the ensuing day's journey is very great; moreover, during the time thus occupied, that which is found at the inn must be used as a temporary substitute, the dryness of which cannot always be depended upon. If horses travel by the road a distance of a hundred miles, at least four, or most probably five, days will be occupied by the journey, at an average cost of ten or eleven shillings per diem for each horse and attendant boy, independent of the expenses incurred by the trainer or head lad who accompanies them; and they require to be at the place of meeting four clear days prior to the race for the purpose of being sweated; 
thus upwards of a fortnight must necessarily elapse from the time of leaving to that of their return to their stables. The railways obviate all these inconveniences without materially enhancing the expenses.

It is a singular fact, that very few horses evince any great degree of alarm on travelling in this fashion; but some do, and therefore there are a few precautions necessary to avoid danger. In many cases winkers are of important service if put on for the purpose of leading horses into the boxes. There are so many objects constantly presenting themselves at railway stations to which neither race-horses nor hunters have been accustomed, that alarm may be occasioned very unexpectedly, and which a pair of winkers may be the means of preventing. The legs require the protection of knee-caps, and boots or bandages. It scarcely appears necessary to sugrest the propriety of a boy riding in the same vehicle which contains the horse.

If time, weather, and circumstances permit, it is advisable to take horses off the rail five or six miles from the place of their destination, so that they may walk that distance to their stables. It circulates their blood, occasions muscular action, and prepares them for being dressed and fed more after the manner to which they are accustomed. It likewise disappoints the prying and often impertinent eye of curiosity which constantly attends the terminus of a railway prior to a race meeting. 
Nost of the modern race-horse vans are so constructed as to be capable of being forwarded by the railways; that is to say, their height is restricted so that they may pass under the tunnels and bridges; and wherever railway locomotion is. not available, post-horses supply the place of steam. Posting is considerably more expensive; hence on some oceasions it may be necessary to travel by the road, - a means, however, beset with many difficulties. In such cases it is desirable to set off early in the morning during summer; but in the spring and autumn, from half past eight to nine o'clock is a more seasonable hour. It is essentially necessary that the trainer, head lad, or some confidential person should accompany them. As there are very few stables kept in a sufficient degree of preparation for the reception of race-horses on a journey, it is desirable to send information of the intended visit, unless the trainer or head lad precedes the horses to make the necessary arrangements. The custom formerly prevailed of making the boys walk and lead their horses all the way; but I am not prepared to recommend that plan; indeed, there are many objections to it. Horses are much more likely to hit their legs when leing led than when they are ridden, from the circumstance of the head being frequently drawn to the near side; moreover, the boys are unnecessarily fatigued, and therefore less capable of doing justice to their horses by dressing them effectively and expeditiously on their arrival at the place of rest. 
All parts of England are so thoroughly provided with railway accommodations, that the necessity for horses travelling by the road is nearly superseded. There are few places where race meetings are held which are not within a short day's journey of a railway station. Indeed it appears almost an essential feature to the success of "Olympic Festivals," that such accommodation should be available. 


\section{CHAP. XIX.}

\section{CLIPPING AND SINGEING.}

lipping very generally practised. - Nimrod's approval. - Necessity for artificial Remedies. - Inconvenience of a rough Coat. Trouble and Labour avoided. - Delicate Skins and fine Coats. Singeing preferable to Clipping. - Reasons thereon. - Horses can be singed however long their Coats. - Practical Mllustration. Gas versus Naphtha. - The Apparatus to use Gas. - Nonsusceptibility of Cold. - Eridence thereon. - Objections. - Phenomenon of blind Horses.-Not accounted for, although attempted. - Blind Horses formerly used in Stage Coaches. - Importance of a fine Coat. - Health of the Skin promoted. - Objectionable Nostrums. - The Skin can be most thoroughly cleansed when the Coat is short.

HE operation of clipping has now stood the test of ome thirty years' experience, with horses of all lasses required for speed and endurance, race-horses xcepted, whose services are not usually called for at he season of the year when it is necessary; namely, uring the four months of midwinter. The converts ) the practice have been annually on the increase Il it now may be denominated universal, save where te more modern introduction of singeing is taking recedence in stables containing horses of the best escription.

When "Nimrod" introduced the subject in his well nown works, clipping was in its infancy, and singeig had not been adopted; but he, with his usual ood judgment, strongly recommended the perform- 
ance upon all hunters and hacks with long coats With respect to clipping, it is a fact well known $t$ all who use horses during the winter season, whe: their coats are long and thick, that some artificis remedy is necessary to diminish the substance, if th animals are engaged either as hunters or on the roac A horse enveloped in a long, thick, and woolly cc vering, when destined to accelerated exertions, ma be compared to a man taking strong exercise in great coat; either of whom must suffer great incor venience from the profusion of perspiration whic ensues, and which, being constantly repeated, inus have the effect of weakening the constitution, redi cing the muscular power, and likewise the digestiv faculties. Much trouble is also experienced wit horses under such circumstances on their arriv: in the stables; because, independently of the labor required to dress them, they will, in defianc of every precaution, continue to break out in co] sweats, very prejudicial to condition. Here, how ever, it is necessary to remark that some horses har such very delicate skins, and coats so fine, eve through the winter, that, with proper care, they d not require such treatment, unless it be the use ( the singeing-lamp, applied very lightly; and $I$ al quite prepared to recommend that process in prefer ence to clipping, from practical experience of th advantages derived from it by all hunters, hacks, an steeple-chase horses. After having been singed, the do not experience that degree of chilliness, evider by their appearance when exposed in cold and wind 
eather, which they do when clipped, although they in be singed closer than they can be clipped; in ct, the singeing may be regulated to any degree at may be considered desirable.

I imagine this distinction may be attributed to the ct that the process of singeing has the effect of osing or, as it were, sealing up the outer extremity each hair, which, being a hollow tube, when erely cut with the scissors, is left open, and there.re acts as a conductor of cold to the skin; for though after clipping it is usual to make use of the ngeing apparatus, the flame does not come in conct with every particular hair, or evon one in twenty; onsequently, the inconvenience alluded to still exists a very considerable extent. When singeing is nicely erformed, the coat will retain its original colour and loss, but that is not generally the case after clipping. Many persons entertain an idea that singeing is nly practicable with horses whose coats have not ecome very long and thick, and therefore, to prevent at, it must be commenced very early - before they ave grown. Although it is very desirable to do so, nd, by repeating the operation every week or ten ays, keep them short, it is not imperative. Very ecently a horse came into my possession with a parcularly long and woolly coat, and the day after he rrived, a friend, who happened to call, a very good adge in such matters, observed it was a decided case r clipping. " "No," I replied, " he shall be singed." Iy friend was of opinion it could not be done satisictorily; nevertheless, I was determined it should 
be tried. The process was conducted as follows :The horse was singed as close as circumstances wou permit, because, it must be observed, when the co: is in that state, after the singeing-lamp has ber applied several times in succession to one part, dampness arises from perspiration, occasioned by t] warmth of the flame, in which state the operati cannot be continued. After singeing, the horse w sweated moderately, and, immediately on his retu to the stable, well washed with warm water and sc soap, thoroughly scraped, and dressed. On the fo lowing day the operation was renewed in a simil manner, and repeated with intervals of a few da till the coat was reduced to the state in which I wish it to be. But without the precaution of sweatis and washing, to cleanse away the charred particl of hair, and the perspiration already noticed, both which adhere to the coat, the process of singeing ca not be advantageously renewed. The recent intr duction of gas for this purpose is a decided improv ment upon the spirit of naphtha heretofore made $u$ of, particularly when the coat has attained a con: derable growth; because the gas takes it off quick and more regularly. Besides, the flame from $t$ l gas can be regulated with the greatest nicety, to st particular parts or circumstances, which cannot be readily managed with the spirit. Wherever gas ce be obtained (and there are very few country tow where it is not consumed), by means of the apparati constructed for the purpose, which is to be had most saddlers', the use of gas is less expensive the 
phtha. Being provided with the flexible tube and $\mathrm{mp}$, and the former attached to any pipe supplied th gas, the operation may be performed expediusly and with great precision.

Apprehensions might be entertained that the act depriving a horse of a great portion of his natural vering would occasion him to be very susceptible taking cold; but experience proves that not to be e case. An accident which occurred to me several ars ago may serve as evidence of this assertion. I as returning home, one evening in the month of ovember, and, passing through a gentleman's park, ider some trees, the branches of which I could not scern in consequence of the excessive darkness, I was ereby pulled off my hack, a mare which had been ipped only the day previously. This disaster gave r her liberty, and, although I obtained the aid of e keeper and other assistance, I could not succeed in ding the mare: she therefore remained in the park ithout shelter all night. Moreover, it was bitterly ld, foggy, and frosty. When daylight appeared, e mare was discovered; and I fully expected, espeally as I had ridden her fast up to the time we rted company, that she would be laid up with a olent cold. That, however, was not the case. On r return home she had a bran mash, with two inces of spirit of nitric ether, and, on the following $y$, gave no evidence of the slightest indisposition. ad she not been clipped I am inclined to think the sult would not have been so fortunate; because, om the pace I had ridden her, with the perspiration 
remaining in the coat, she would have been wet : night, whereas she quickly became dry; hence t] coldness of the atmosphere had not such an injurio effect as might have been expected. This, hor ever, is not to lead to the impression that I wou expose an animal to the inclemency of the weath immediately after clipping or singeing - quite $t$ reverse; and in the stable a moderate addition clothing may be used with propriety, depender however, on the state of the weather, and the inc cations which will be readily discovered by the a pearance of the animal.

The only objection that can be raised against cli ping or singeing is the dull appearance which entails upon all horses at the spring of the year, $\mathrm{jt}$ at the period of shedding their coats. These oper tions have likewise an influence in postponing $t$ time when the new coat makes its appearance, $-i$ conveniences which are trivial compared with $t$ advantages derived at that season of the year wh the services of the hunter are most valuable to $t$ sportsman.

There is a most extraordinary phenomenon co nected with horses' coats, which I believe has nev yet been accounted for; that is, blind horses w have fine coats in the winter, and rough ones in t? summer, thereby reversing the order of those whi enjoy the faculty of sight. It is far beyond my cor prehension to explain or even guess at the cause; the same time it would be esceedingly interesting all who are concerned in the management of horses, 
1e knotty point could be elucidated. If it could e discovered, there is a possibility that the result iight lead to the substitution of means whereby the oats of horses conld be kept fine throughout the inter without resorting to the alternatives of cliping or singeing. An attempt has been made by a eterinary surgeon, whose name I am not acquainted ith, to explain this mystery; but he unfortunately iled at the outset by stating that blind horses are lways rough in their coats, which is not the fact. in the days when stage coaches triumphed, many lind horses were employed; and any superficial oberver would readily detect those which were so flicted in the winter months by the peculiar fineness $f$ their coats. No difference of treatment would ccasion this, as the horses composing a team most ssuredly fared alike; hence it is more conclusive that me physical influence, as yet unknown, produces is extraordinary characteristic.

The healthy condition of the skin, and the fineness $f$ the coat, are essentials to the well doing of all inds of horses; they proclaim the state of the stoach, with which there exists a direct sympathy, and Id vastly to appearances. To obtain these desierata during the winter, hot stables, alteratives, iuretics, diaphoretics, and all sorts of diabolical nosums, are resorted to, many of which are capable of roducing a temporary effert at the expense of the onstitution. One of the recommendations applicable , clipping and singeing consists in the facility forded of thoroughly cleansing the skin from all 
superficial accumulations of sweat and dust, which: being allowed to remain, obstruct the pores, anc interrupt a very important function. When a horse has a thick and long coat, it is impossible to eradicats those impurities effectually; - they may be removec from the surface, while the most important part, the skin itself, is left uncleaned. 


\section{CHAP. XX.}

\section{WASTING.}

Effects on the Constitution.-Erents which influence those Effects. Caution. - Stimulus to Exertion. - Race Riding, a laborious Occupation. - Importance of Condition in a Jockcy. - Recommended to Hunting Men. - Severe Abstinence from Food deprecated. Practical Experience of moderate Living and long Walks. - De. privations of Jockies._- Hunger and Thirst.-Causes which affect Hunger.-Causes which affect Thirst.-Selection of appropriate Food and Drink. - Comparison between Wasting and Training. - Preliminary Obscrvances. - Apcrient Medicines. - Excessive Use of Epsom Salts. - Practical Anecdote. - Walking, and the usual Observances. - Pace. - Perspiration promoted. - Remedy for blistered Feet-Walking on the Morning of a Race. - Amount reduced. - Temptation. - Diet. - Beverage. - Smoking.

WHETHER wasting is injurious to the constitution or not depends upon how the process is conducted, and the extent to which it is carried. If excessively severe measures are adopted, in order to effect a considerable reduction of weight in a very brief space of time, great prostration of strength results from the want of sufficient nutriment, and the escape of a vast quantity of fluid in the form of perspiration; but with careful treatment and judicious regimen, so far from the health being injured, it is promoted by the ordeal. If every person were to ascertain his weight when in the most perfect state of health, and in condition to endure the utmost amount of fatigue, after a regular course of 
training, it would generally be found at a lower standard than upon ordinary occasions, when he takes no more exercise than inclination and the common occurrences of life dictate. We lose incessantly by different ways, as by perspiration, respiration, and other evacuations, a part of the ele. ments of which our bodies are composed, amounting to some pounds in the course of twenty-four hours; and we should perish if we were not to re-supply them and our strength together with nourishment obtained from food and drink. Strong exercise, accompanied by spare living, are the means adopted to reduce the weight; and it is by careful attention to the extent of work and abstinence which the constitution is capable of sustaining safely; that determines the question whether or not wasting is injurious to the constitution. An individual labouring under chronic disease of the lungs, the heart, and those organs employed in respiration, can scarcely expect to undergo the process of wasting without danger. When due notice has been given, and time will permit, it is far more prudent and advantageous for a jockey to take two or three extra walks to get himself down to the prescribed weight, and to live moderately, than to tamper with the constitution by taking strong doses of aperient medicine, and rery little or no food containing the elements of nutrition. The prevailing passion -- love of gain, or, what is more excusable, a laudable desire to serve a respected employer - will sometimes tenupt jockies to waste to excess on short notice. Excessive perspiration 
and abstinence from food reduce the muscular as well as the adipose tissues: this, in order materially to reduce the weight, is necessary, and, to a certain extent, can be accomplished without inconvenience; but when the muscular system is diminished beyond a reasonable standard, the stamina is enfeebled, strength prostrated, and the powers of endurance impaired, in which state no man is capable of riding a race to the best advantage. Some individuals can bear a much more extensive reduction of muscle without inconvenience than others.

For a jockey to be in good condition to ride, he requires preparation. Race riding is a very laborious undertaking so long as it lasts, especially with a hard-pulling horse, or one that requires great exertions to get him out. A man is no better qualified to perform on an animal of this kind if he is not in condition, than a horse would be to run if taken up from the grass field. He may hang on, it is true; but instead of being able to assist the animal when assistance becomes necessary, he is like so much dead weight upon the creature's back. From not being in condition, gentlemen jockies frequently make absurd exhibitions. Gentlemen may ride as well as jockies, and there are many who can, but they prepare themselves with equal care. If a man has to ride two stone or more above his ordinary weight, and is not in practice, he should take three or four walks in flannels, not with a view of reducing himself, but to get rid of superfluous fat, and thus relieving his lungs; the muscular system will also be 
improved by the walking exercise. This is a practice which every hunting man who consults his own ease and comfort will do well to adopt, unless he is of a very spare habit, and prepared by the exertion of shooting and taking a vast deal of strong pedestrian exercise.

The custom of very severe abstinence from food, or, as it may be appropriately termed, absolute starvation, cannot be too seriously condemned. Any excess of labour is preferable to that. A man may get off a considerable quantity of weight if he will work. Some years since I was requested by a friend to ride a three years old filly for him, engaged in the "Cup" at Heaton Park. The request was made at Doncaster, but not till the Friday, and the race took place on the same day in the following week. Without wasting more than I had then done, I could not have ridden under 9 st. $12 \mathrm{lb}$, and it was expected the mare would not be handicapped higher than 8 st. $7 \mathrm{lb}$. My reply was, that on so short a notice I feared I could not do it, but I would get off as much weight as possible; consequently, instead of riding, I walked from Doncaster to Manchester, a distance of fifty-four miles, during the first two days in flannels. This I could not have accomplished had I not lived moderately; but I experienced not the slightest inconvenience beyond considerable fatigue, and on the day had reduced myself to 8 st. $9 \mathrm{lb}$. If I had lost a day's walking by riding my hack, and observed greater abstinence 
from food, I might have got to the same weight; but it would have produced emaciation and feebleness.

Jockies who are under the necessity of wasting extensively must undergo considerable personal deprivation. Not only do they experience a vast deal of fatigue from walking eight or ten miles nearly every day at a fast pace enveloped in flannels, but they have to contend against two very unpleasant sensations hunger and thirst. The first of these is influenced by various causes, some of which the wasting jockey cannot control, and others he is compelled to adopt in order to reduce himself. A cold and dry atmosphere, such as we frequently experience in the spring season, will tend to sharpen the appetite; so will cold bathing, which on that account should be avoided. Exercise on horseback, walking, in fact every species of labour, in the open air more particularly, will produce hunger, from the reason that the digestion is accelerated by the exhaustion of the system which takes place, occasioning an increased demand for nutrition. These labours are, in fact, the duties of a jockey; and it is therefore a subject of considerable personal mortification, that, being compelled to follow employments which, more than almost any other's, create an appetite, he should be obliged to refrain from the indulgence of eating, except in very parsimonious quantities. Any person who has taken a ride of twenty miles before breakfast on a cold frosty morning will acknowledge the relish he has for the morning meal, which is augmented by two causes, - 
the exercise, and the effects of the air on the digestive organs. On the other hand, the appetite is less keen when the atmosphere is warm and humid. Warm liquids have the effect of appeasing the appetite, and for that reason, as well as for creating an increase of perspiration, are frequently taken: at the same time, it is necessary to offer a caution against excess, whereby the healthy action of the stomach may be impaired. The sensation of thirst is with most persons, when wasting, much more acute than that of hunger, but it varies very greatly in different persons, and, at times, with the same individual. Excessive perspiration naturally increases thirst, from the escape which it occasions of the fluid humours contained in the body. To the wasting jockey this is the greatest deprivation; for, if he intends to reduce his weight to any extent, he must abstain as much as possible from liquids. Thirst is greatly influenced by the nature of the food which is partaken of. Flesh of all kinds, but more especially those which have been salted, and fish, will create thirst; but vegetables have a contrary effect, as a great portion of their substance turns to water in the process of digestion.

Thus will be understood the advantage of making a. proper selection of food and beverage; and, prior to commencing the process of wasting, it is desirable to adopt a regimen suitable to the purpose and the constitution, which latter property varies so greatly in different individuals, that a course which would be appropriate for one would be prejudicial to many 
others. Persons of a spare habit require more nourishment than those who have a tendency to become fat. Some partake of a small portion of animal food daily, and, by taking plenty of walking exercise, are enabled to reduce their weight; while other's would not lose many pounds unless they restricted themselves to a regetable diet. But, in general, a small portion of meat once or twice a week is to be recommended. It should be remembered that training for any athletic purpose, and wasting, are too widely different objects, although there are certain observances applicable to both. The amount of weight which a jockey desires to disencumber limself of will be a guide, both as to the regimen which he must adopt, and the time which will be occupied in the process. The facility with which some persons can reduce their weight vastly exceeds that of others. Those who perspire freely have an advantage in this respect. Two or three doses of aperient medicine previously to commencing pedestrian exertions are indispensable, not only for the purpose of decreasing the weight, but also of preparing the system; but the quantities of Epsom salts, which many jockies are in the habit of swallowing almost daily, cannot be too strongly denounced. When the stomach and intestines are very sparingly supplied with food, that medicine is calculated to promote injurious effects when taken in large doses. As a laxative, in order to keep the bowels free, once, or even twice, in a week they may be taken without impropriety; although jalap, in 
doses of from fifteen to five-and-twenty grains, combined with five or ten grains of nitre, is preferable in its operation, and less nauseous to the taste. On the necessity of making a suitable preparation by abstemiousness and medicine, I will relate a circumstance which occurred when Heaton Park races tempted many gentlemen jockies to undergo the ordeal of wasting. A young friend of mine who had been enjoying himself at Doncaster during the previous week, ambitious to distinguish himself in the pigskin, and as light weights were likely to be in requisition, proposed to accompany me in my walks, and without any introductory preparation, except refraining from his breakfast on the first morning, having procured the most suitable woollen fabrics obtainable in Manchester, on short notice, with which he enveloped himself most profusely, in defiance of my caution not to overclothe himself, we commenced our toils. TVe had not, however, gained the summit of the well-known Cheetham Hill, about two miles from the town, when my friend, who was following, called out for me to stop. On turning round, the only portion of his face discernible for shawls was as red as crimson, and he was completely blown. Halting a few minutes, I recommended him to unbutton his great coat, and relieve himself from some of the comforters with which his neck was enveloped, suggesting also that he should return and arail himself of the first vehicle he might meet with; that, however, he declined, fancying he would be laughed at. I then proceeded on my walk, and regained the Albion Hotel just as 
e had crawled home. Commencing in this unpreared state the exertion of walking, encased as he ras in flannel and other woollen textures, the great reat generated in his body being unable to escape in onsequence of the retentive powers of his dress, he vas completely overcome; he did not perspire, but ras in an actual state of fever. A little mutton roth, and three or four hours between the blankets, pened the pores, and in the course of the evening he ecovered; but he lost very little if any weight, and xperienced considerable temporary inconvenience.

The first walk should be a short one, the pace aoderate, and the quantity of flannels regulated by he weather. The usual plan is to walk out a cerain distance, that is from three to four or five miles, shere there is an inn or a friend's house, on entering rhich warm water is used to wash the mouth, a lanket procured to throw over the head and houlders, and a glass of some hot beverage taken, to ncrease the flow of perspiration. On these occasions are is necessary not to remain too long; otherwise, he perspiration ceasing, the flannels, which are wet, ecome cold, and in that state a reaction takes place, ot unattended with danger, and, at all events, reuiring much exertion to get up the steam again. 1 considerable amount of resolution is called into ction, inasmuch as, fatigue prevailing, few persons re very anxious to encounter the latter most disressing portion of the walk. At these times a jockey eserves - in fact, he requires - attention; and for hat reason, when at home, it is more conducive to 
his comfort to walk a certain distance, - that is, the half of what he intends to perform, - and make his own home his resting-place, where he can be properly waited upon, and, having refreshed himself again, set off to complete his task. A route should be selected sheltered as much as possible from the wind; and it is also desirable to arrange it so that the wind may be at the back when returning or completing the walk; for meeting a brisk wind, especially when the individual is fatigued, will tend very powerfully to check the flow of perspiration; and the endeavour should be to perspire as freely as possible with the least expense of labour. The pace should be regulatec moderately at first, and increased towards the conclu sion of the walk, in order to enter the house with the perspiration flowing profusely. It is a great error $\mathrm{t}$ walk too fast at first, for, when blown, the perspira tion will not escape, and, when greatly fatigued, person cannot go fast enough to effect his purpose When the distance is completed, after having washer the mouth with warm water, an hour's rest on a bed covered over with a good allowance of blankets, pre vious to which drinking a glass of warm liquid, is th most effectual method to promote the flow of perspi ration; and, at the expiration of that time, a larg, foot-bath, wherewith, by the aid of sponges, thorough ablution can be performed, is not onl: highly refreshing, but otherwise salutary. If th feet are inclined to blister, rubbing the inside of th stockings with yellow soap is, in most cases, a pre ventative; and, with shoes sufficiently capacious 
wearing two pairs of stockings will tend to avert that painful injury. When a jockey has occasion to walk on the morning of a race, it is desirable that he should start early, so that he may have plenty of time to become cool previous to dressing himself. If the weather be cold, this caution is particularly worthy of attention.

After having taken two or three walks, a person is better able to perform that labour, but he will not reduce himself at the same ratio. He may get off five or six pounds the first walk, three or four the second; but after that the weight will be diminished in small proportions. Self-control is a virtue which a jockey must possess, for if he indulges himself with only one satisfactory meal, he will not find himself much lighter after his morning's exertions. To see a good dinner on the table, and a party of friends partaking thereof, after a severe walk, when a jockey has a very keen appetite, requires some resolution to withstand; and the better plan is to keep away from such temptations. Take a stroll during the period, just drop in at pudding-time, and so endeavour to cheat yourself into the idea that you have dined.

To enumerate precisely the diet which a wasting jockey should partake of, would be something akin to dictating what he should prefer; and, as he must be restricted in quantity, it is but fair he should indulge himself with that which he likes best, provided he confines himself to such kinds of food as are adapted to the purpose. A similar remark applies to beverage, with the cxception of spirituous liquors undi- 
luted. Provided the quantity is controlled, a man'? taste is his best monitor ; but the very general practice of constantly smoking cannot be too strongly deprecated. Many do it with the idea that it allay the cravings of the appetite; but, if it does, it is a the expense of a vast amount of vigour which enable a person to walk. I do not mean to infer that : jockey is to be denied the gratification of smokin! moderately if he likes it, - for, in all conscience, h undergoes many privations; but I feel convinced tha inveterate smoking, with a view of keeping down th weight, is a most mistaken and injurious practice. 


\section{CHAP. XXI.}

RACE RIDING.

Race Riding as a Profession for Gentlemen. - Difficulty of the Art. - Incapability of young Jockies. - Attainment of Superiority. Comparison between good and inferior Jockies. - Integrity. Initiation. - Patience.-Pace.-Definition of the'Term.-Examples. - Peculiarity of Temper and Action. - Indications of Pace.-Starting. - Precantions. - Starting when the Orders are to wait. Starting when the Orders are to make rumning. - Securing a good Start. - Challenges in ruming. - Distinction between Jockies and Boys respecting Orders. - Turning Courses. - A Rule of Racing. - Example thereon.-Queries. - A fine Race._A Stratagem. - Disadvantage of making running. - The Rush. - Preparing to set to, and finishing. - Whip and Spurs. - Praise and Censure. - Circumstances which denote the Propriety of making a waiting Race. - Of making Play.

JoNSIDERING the enormous responsibility connected vith the occupation of a jockey, there exists no stensible reason why it should not be an employment or the better orders of society, to whom nature has lot been too prodigal in bulky proportions, and who equire some remunerative engagement as a source of living. Many of our celebrated jockies have aised themselves from a state of comparative dependnce to affluence by superior skill and integrity. It s a calling which by no means entails a necessity for ulgarity or association with persons of low habits, 
and, with a character established for skill and honour it is a lucrative one. Employment is constantl? sought by gentlemen for their sons in public office and on railways, where the compensation affords bu a bare existence. They have to give security for pro bity; yet no undertaking of the kind is expecte from a jockey, although he has frequently the contrc over thousands. Ere steam-engines sent coaches 0 the road, many men of good birth sought the occupa tion of driving to augment their resources: assuredl race riding is quite as aristocratic. But at the sam time that it is a lucrative engagement, proficiency $i$ the calling, united with undeviating honour, leads $t$ fame.

The general opinion that this is an accomplishmer difficult of acquirement may appear paradoxica when we see so many lilliputian, infantile compet tors riding, and often successfully, against olde wiser, and more practised heads. Of many of th important points in the science of riding suc juveniles cannot, by any possibility, have any expe rience; of some others, they cannot poseess th physical power to put what instructions can be give to them into effect. They sit on; and the horse which they ride, for the most part, run their ow races: the extreme lightness of the weight - if sixt pounds avoirdupois can be called weight-enable them to win, provided the natural tempers of th animals induce them to run kindly; but if the require riding, in the common acceptation of th term, their success must be very problematica 
Sluggish horses take a great deal of rousing and holding together to induce them to exert themselves; those which are irritable, and inclined to pull till they have spent themselves, can have but little chance with very light boys, who cannot either rouse the one or restrain the other. How the horses get safely round the turns on country courses, when ridden by very light weights, is perfectly miraculous. These are circumstances which must not lead to the misapprehension that great superiority is not attainable in he science,- one on which it is much easier to express pinions than to put them in practice. When we conemplate the splendid performances of our first-rate ockies, and compare them with the miserable preensions of others possessing similar physical capaoilities, the distinction suggests that there must be omething more than ordinary endowments necessary 0 the attainment of eminence in this calling; and rhen it is likewise granted that the artistes and the nuffs have equal opportunities of becoming profiients in the art, the assumption becomes the more robable. There are evidently many qualities essenial to the acquirement. The symmetrical proporion of the body may be mentioned as one, which, Ithough it cannot influence many important qualities, ertainly does that of firmuess and elegance of seat. Vithout having any connection with a jockey's skill, ategrity of purpose is a virtue not to be disregarded; or, however accomplished he may be, if his character e once tarnished, he may exclaim with the jealous Ioor, "Othello's occupation's gone!" 
The preliminary instructions which boys usually receive in this art are in riding trials where experienced jockies can give them directions during the contest. A horse tolerably easy to ride, and not required to make running, is most suitable for the purpose. The importance of sitting still, the seat, proper position of the hands, and such like precautions, will naturally be instilled into the youth in riding exercise; and, if he has not profited by the instructions, he is not worthy of this promotion. He has now to learn the necessity of patience. All tyros are in too great haste to get home, - a fault very prevalent in riding exercise; but in riding exercise, each lad having a place assigned to him, it is the fault of the one who leads the gallop if the pace be too strong. Some idea of pace may be gained in riding trials, but thorongh discretion in that very important quality can only be acquired by extensive practice and shrewd observation. It is not simply the pace with regard to time that should be exclusively understood by this expression, but more distinctly with reference to the animals engaged, and the weights they are carrying. To explain this more at large; a moderate horse, aged, carrying 8 st. 10 lb., will run the Ditch mile at Newmarket in 1 minute and 50 seconds, and a good three years old, with 8 st. $7 \mathrm{lb}$, will perform the same distance in 1 minute and 40 seconds. A jockey cannot form an opinion during the race which of these times will be occupied in running the distance, neither would he profit by such a calculation, because the pace with reference to 
time must be subservient to the qualities of the horses engaged; his object, therefore, is to regulate his own pace comparatively with the powers of the horse he is riding and the animals he has to contend against. Experience enables a jockey to discover when his own horse is overpaced, by his manner of going: in this he has to distinguish the difference between the horse pulling from anxiety to go faster, or hanging on his arms from distress. To this end it is essential that he should be acquainted with the animal's disposition; for there are some which will not try to run a yard after they have left off pulling; others that will continue to answer every reasonable effort; many that will cease to exert themselves unless their riders are pulling at them; and idle horses that will not pull at all, yet require to be held fast by the head, and to be roused all the way. These peculiarities must be ascertained to enable a jockey to distinguish the effect of pace, in which he will likewise be guided by watching the action of the horses opposed to him. The movements of his contemporaries will also give some indications which may be turned to account; for example, whether their horses are pulling, or being urged to greater exertions, provided they are in such a position that their tactics can be seen; but a shrewd jockey, who is riding a waiting race, will endeavour as much as possible to follow the tracks of the horse he has most reason to fear, in which situation he cannot be seen by the person who is making the running. Most horses follow in that way with the least inconvenience; whereas, if they lay wide on 
either side, their endeavours to go up to their adversaries will often cause them to pull and exert themselves unnecessarily. There are of course exceptions ; and this is one of the events by which the artiste is distinguished from the muff, when the former adopts those tactics most suitable to the horse he may be riding. The quick discernment of these particulars is another feature of essential importance. If he does not catch the ball upon the hop, in all probability it will not again be within his reach. The mind, as well as the body, is most energetically engaged during a race.

When a young jockey is put up to ride a race, one of the first directions given to him will be, to get a good start, - a caution unnecessary to one of experience. At the same time, this instruction requires to be qualified, the natural properties of the animal consulted, the way the race is to be ridden, and the distance, considered. Some horses get into their action immediately, others do not; and, unless they are allowed time to fall into their stride, will be inevitably beaten by injudiciously hurrying them. The former of these will sometimes cut down their opponents in the first quarter of a mile from their quickness, although they may not be the speediest, as there is a distinction between quickness and speed. A speedy animal, with great length of stride, is not, in general, a good beginner, but his success depends upon his efforts being reserved for the final rush.

Presuming a waiting race is to be ridden, it is highly desirable to get well off, when the horse must 
be drawn back, and steadily held at a pace which he can continue, at the same time never to lie so far away from the leading horses as to endanger the possibility of reaching them, unless they are rattling away at a pace they cannot maintain, in which case a jockey's ability will be evinced by patiently preserving his horse till his opponents, having tired themselves, diminish their speed, or, in racing language, come back to him. If it is deemed desirable to make the running, having secured a favourable start, the animal is sent striding along at such a pace as may be expected will defeat the others, nursing a sufficiency of power for the final struggle - the most difficult part of the science. In short races a good start is half the battle. To effect a good start, each horse's temper has to be consulted. With many it is a difficult point to prevent their jumping off before their competitors, others are ready on the first indication of the hand, and such as are idly disposed require the assistance of the spurs. In any case, in order to have perfect command, the jockey sits well back in his saddle, without attempting to raise himself in his stirrups, till the horse is in his stride.

A very important caution to be given is, not to race with every adversary who may be so disposed, and to avoid, as much as possible, another horse running parallel with your horse's head, even though you may not be going at your best pace. Such an honour may be politely declined in two ways: if your horse is going well within himself, and can without difficulty dispose of his friend in a few strides, it is advisable 
to do so, as, in all probability, that will settle his pretensions to further distinction: but this must be attended with great caution, and not repeated with other animals, which, with a numerous field, would certainly be productive of defeat. The other plan is, to pull behind; and that likewise must be performed discreetly, or you may lose ground by doing so. A jockey riding a waiting race, with discretionary orders, entertaining a doubt whether his horse has the best turn of speed, will be very probably inclined to go up to the horse he has to fear at a distance from home, and endeavour to satisfy himself upon that point; but it is the fault of his opponent if he gains any thing by the attempt, unless positive orders have been given to the opponent aforesaid to make the running throughout. When a jockey is desired to make running, or to ride a waiting race, without any discretionary power, he has, of course, no alternative but to put those orders into effect to the utmost of his power; but a distinction should always be made between the inexperienced and the accomplished jockey, especially if the latter has a previous knowledge of the character of the horse he is about to ride. In that case he is the most competent person to advise how the race should be ridden. Boys must necessarily have their orders, and it will depend upon a variety of circumstances whether they are able to put them into effect; but, having previously given them ample instructions on the principles of race riding, the more simple the final orders, the less likely are they to be forgotten or misunderstood. On a 
turning course it is very necessary to keep as near as possible to the inside, that being the shortest distance to the winning post; and it is also important to avoid being driven out at the turns by other horses; nevertheless, it is contrary to the rules of riding to force an antagonist on the wrong side of a post, or to cross him in such a way as to prevent his getting up. There is a complicated rule of racing law, rather difficult to comprehend. It is thus expressed - "And when one horse crosses the track of another next behind him, it shall be deemed a sufficient cause of complaint, even though he be a clear length or more before the horse whose track he crosses; it being desirable, that when once the jockey has taken his ground he should not prevent any other jockey from coming up, either on his right or left hand." This is quite practicable on a straight course ; but, supposing only six horses run over Chester or any similar course, --if the rule were to be adopted to the letter, - No. 1. having taken his ground nearest to the rails, No. 2. next to him, and so on, the sixth, or outside horse, would have to run somewhere about the middle of the course, and, by so doing, would be compelled to travel thirty or forty yards further than No. 1. There is also another feature in this rule, supposing it to be carried out, - by what authority has any horse a right to assume the inner portion of the circle? The expression "a clear length, or more," is likewise very indefinite, - how much more than a clear length is admissible in establishing a case? In further opposition to this clause, it is exceedingly unfair that one 
horse should run up to another on the inside at a turn, and force the latter out of his ground. In such a case there might be a foundation for a charge of jostling; but, providing the offender did not come in first, or another horse the property of the same person, a complaint would be of no avail.

Presuming a race to have been ridden with the most perfect discretion to the distance post, and two or three horses, of nearly equal pretensions, have arrived at that point, the acme of the jockies' superiority remains to be tested in the final struggle. Here the caution with which he has ridden so far will be manifest; but he has now to decide whether in a few strides he can effectually dispose of his opponents, or whether by a well timed effort of speed he can land his horse first on the post by an electrieal rush. At this crisis, riding is a nervous and critical engagement. Instances are not wanting of highly accomplished jockies having been defeated, or rather outwitted, by keen-sighted opponents. For instance, it shall be supposed a jockey has won his race fifty yards from the winning post, with enough left in his horse for an increased effort of speed, if necessary, but, looking round to the right, to see if that antagonist has a chance of reaching him, another horse which has stolen up to him unexpectedly, slips up on the other side, and wins before he is aware of the nearness of such an adversary. This stratagem is performed after the following fashion:-The jockey finding he has not a chance of winning by superiority of speed, yet enabled to lay well up, follows track 
for track with the leading, and we will assume the superior horse, where watching the rider in the expectation that he will turn his head either right or left, with a well directed effort passes him on the contrary side to that which he happens to look. The following are cases in which the disadvantages of making running may be exemplified: - those jockies who are waiting have a better opportunity of watching the action of the horses and their riders; they can see when a horse's long compounding stride is exchanged for short laborious efforts, staggering in his gallop; they can see when their opponents' spurs are at work, however insidiously they are applied; they can see every motion of the hands, and are therefore enabled to profit by observation.

The final "set-to," or as it is with equal propriety termed, "the finish," is an accomplishment not easily attained. To behold silk jackets in convulsions is a distressing sight, but yet it is one too frequently witnessed. Skill, elegance, and determination in this art, mark the distinction between the superior jockey and the muff. When the set-to becomes necessary, the rider prepares himself and his horse for it, by sitting well down in his saddle, collecting his horse, and taking the reins usually in the left hand, (unless he has the power of using the whip with either, in which case the position of his adversaries will be the best guide); he then turns his whip, by passing the three outer fingers underneath, and is then enabled to make use of that instrument, if the spurs fail in their intentions. Not that much benefit 
often results from it, except with game but indolent animals; and in using both that and the spurs, unless the horse is found to respond to the call, good feeling and prudence forbid their use. Inflicting pain on an animal when he is doing his best, is not only wanton cruelty, but appears something like punishing him because he is going as fast as his powers will enable him.

Horses have retentive memories, and there is no doubt many will cease to struggle at the moment they are called upon to do so from reminiscences of former punishment.

The termination of a well ridden race is an enthusiastic moment, not merely with the spectators, but also with the performers. Many a winning jockey is lauded to the skies for his incomparable exhibition of jockeyship; yet the unlucky wight who happens to be second, although he may have evinced greater skill, seldom receives any honours, and is frequently censured for not having made his rush earlier - for having made it too soon - for having made the pace too strong - or not fast enough, - in short, for having attempted, or having omitted to do, something it was not in his power to accomplish.

Whether it is most judicious to make running, or ride a waiting race, is a question to be settled by a variety of circumstances. The natural endowments of the horse are paramount considerations, - his age, condition, the weights, the distance, the character (whether it be assumed or known) of his opponents, are subjects by which the determination must be 
governed. So many advantages attend the waiting principle, that it is most frequently advisable to adopt it. When there is a considerable number of runners the pace is usually strong enough; in such cases, a horse that waits most frequently has the best of it at the conclusion. The general opinion that, if a horse has greatly the advantage of weight, he should make the running, must not be received as an invariable rule. That a true run race will be favourable to him is very likely, when, if he possesses a good turn of speed, the lightness of the weight will, in all probability, enable him to get home by waiting. Here it is necessary to remark that every horse has his distance; and although it does not appear to be in conformity with good judgment to disregard this circumstance, there may be occasions when it is expedient to do so: in those cases the best alternative will be to assimilate the distance as nearly as possible to the mode of running.

There are, doubtless, many occasions when it is imperative to make the running: this applies to stout game horses, having undergone a strong preparation with favourable weights, but deficient in speed. The known or assumed want of condition in an opponent also affords a reason for making the pace effective.

All these events, conjointly or singly, require to be maturely studied, and the favourable issue denotes the skill of the owner or trainer in this important branch of racing tactics. 


\section{CHAP. XXII.}

HANDICAPPING, AND THE EFFECT OF WEIGHT.

Prevailing Taste. - Comnection between Betting and Handica Races. - Policy of Handicaps. - Tendency to encourage Frauds - Protest of the Jockey Club. — Penalties for Frauds. — Useles: Punishment censured. - Qualifications of Handicappers.—Difficul ties connected with the Duty. - Reasons why the Public are ler into Error. - Pace. - Influence of Pace. _ Light Weights. - Ar gument relative to Weights. - Mistaken Notions respecting Weights - Handicapping dark Horses. - Necessity for a System of Han dicapping. - Handicappers should see Horses run. - Stratagem detected. - Extra Weights for Frauds. - The Principle denouncer by Offenders. - Their Arguments confuted. - Impossibility of Han dicapping from Paper. - Handicap Committee. - Illicit Practice defeated by System. - Paid Handicappers. - Horses started a Country Meetings, for certain Purposes. - Adrantages of a Com mittee. - Firmness indispensable in a Handicapper. - An Occur rence. - Responsibility of Stewards and Committees. - Distinctio between Handicappers, Starters, and Judges of Races. - Re strictive Powers. - Owners of Horses and Trainers complete th Handicaps.

However numerous the objections which may br urged against the prevailing number of handicap en. gagements entered into at every meeting, to inveigl against them would be useless, for they engros: public favour; and to attempt to turn the current 0 : fashion, although the waters may abound with im. purities, is an unavailing task. The propensity for betting, which has been for years on the increase and which has arrived at an unprecedented height 
HANDICAPPING, AND EFFECTT OF WEIGHT. 219

1as in a great degree been promoted by handicapping. 3etting has likewise encouraged handicapping; so hat they have cherished each other, and have each gained an ascendancy with which it is difficult to sontend.

The welfare of racing has a formidable adverary in the present system of handicapping; not hat the principle would be objectionable if it could e fairly dealt with, but the difficulty exists in working that principle justly. Handicap races are pen inducements to commit frauds, because they juggest premiums to persons to run their horses for stakes which they do not intend to win; or others, with, as they imagine, a shade more of compunction in their consciences, start their horses without giving them due and sufficient preparation. Neither in logic, theory, or practice, is there much distinction between the two devices; they are both intended for the same purpose, that of leading handicappers and others astray. The Jockey Club give notice of their extreme disapprobation of horses being started for races without the intention on the part of the owners of trying to win with them. To this might be addec? with equal effect, of horses being started when out of condition, or of persons in any other way mislcading the public by delusive practices. Such artifices carnot be controlled by any mandates, rules, or laws; they can only be met by disappointing and defeating the purpose; in plain terms, by weighting such horses, not in accordance with their running, but according to the intended fraud on the part of their 
owners. There is likewise another difficulty con. nected with handicapping which cannot be overcome that is, with respect to horses absolutely and fairl? beaten, and consequently pulled up a long way from the winning post. Supposing, for example, a dozer horses start for a stake, distance one mile; when : quarter of a mile from home eight or nine of then may be in difficulties; and their jockies perceiving that will not attempt to persevere. Useless, wanton, ill judged punishment is at all times censurable. A lav that would promote it would be even more censurabl on the part of those who proposed it, than the ac itself. No rule or decree could ever be brought int effect to compel persons to run their horses to th end when decidedly beaten; and humanity woul intercede even if any such rule were to be suggested

To be enabled to make good handicaps it is neces sary to be well acquainted with pedigrees, and th peculiar qualities which are inherited. A handicappe must, in every sense of the word, be a good judge 0 racing, the effects of weight and condition; moreove: he should be a very critical observer of mankind; tha is to say, without there being a necessity for persona intimacy, it is highly desirable that he should know how to handicap the tactics and intentions of the owners, as well as the capabilities of their horses If horses always ran to win, handicapping would be a more easy and a far more agreeable duty, and still there would be quite sufficient in the items wherewith the glorious uncertainty of the turf is iden. tified, to maintain the aphorism, and create ex- 
itement. The supposition that any man can hanlicap a dozen horses to run a mile, which shall all ome in within three or four lengths of each other, 3 too chimerical to be realised, even if every orse had run upon his merits on former occasions. [here are the variations of condition, or rather erfect fitness on the day, to be anticipated, which no aortal can determine with accuracy; the effect which articular courses may have on the action of certain orses, and the state in which the ground may be on he day of running; the science of the jockies enaged, the qualifications of some to ride particular orses, the incapacity of others; the tempers of orses, and other incidents, at all times beyond the each of human foresight. There is also another ircumstance which frequently baffles the good inentions and skill of a handicapper,-that is, the disance which horses are able to run. There are many which cannot stay more than a mile, or even that, in noderate company; a vast number that cannot stay he same distance in good company; and yet these torses are to be handicapped to run two miles with uch a distinction between the weights as shall be suprosed to give each horse a chance. But without an normous disparity in the weights it is impossible to ring horses together when some can only run half a nile, and it is the forte of others to run two miles. Chis is what so often leads the public into error. Chey conceive, because a horse has run forward in a hort race, with a certain weight, that in a longer ace, with a much more liberal allowance, he must 
win. In many instances a handicapper has no oppor tunity of knowing the length of ground over whic] certain horses can run, from their not having bees engaged in races beyond a given distance; in som cases their owners are equally in the dark, from no having carefully tried them; but it may generall: be inferred that the course a horse is most frequentl: in the habit of showing upon, is that which is sup posed to be the most suitable.

The pace at which a race is run has a most pro minent influence on the performance of most of th candidates, and especially with reference to weight In fact it is only when the pace is true that th effect of weight is brought into operation. There $i$ generally but little to complain of in this respec with the great handicaps under the present custor of exceedingly light weights. It is absurd to sur pose that children, riding 4 st., can hold all sorts c horses; they can merely sit upon them, and if the can guide them, it is as much as can be expected.

One of the prevailing inconsistencies in racing, $\varepsilon$ the present time, is the extraordinary infatuation $\mathrm{fc}$ light weights. If a handicap begins at $8 \mathrm{st} .7 \mathrm{lb}$ and goes down to 4 st., with any thing like a jus proportion between the respective animals, there wi be a good acceptance; but if it commences at $10 \mathrm{~s}$ $7 \mathrm{lb}$, and descends to $5 \mathrm{st} .7 \mathrm{lb}$, , the contented part will not be numerous. It may be imagined that a the difference between the highest and lowest weight proposed in the light weight handicap is 4 st. $7 \mathrm{lb}$ the same distinction should be made in the heav 
HANDICAPPING, AND EFFECT OF WEIGHT. 223

weight handicap, and therefore the lowest weight in he latter must be 6 st. $7 \mathrm{lb}$; but that should not be the case, because the inferior young ones would require a trifle more allowance in the higher than the ower scale. It may be assumed, as one of the reasons why the light handicaps are mostly in favour, that the owner of a good five years old horse fancies he cannot give the bad three years old 5 st., but holds him cheap, giving 4 st. $7 \mathrm{lb}$. In favour of the light weight scale, it will be argued that 4 st. is nothing for a horse to carry; but it must be remembered that the high weights will admit the services of riders with some pretensions on the young ones, which in reality more than compensates for the extreme lightness.

There are many persons who entertain very mistaken notions respecting the effect of weight, presuming that a high scale of weights is favourable to slow horses; but that is not the case, as a general principle. If three or four horses are close together, each carrying 9 st., they will not be far apart carrying 12 st., unless it be some weak, bad-actioned, half-trained brutes not worth keeping; and even with them the difference will not be found upon trial to be very considerable; distance, as I have already remarked, and the state of the ground, will make a wonderful alteration.

It frequently happens that a handicap includes a number of horses that have never run: to adjust their weights must be a matter of chance; for there is no line to be taken as a guide. The only 
alternative, in such cases, is to handicap them from pedigree, - the performance of their sires and dams, and that of brothers and sisters, if any have been running; and at the same time that it would be an act of injustice to their owners to assign them the top weights of their year, it would be equally unjust to other persons to turn them loose.

The practice of handicapping requires remodelling altogether; and, to be rendered satisfactory, must be reduced to a system. It is utterly impossible for any man to make a just handicap unless he has seen all the horses run that have been out, or receives information from some competent person, upon whom he can rely, who bas seen them, and carefully noted the appearance, condition, and manner of running of each horse. An attentive and experienced observer can in most cases detect the stratagem when horses are brought to the post unprepared, are pulled up purposely, or do not run to the end. In the first two cases, the owner should be complimented with an additional $10 \mathrm{lb}$. penalty on his horse. Many precedents have been given for doing so; and much has been said and written against it by the offended, or rather offending, parties; but it is in strict conformity with justice.

I remember, some years ago, an instance of this kind, when much eloquence was expended against the hardship and alleged cruelty of inflicting upon the horse the sins of his owner - than which argument nothing can be more fallacious. No man, endowed with Nature's inestimable gift - the common 
HANDICAPPING, AND EFFECT OF WEIGHT. 225

feeling of humanity-would ever lend himself to the punishment of an animal for the purpose of retaliating on his delinquent master. But that is not the spirit in which it is done, or the effect produced; the intent and meaning of a handicap is to adjust the weights so equitably that the chances of every one shall, in human estimation, be the same. A man who has been running his horse, to "get him well in," as it is termed, will not punish the horse by running him with the extra weight, - and even if he did, the twofold sin would lie on him, - but rather than run, he will pay the forfeit; in which case, it is the owner's pocket and not the animal which suffers. To handicap horses fairly from their running, on paper is out of the question. Suppose, for example, a horse is returned as having been beaten ten lengths, which is tantamount to the expression that it was no race at all, ergo no trial; in such a case, it is not improbable, the winner could have won double or treble the distance with any thing to run him in; and it is equally probable, had the second horse persevered, which he may or may not have done, that he could have got nearer than ten lengths at the winning post. A person who sees a race so terminated has a far better chance of forming a correct estimate of the true form of the horses which ran, than he can possibly do by the vague intimation already mentioned. One individual could not, by any possibility, see every race that is run, as it frequently happens that there are two or three meetings on the same day in distant parts of the 
kingdom. No other plan than that of having a committee of experienced persons to make the handicaps can ever be satisfactory. They are as necessary to form a portion of the staff of the turf as Messrs. Hibburd, the starter; Clarke, the judge; and Manning, the president over the scales. These stakes have now grown to so much importance as to render such an arrangement evidently requisite. Twenty years ago there was not the same occasion for it; handicap races were not so numerous, neither was there any thing like the number of horses entered for the respective stakes. A system has been adopted by a certain class of racing men, to take advantage of their competitors; and it has, therefore, become desirable to adopt a system to defeat their purposes.

Many of the great handicaps are made by persons who are employed by the committees, and are, consequently, paid for their labour. When the person selected has been one of experience, the result has usually been successful: but there are many objections against the employment of one person only to make the handicaps, - not because it would be impracticable to select one perfectly free from bribery, corruption, or contamination of any kind, or who would be deficient in every species of probity, or the knowledge which is requisite, - but simply because the faculty of ubiquity cannot be procured, and it is imperative that every meeting in the kingdom should be attended. Horses are sent to little, unimportant country meetings, to run for trifling stakes, which they do not win, in order to 
get light weights in future handicaps, quite as frequently as to the popular races. It is an invidious position for any individual to be placed in, if singly he is subjected to the attacks of dissatisfied persons : that would, in a great measure, be obviated if the handicaps were made by a committee. It would be the committce, not an individual nember of that committee, who had decided upon the weights; and no person would be so foolish as to evince discourtesy to a respectable body, possessing much influence.

No man should ever attempt to make a handicap, unless he has resolution sufficient to bear with calmness the insignificant remarks that may be passed upon it; and if any owners of horses are so indiscreet as to behave discourteously to a handicapper, the better way to ensure their respect in future is, for him to favour their horses with a trifle more weight on subsequent occasions. I was once placed in this predicament. At a country meeting I was requested, by one of the stewards, who was not a racing man, to assist him in making a free handicap of all the horses at the meeting; and when it was published, a certain individual, knowing I was concerned in fixing the weights, attacked me with much discourtesy, declaring he would not accept. My reply was, he must please himself, but I doubted whether he would find his horse more favourably regarded. On the following day his horse won a plate; and there was a forced handicap as a finale, with which I was entrusted. I put $5 \mathrm{lb}$. on this person's horse for winning the plate, and $7 \mathrm{lb}$. extra for his impertinence: he 
started for the forced handicap, and won it; and I have assisted in making several handicaps since, in which the same individual's horses have been entered, but I have experienced no recurrence of his incivility.

Whether the stewards or committees of race meetings make the handicaps themselves, or depute other persons to do so, the former ought to be regarded as responsible for the justness of their handicaps. In the first instance, the proposal emanates from them; and as they have the power of fixing the weights, or in the event of their feeling themselves inadequate to that task, of appointing a deputy, the onus of the composition ought, most undeniably, to rest with them.

Handicappers are in a different position to starters and judges of races. Until the event is decided, the weight which any horse ought to carry is a matter of opinion. The fairness of a start is a matter of fact, and so is the decision of the judge. A starter has the power of levying a penalty, or fine of money, on any jockey who attempts to take unfair advantage; and, on the same principle, a handicapper ought to be armed with the authority to award a penalty in the form of weight upon every horse that has been run unfairly. The fiat of a judge is scarcely ever impeached. A handicap committee would go far to discourage the expression of captious, vexatious, and impertinent cavillings. If it were not thought expedient to invest them with the power of apportioning extra weight for notorious offences or petty 
delinquencies, that difficulty might be readily overcome by an understanding that such penalties should be awarded on representing the cause or causes to the stewards, in whom the power now exists.

After all, it must be remembered that it is the owners of horses and their trainers who give the finishing touch to the handicaps. It is they who separate the worthy from the unworthy; and if a handicapper makes mistakes in overweighting those which are beaten off, how much greater reason have the owners to feel annoyed with themselves for running, than with the handicapper, who had held the animals in too great estimation, without having the same opportunities of ascertaining their real qualifications. 


\section{CHAP. XXIII.}

\section{REMARKS.}

Commencement of Racing. - Progress of Racing. - Introduction of Betting. - Book-making. - Importance of Betting to Racing. - A Delusion. - Way in which Betting is prejudicial to the Turf. - Analysis of Betting. - Popularity of Racing. Effects of populous Meetings. - Present Condition of Racing. A Glance at the Rules of Racing. - Racing as an Amusement for the People. - Not suitable as a Speculation for the Million. - Effects of Handicaps on the Breed of Horses. - Their Effects on Racing. - Comparison of the Condition of Hunters and Race-horses. Condition promoted by suitable Food. - Necessity of pure Air and Exercise. - Large Enclosures not conducive to Exercise. - Comparison. - Evils of large Pasture-fields. - Reasons why half-bred Stock is, in general, longer in coming to Maturity than thoroughbred. - Argument. - Conclusion.

RACING in this kingdom is generally considered to have originated in the reign of Henry II., when the young citizens of London were wont to assemble on Sunday mornings during Lent for the purpose of exercising and diverting themselves on horseback at Smithfield,--or, as it was then called, Smoothfield, - where they exhibited a sort of tournament, armed with shields and lances; the younger branches amusing themselves with racing. There are, however, no records of the results; and although it is probable these diversions were never entirely discontinued, it was not till the reign of James $\mathrm{I}$. that 
public races were established. From that period we may date the commencement of this amusement as a national spectacle, which, with some interruptions during the disturbed era of the Commonwealth, have been gradually advancing to the present day. James I., Charles I., Oliver Cromwell, and Charles II., individually countenanced the establishment of racing by importing sires and dams to infuse noble blood among the native breed of horses, and the Merry Monarch gave great encouragement to the diversion; but I am not able to discover any regular records of racing performances till the time of Queen Anne, who patronised the sport by keeping horses and offering gold cups for prizes. Thus it is near upon two centuries and a half since racing commenced as a public amusement; and about one century and a half, that we are in possession of documentary evidence of events. Very great advancement is perceptible during the last five-andtwenty years.

When betting was first introduced as an additional excitement is a fact which cannot be accurately determined; but it was evidently in operation as early as 1718, when one Thomas Duck, who was riding a horse named Crutches, at York, on whom high odds were laid, and who was leading near the distance, threw himself off intentionally: thus a man incurred the risk of breaking his bones to do that which is now perhaps sometimes accomplished, but with less danger, less probability of detection, and 
with more adroitness. The period when book-making was ushered into existence, was not, in all probability, till the St. Legers, Derbys, and Oaks engagements had assumed an importance. The "ring," like a goodly family, has increased vastly; and if it continues to multiply in a similar ratio, it will in the course of time include every member of the human species.

Some of the most zealous supporters of the turf sanction and approve of betting, and argue that it is essential to the interest of breeders, and owners of race-horses, affording them opportunities of augmenting their profits, whereby they expect to meet the outlay of capital incidental to the enterprise for which the mere chance of winning public stakes is held to be insufficient. I rather fancy there is some delusion in this. If betting could be confined within the limits of moderation it would be another affair; but it is in consequence of the immense stakes upon various great events that the infamous practices of making horses safe are resorted to. The unfortunate extent which such species of robberies have reached renders it very difficult on all occasions to guard against them. The majority of those who make books live by that means, and their annual expenses are not trifling items; they no doubt, in many instances, gain extensively from the public; but I am quite inclined to the belief that they draw annually a vast deal more money from the turf, that is from owners of horses, than they, the betting com- 
munity, pay to those sources. A nobleman or gentleman may have a very superior horse engaged in a popular stake : he may back the horse; the exciting propensity for betting enables him to do so to an unlimited amount, and probably enables him to obtain longer odds than he would otherwise be able to procure; but what is the very frequent result? Various attempts to make the horse safe are devised, which, when they are successful, necessarily occasion loss. These peculations cannot enrich breeders and owners of horses; and I think, on the average, those who are actually engaged in the legitimate pursuit of racing, will acknowledge they do not derive a profit from betting on their own horses. An objectionable influence may be recognised as the companion of heavy betting in the inducement afforded to persons having control over horses to perpetrate nefarious actions. What would cause a man to draw his horse at the eleventh hour, when quite well and fit to run for a great stake, but the money he can gain through agents by betting against his horse? Entering a horse for a race implies, in its abstract meaning, the desire of the owner to win the stake; and in that light the public are entitled to consider the transaction. Then, again, the owner of the horse does not compel people to bet, though, by specious persuasion, he may sometimes be the occasion of their doing so. It is a voluntary act, and as such, when men bet and lose their money, it should operate as a caution not to suffer themselves to be duped in future. If people 
bet concerning events over which they have no control, - but over which, to a certain extent, others have, - it behoves those who are determined to speculate, to ascertain, as nearly as possible, the probable intentions of those who are invested with so much influence. To render humanity immaculate is an impossibility; and in pecuniary transactions it only betrays ignorance of human nature whenever a proper want of caution is displayed.

An analysis of betting really exhibits some very curious anomalies. Bets are transactions founded on the opinion or judgment of one person contrasted with that of another. They are transactions dependent entirely upon the honour of each party, because there is no legal authority to compel the liquidation of contracts, or adjudicate on disputes. Bets on horse-races are decided by events upon which the most dishonourable tricks are capable of being practised; and although it cannot be denied that there are a vast number of fraudulent devices concocted, it is more than doubtful whether they are in equal ratio with similar delinquencies perpetrated in the commercial world, and other fields for speculation where law exists for protection.

An excessive amount of betting certainly attracts a vast concourse of people to the scene of action whenever any great event has to be disposed of, but whether it is conducive to the welfare of racing appears very questionable. However the million may contribute to the increase of attendance at a race 
meeting, and thereby augment the receipts of grand stands, and other places of accommodation and amusement, it is the nobility and gentlemen who breed and keep horses who are the real supporters of racing. At the same time, it is fair to remember, that at most meetings the public contribute something towards the expenses, inasmuch as sums of money are often given by proprietors of grand stands, railway companies, and others, who derive profits from the multitude. There has been a conflicting struggle for some time past as to whether racing should maintain its original character as a national amusement, or become a pursuit of speculation. With some exceptions, so far as those are concerned who are actually engaged in it, it has very nearly arrived at the latter condition. And yet thousands attend the course merely as spectators to enjoy a holiday.

There is great occasion for a revision of the rules by which racing transactions are controlled, for they have not been altered and adapted in all cases to meet circumstances. Speculative engagements require rules and restrictions which are not essential to the prosperity of an amusement. A law to restrain the great propensity which reigns among the people, for betting on horse-racing, would unquestionably afford a great assistance to the sport, whether it be regarded as a national amusement, or a speculative engagement: such laws would no doubt be introduced with a view to the preservation of public morals; still their effects on racing would be equally 
beneficial. Simply received as an amusement, racing presents many attractions to the public. It enables the peer and the peasant to enjoy one object; and it is quite certain the lower orders conduct themselves with more decorum in those assemblies, where their superiors preside over them; and so long as the tradesman, mechanic, or labourer, conducts himself with propriety, he is as much entitled to the enjoyment of a popular field sport or spectacle, as his patron or employer; and it is really wonderful, but exceedingly gratifying, that such immense numbers should congregate together without committing any kind of disturbance or acts of confusion. But when persons, who have other occupations, meddle with the machinery of the race-course, they assuredly involve themselves in difficulties, as much as a jockey would if he were to attempt to amuse himself with mules and spinning-jennies. The public amusements of a nation ought to be common to all, but it is impossible for different classes to enter promiscuously into engagements and occupations of a private nature; their manners and modes of living are widely different, and indeed opposed to each other, and the properties of distinction must be preserved. Republican principles may be very delightful in theory, but when put in practice in old countries they produce constant contentions and revolutions.

The very commonly expressed opinion that handicaps are conducive to the production of a weedy, degenerate class of horses requires to be qualified. 
That they are the very hot-beds of fraud there is little doubt, and they certainly are means whereby a worthless wretch is sometimes enabled to realise a good stake; but that is not logically an encouragement to persons to breed powerless stock; it is simply an inducement to persons to breed a greater number, and in that greater number the fair assumption is that there will be a proportion of good ones. When handicaps are conducted upon the principle, that every horse which runs fairly to win is weighted according to his merits, and every horse that does not run honestly is weighted accorling to the intentions of his owner, then will handicapping no longer retain an objectionable position on the British Turf.

Taking into consideration the great attention bestowed on the condition of hounds, and, consequently, the pace at which they cross the country, it needs but very little argument to show that hunters which are to accompany them require to be quite as fit as race-horses, and the means of promoting their condition is nearly alike. Hunters are called upon to go indefinite distances at considerable speed over all kinds of ground, - some hard, some deep and holding. Race-horses are only required to run specified distances. The bodily exertion which they undergo in running is therefore frequently less severe than that of hunters. It is the ordeal of training race-horses that involves the principal portion of their labours, and it is the quantity and pace of preparatory work which forms the distinction be- 
tween the treatment of the two. In the stable no difference should be observed.

The difficulties of the trainer and hunting groom will be very greatly diminished, if the animals placed under their care have been well managed in their younger days. The recommendations which I have offered are such as are calculated to produce that effect. By the selection of the most appropriate food, namely, hay and corn, as the prevailing source of nourishment, in preference to a quantity of green, succulent food, the healthy condition of the blood is promoted, which, as I have endeavoured to explain, is the source from whence health is derived, and also the formation of those elements which constitute muscular fibre - tendinous substances, and bone. This must be assisted with a pure atmosphere, and an abundance of exercise bordering on work suitable at all seasons to the age and constitution of the subject. It is absurd to suppose that these desiderata are to be obtained by enlargement in spacious grass fields or parks abounding in herbage, where the exercise of the occupants cannot be expected to assimilate with the proportion or extent of the pasture; if so, an immense expanse would be the most desirable; but horses seldom, if ever, take more exercise in enclosures of one hundred acres than in paddocks of one acre. In either case, they saunter about in search of food; but that is not exercise conducive to the vigorous development of the frame. As well 
might we call that man in condition who enjoys his ease during the winter season in London, and in the summer lounges on the parades of Brighton, or other watering places, compared with another who devotes his time to fox-hunting and other field sports in their succession, with cricket to keep up the exercise in summer.

In large fields horses may, at times, be alarmed and excited to gallop about; and having done so to the inducement of perspiration, they stand still to cool themselves, and lay the foundation of incurable disorders. Upon that principle, any restriction of food essential to health is impossible. This is one of the chief reasons why half-bred stock reared by the generality of farmers is not so capable of enduring as much labour at five years old as thorough-bred ones, treated as they ought to be, and as they generally are, at four years old. Yet, when properly managed, half-bred stock are equally fit for work at the early period.

The aid of arithmetic is not necessary to prove that if an animal is rendered capable of performing, at four years old, what another is not equal to endure until the succeeding year, whereby an unnecessary addition of expense is incurred, the former is the most profitable course.

With this brief summary I will therefore close my labours, in the hope that the observations conveyed in this little work may assist in bringing many win- 
ners to the post; whose success, in the hands of popular sportsmen, will be hailed with enthusiasm; - and also, that such as may be devoted to the hunting field will, on numerous occasions, carry their riders in prominent positions, and bear them to the end of many a good chase to join in the exulting Who-oop!

THE END. 









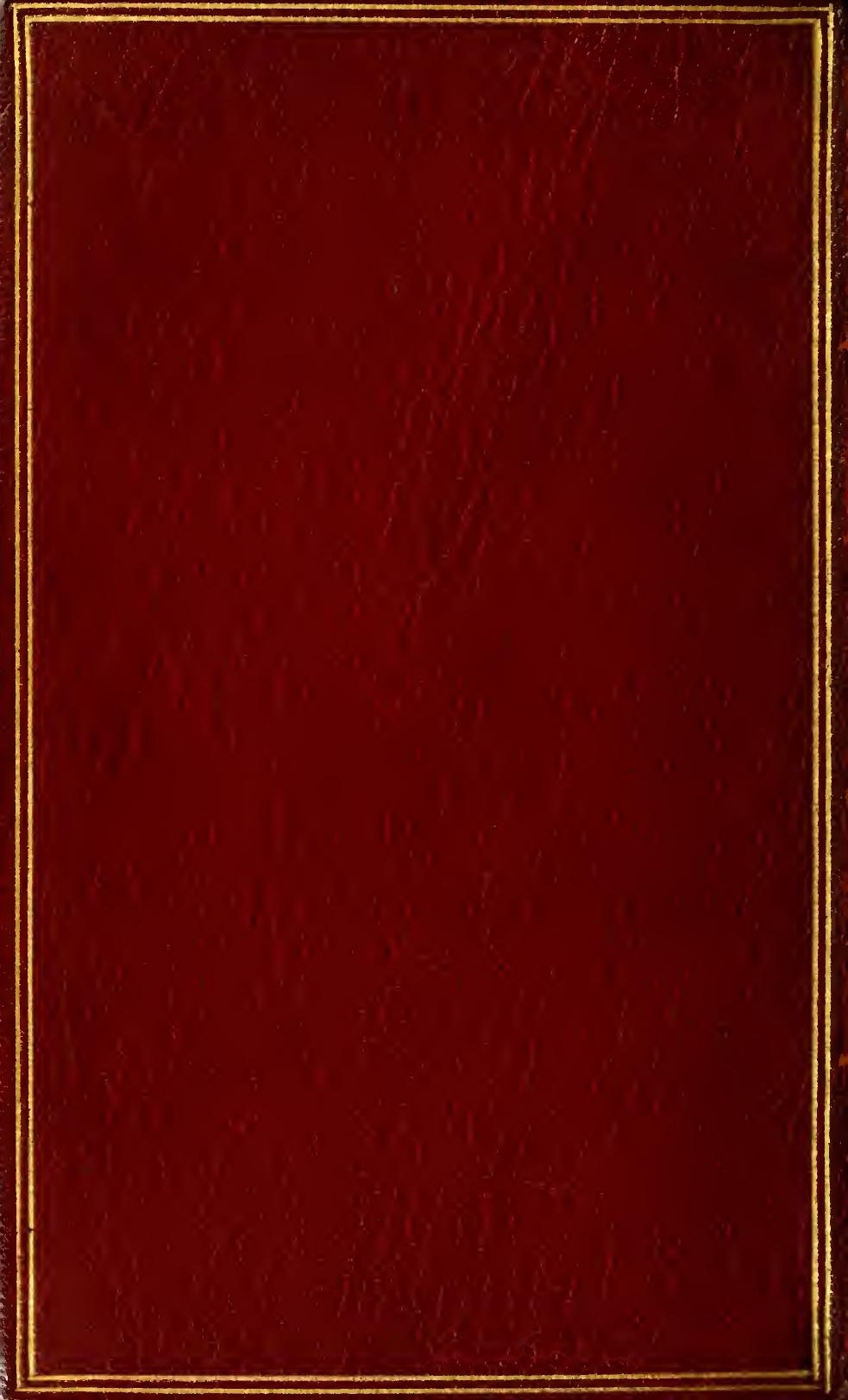

